\title{
Estudo de Índices Antropométricos na População Adulta de Goiânia
}

\section{Maria do Rosário Gondim Peixoto}

Tese de doutorado apresentada à Comissão de pós-graduação da Faculdade de Saúde Pública da Universidade de São Paulo para obtenção do título de Doutor em Saúde Pública.

Área de concentração: Nutrição

Orientadora:

Profa. Dra. Maria Helena D’Aquino Benício.

São Paulo

2004 
Autorizo, exclusivamente para fins acadêmicos e cientificos, a reprodução total ou parcial desta tese, por processos fotocopiadores. Ao usá-lo, cite a fonte. Assinatura: Data: 1

$$
4548812005 \text { doe }
$$


Aos meus pais, Esmeraldo e Francisca

Ao meu companheiro, Hélio Aos meus filhos, Isadora e Matheus

Com todo o meu amor. 


\section{AGRADECIMENTOS}

À Profa. Dra. Maria Helena D' Aquino Benício, minha orientadora, pelos valiosos ensinamentos e, principalmente, pela paciência, carinho, compreensão e apoio na execução desta tese.

Ao Professor Titular Carlos Augusto Monteiro, pelos expressivos comentários realizados no exame de qualificação e pelos preciosos instantes de aprendizado proporcionado nos seminários de Epidemiologia Nutricional;

À Professora Associada Maria do Rosário Dias de Oliveira Latorre, pelas proveitosas sugestöes na análise estatística dos dados e, principalmente, pela competência e entusiasmo com que exerce a carreira de docente;

Ao Professor Dr. Paulo César Brandão Veiga Jardim, Coordenador da Liga de Hipertensão/UFG, por propiciar as condiçōes necessárias para a realização deste estudo. Grata pelo apoio, estímulo e sugestões tão pertinentes.

À amiga Estelamaris Tronco Monego, amiga de todas as horas, pelo constante estímulo e também por suas idéias sempre coerentes e criativas, que só enriqueceram este trabalho;

Ao Wolney Lisboa Conde, pela competência e presteza em que atendeu minhas dúvidas com o STATA.

Aos amigos da Liga de Hipertensão Arterial de Goiás pelo apoio e incentivo;

Aos bolsistas da Liga de Hipertensão e pesquisadores de campo, em especial o bolsista Humberto, pelas inúmeras contribuições na execução e análise do Estudo Centro-Oeste, base desta tese.

Às amigas Ida Helena, Raquel $\mathrm{H}$, Fátima, Claret, Raquel C e Rosana por compartilharem comigo as dificuldades e conquistas de uma pós-graduação. 
As docentes e amigas da Faculdade de Nutrição da Universidade Federal de Goiás que, apesar das dificuldades, permitiram minha liberação durante a realização do doutorado;

Ao Instituto Brasileiro de Geografia e Estatistica de Goiás (IBGE), que permitiu o uso dos endereços dos setores censitários da PNAD, da área urbana de Goiânia, para o sorteio da nossa amostra;

Às funcionárias da Biblioteca da Faculdade de Saúde Pública, pelo excelente atendimento prestado à comunidade.

À Coordenação de Aperfeiçoamento de Pessoal de Nivel Superior (CAPES), pela concessão de uma bolsa de doutorado, dentro do Programa de Incentivo e Capacitação de Docentes e Técnicos (PICDT) das Universidades Federais;

Finalmente,

À minha mãe, Francisca, por ter assumido tantas vezes e com tanto amor o meu papel de mãe, dando assim condições para que eu concluisse este trabalho.

Ao Hélio, pelo apoio, carinho, compreensão e por realizar parte de minhas responsabilidades cotidianas.

E, principalmente, aos meus filhos, Isadora e Matheus, que aguardaram impacientemente pelo término desta tarefa. Obrigada pela alegria que representam na minha vida. 


\section{ÍNDICE}

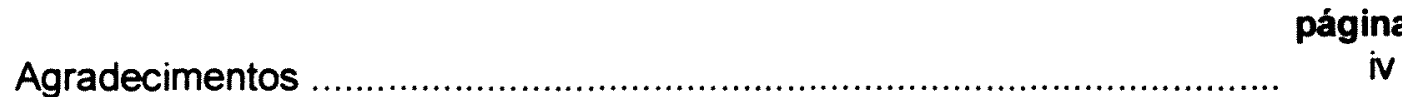

Apresentação …..................................................................... vii

Lista de Tabelas, Figuras e Quadros ................................................ viii

Lista de Siglas ....................................................................

Artigo 1 - Fatores determinantes do indice de massa corporal (IMC) na populaçăo adulta de Goiânia ............................................................... 12

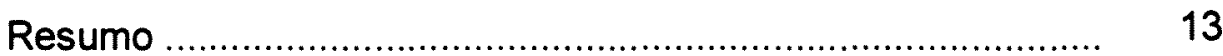

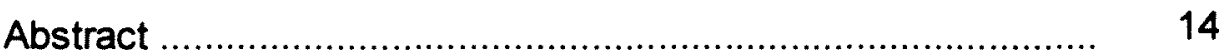

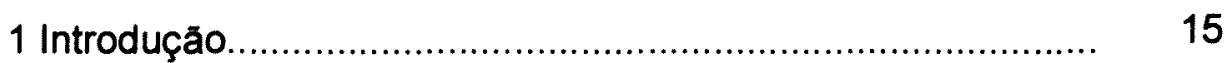

2 Material e Métodos ......................................................... 17

3 Resultados ……..................................................... 24

4 Discussão ............................................................ 32

5 Referências Bibliográficas................................................. 41

Artigo 2 - Circunferência da cintura e índice de massa corporal na predição da hipertensão arterial ...

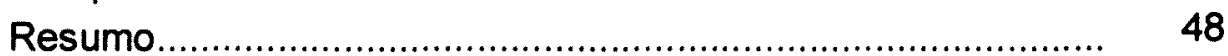

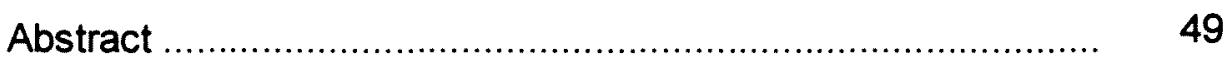

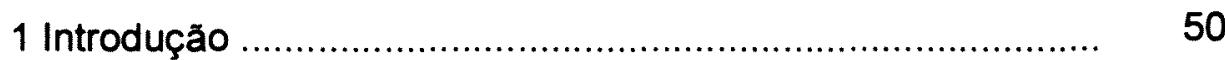

2 Material e Métodos …................................................. 52

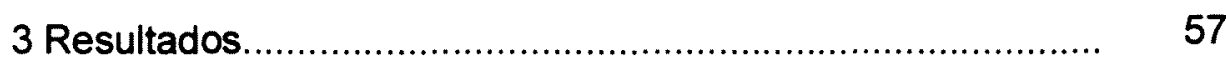

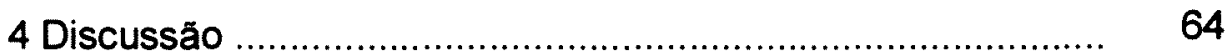

5 Referências Bibliográficas................................................... 70

Artigo 3 - $O$ uso do peso e da altura referidos em estudo epidemiológico: o estudo de Goiânia …………………............................ 75

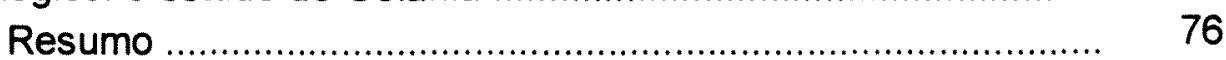

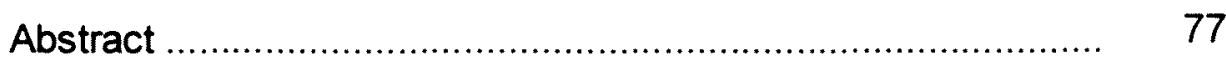

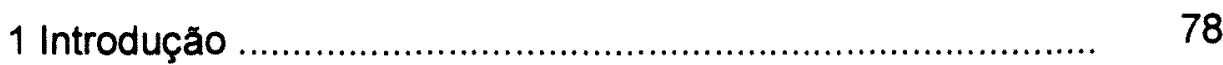

2 Material e Métodos ........................................................ 79

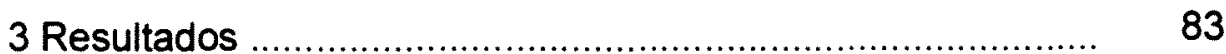

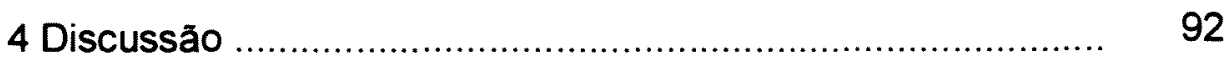

5 Referências Bibliográficas ............................................... 98

Consideraçōes Finais $\quad 101$

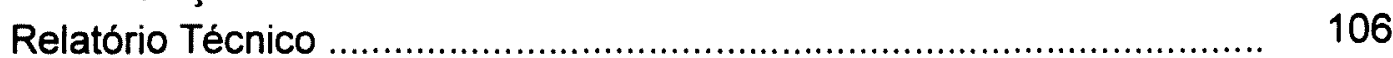

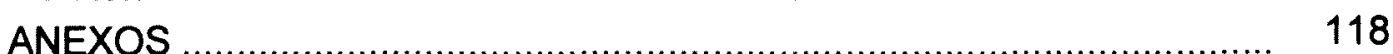

Anexo 1 - Parecer do Comitê de Ética ............................................... 119

Anexo 2 - Termo de Consentimento e Questionário da Pesquisa .......... 120 


\section{APRESENTAÇÃO}

Esta tese foi escrita no formato de trés artigos científicos, um relatório técnico e anexos.

O primeiro artigo apresenta a prevalência de sobrepeso e obesidade e investiga, através de análise de regressão linear múltipla hierarquizada, a associação de variáveis relacionadas a condições sócio-demográficas, estilo de vida, atividade física, comportamento alimentar e freqüência de consumo alimentar e o indice de massa corporal (IMC) de individuos adultos do Municipio de Goiânia (GO).

O segundo artigo explorou a associação entre os indices antropométricos, IMC e circunferência da cintura (CC), e a hipertensão arterial por meio de análise de regressão logística múltipla. Foi também determinada a capacidade preditiva dos pontos de corte recomendados para estes índices antropométricos na identificaçăo da hipertensão arterial da população adulta do Municipio de Goiânia.

O terceiro artigo avaliou a precisão do peso e altura referidos no diagnóstico da obesidade e a influência de características sóciodemográficas $e$ individuais sobre a validade da informaçāo recordatória. Diferenças entre as medidas referidas e aferidas foram avaliadas utilizandose diferenças de médias, limites de concordância e coeficiente de correlação intraclasse. 


\section{LISTA DE TABELAS, FIGURAS e QUADROS}

\section{Artigo 1}

página

Tabela 1.1 - Médias e IC (95\%) de variáveis selecionadas para homens e 25 mulheres. Goiânia-GO, Brasil, 2001

Tabela 1.2 - Distribuição de homens e mulheres segundo o índice de massa corpórea (IMC) e a circunferência da cintura (CC). Goiânia-GO, Brasil, 2001

Tabela 1.3 - Influência de caracteristicas sócio-demográficas e de estilo de vida sobre o IMC - média e coeficiente de regressão linear em homens e mulheres. Goiânia-GO, Brasil, 2001

Tabela 1.4 - Influência da atividade física e das práticas alimentares sobre o IMC - média e coeficiente de regressão linear em homens e mulheres. Goiânia-GO, Brasil, 2001

Tabela 1.5 - Coeficiente de correlação de Spearman entre valor do IMC e 30 frequéencia de consumo alimentar segundo sexo. Goiânia-GO, Brasil, 2001

Tabela 1.6 - Fatores associados ao IMC identificados mediante análise de regressão linear múltipla hierarquizada em homens adultos. Goiânia-GO, Brasil, 2001

Tabela 1.7 - Fatores associados ao IMC identificados mediante análise de regressão linear múltipla hierarquizada em mulheres adultas. Goiânia-GO, Brasil, 2001

Figura 1.1 - Modelo causal da obesidade.

Figura 1.2 - Distribuição por faixa etária e anos de estudo por sexo, segundo os dados do estudo e do IBGE (Censo 2000). Goiânia-GO, Brasil, 2001. 


\section{Artigo 2}

página

Tabela 2.1 - Médias e intervalos de $95 \%$ de confiança de variáveis selecionadas, segundo sexo. Goiânia-GO, Brasil, 2001

Tabela 2.2 - Prevalência (\%) de hipertensão arterial segundo a classificaçăo do IMC e da CC em homens e mulheres por faixa etária.

Goiânia-GO, Brasil, 2001

Tabela 2.3 - Odds ratio (OR) bruto e ajustado da hipertensão segundo indice de massa corporal e circunferência da cintura em homens e mulheres. Goiânia -GO, Brasil, 2001

Tabela 2.4 - Capacidade preditiva do nível 2 da circunferência da cintura (CC) para a detecção da (do risco de) hipertensão, segundo sexo e faixa etária. Goiânia-GO, Brasil, 2001

Tabela 2.5 - Capacidade preditiva da obesidade total (IMC $\geq 30 \mathrm{~kg} / \mathrm{m}^{2}$ ) para a detecção da (do risco de) hipertensão, segundo sexo e faixa etária. Goiânia-GO, Brasil, 2001

Tabela 2.6 - Pontos de corte da CC e do IMC onde a sensibilidade é igual à especificidade $(S=E) *$ na prediçăo da hipertensăo, segundo faixa etária em homens e mulheres. Goiânia, Brasil, 2001

Figura 2.1- Porcentagem de homens e mulheres por categorias de IMC e CC. Goiânia-GO, Brasil, 2001

Figura 2.2 - Prevalência (\%) de hipertensão arterial, obesidade total e obesidade abdominal por faixa-etária em homens. Goiânia-GO, Brasil, 2001 Figura 2.3 - Prevalência (\%) de hipertensão arterial, obesidade total e obesidade abdominal por faixa-etária em mulheres. Goiânia-GO, Brasil, 2001

Figura 2.4 - Areas sob as curvas ROC da circunferência da cintura e do índice de massa corporal na predição da hipertensão em mulheres e homens. Goiånia-GO, Brasil, 2001. 


\section{Artigo 3}

Tabela 3.1 - Médias de medidas antropométricas reportadas e aferidas.

Goiânia, Brasil-GO, 2001

Tabela 3.2 - Diferença entre as medidas referidas e aferidas de peso, altura e

IMC em homens segundo idade, variáveis sócio-económicas e antropometria.

Goiânia, Brasil-GO, 2001

Tabela 3.3 - Diferença entre as medidas referidas e aferidas de peso, altura e

IMC em mulheres segundo idade, variáveis sócio-econômicas e

antropometria. Goiânia, Brasil-GO, 2001

Tabela 3.4 - Distribuiçăo da amostra segundo categorias de classificação do IMC a partir do peso e altura referidos e aferidos. Goiânia-GO, Brasil, 2001

Tabela 3.5 - Médias das diferenças entre medidas referidas e aferidas de peso, altura e IMC em alguns estudos com grandes amostras.

Figura 3.1 - Distribuição da diferença entre peso referido e peso aferido segundo categorias de IMC para homens de 20 a 64 anos. Goiânia-GO, Brasil, 2001

Figura 3.2 - Distribuição da diferença entre peso referido e peso aferido segundo categorias de IMC para mulheres de 20 a 64 anos. Goiânia-GO, Brasil, 2001

Figura 3.3 - Distribuição da diferença entre valores referidos e aferidos do peso e altura em homens e mulheres de 20 a 64 anos. Goiânia-GO, Brasil, 2001

Figura 3.4 - Distribuiçăo das mulheres segundo categorias de classificaçăo do IMC aferido e do IMC referido. Goiânia-GO, Brasil, 2001

Figura 3.5 - Distribuiçău dos homens segundo categorias de classificaçăo do IMC aferido e do IMC referido. Goiânia-GO, Brasil, 2001 


\section{LISTAS DE SIGLAS}

CARMEN - Conjunto de Ações para a Redução da Morbidade por Enfermidades não Transmissíveis.

CC - circunferência da cintura.

DCV - doenças cardiovasculares.

ENDEF - Estudo Nacional de Despesa Familiar.

HA - hipertensão arterial.

IBGE - Instituto Brasileiro de Geografia e Estatística.

IC - intervalo de confiança.

IMC - indice de massa corporal.

OMS - Organização Mundial de Saúde

OPAS - Organização Panamericana de Saúde.

PAD - pressão arterial diastólica.

PAS - pressão arterial sistólica.

PNAD - Pesquisa Nacional por Amostragem de Domicílio.

PNSN - Pesquisa Nacional em Saúde e Nutrição.

$r^{2}$ - coeficiente de correlação ajustado.

$\mathbf{R C Q}$ - relação cintura quadril.

$r_{\text {ic }}$ - coeficiente de correlação intraclasse.

SM - salário mínimo.

WHO - World Health Organization. 
ARTIGO 1

FATORES DETERMINANTES DO ÍNDICE DE MASSA CORPORAL (IMC) NA POPULAÇÃO ADULTA DE GOIÂNIA

DETERMINANTS OF BODY MASS INDEX (BMI)

IN THE ADULT POPULATION OF GOIÂNIA

Título corrido: Determinantes do IMC 


\section{RESUMO}

Objetivos: Avaliar a prevalência de sobrepeso e obesidade e investigar a associação de variáveis relacionadas a condições sócio-demográficas, estilo de vida, atividade física, comportamento alimentar e freqüência de consumo alimentar e 0 indice de massa corporal (IMC) de indivíduos adultos da cidade de Goiânia (GO). Métodos: A partir de um estudo de transversal de base populacional, realizado no município de Goiânia, GO, em 2001, foi pesquisada uma amostra de 1252 individuos de 20 a 64 anos de idade. Para avaliar a associação entre as variáveis sócio-demográficas, estilo de vida, consumo alimentar e atividade física e o IMC, foi realizada análise de regressão linear múltipla hierarquizada. Resultados: A prevalência de obesidade foi de $10,7 \%$ e $13,9 \%$ para homens e mulheres, respectivamente. Na análise múltipla observou-se para os homens que a idade, a renda e o consumo de carnes apresentaram associação positiva com o IMC, enquanto que a atividade física nos momentos de lazer, o consumo de leguminosas e o hábito de fazer 4 ou mais de refeições por dia apresentaram associação negativa. Para as mulheres a idade, o abandono do tabagismo e o consumo de carnes apresentaram associação positiva, já o consumo de cereais apresentou associação negativa com o IMC. Conclusão: Concluiu-se que um estilo de vida ativo, juntamente com a ingestão de mais cereais e leguminosas e menos carnes, parece oferecer maior proteção contra a elevação do IMC, sendo que estes fatores sofrem influências sociais, que atuam de forma diferenciada em homens e mulheres.

Palavras-chave: índice de massa corporal (IMC), fatores determinantes, obesidade. 


\section{ABSTRACT}

Objective: The aim of this study was to assess the prevalence of excess weight and obesity and to investigate the association of variables related to sociodemographic factors, lifestyle, physical activity, eating choices, eating frequency and body mass index (BMI) of adult individuals in the city of Goiânia (GO). Methods: As part of a cross-sectional study of the population carried out in the county of Goiânia, GO, in 2001, 1252 individuals (aged 20$64 \mathrm{y})$ were surveyed. In order to examine the association between sociodemographic factors, such as lifestyle, eating frequency and physical activity, and BMI, a hierarchical multiple linear regression analysis was performed. Results: The prevalence of obesity was $10.7 \%$ for men and $13.9 \%$ for women. From the results of the multiple analysis, it is possible to see that in the male population, age, income and meat consumption were positively associated with BMI, while leisure-time physical activity, legume consumption and the habit of having 4 or more of meals a day were inversely associated with BMI. For women, the positive association factors were age, abstention from smoking and meat consumption, and cereal consumption were inversely associated with BMI. Conclusion: An active lifestyle, along with changes effected in eating habits so as to include more cereals and legumes, and less meat all seem to contribute to keep the BMI low. However, these factors are, themselves, affected by other social influences, which in turn may affect men and women differently.

Key-words: body mass index (BMI), determinants factors, obesity 


\section{INTRODUÇÃO}

A obesidade cresce rapidamente entre a população mundial, transformando-se em um relevante problema de saúde pública, afetando não só os países desenvolvidos, como também os paises em desenvolvimento (WORLD HEALTH ORGANIZATION 1997).

Os resultados do estudo "WHO MONICA (Monitoring of trends and determinants in cardiovascular diseases)", projeto multicêntrico englobando 48 populações distribuídas em 23 países, durante o período de 1983-1986, mostraram que 50 a $75 \%$ dos adultos com idade entre 35 e 64 anos apresentavam IMC maior ou igual $25 \mathrm{Kg} / \mathrm{m}^{2}$, a prevalência de obesidade foi de cerca de $15 \%$ para os homens e $22 \%$ para as mulheres, com grande variabilidade intra e entre os países estudados (WORLD HEALTH ORGANIZATION 1997).

A partir dos dados disponiveis de inquéritos probabilisticos de abrangência nacional que descrevem a prevalência da obesidade em diversos países, no período de 1989-1996, MONTEIRO (1998) observou que a obesidade é enfermidade relativamente rara (1\% a $3 \%)$ nos paises pobres tais como Tanzânia, Índia e China. Nos países ricos observou duas condições: de um lado o Japão e Suécia (os mais ricos) com baixa prevalência de obesidade, $2 \%$ e $5 \%$ respectivamente, no outro extremo a Alemanha, Estados Unidos e Canadá com prevalências variando entre 15\% e $20 \%$ nos homens e entre $15 \%$ e $25 \%$ nas mulhees. Já Arábia Saudita, Rússia e Brasil, países de renda intermediária, apresentaram prevalência semelhante à dos países ricos (Brasil de 13,3\% e 5,9\%, na Arábia Saudita $26,6 \%$ e $17,8 \%$ e na Rússia $27,9 \%$ e $10,8 \%$ para mulheres e homens, respectivamente).

A Arábia Saudita, Rússia e Brasil representam bons exemplos de que nos países em desenvolvimento, a obesidade geralmente é mais prevalente nas áreas urbanas e nos países com um maior grau de desenvolvimento, com as mulheres apresentando prevalências de obesidade superiores às observadas entre os homens (WORLD HEALTH ORGANIZATION 1997). 
No Brasil, os dados da Pesquisa Nacional sobre Nutrição e Saúde (PNSN-1989) mostram que cerca de $32 \%$ dos adultos brasileiros apresentam algum grau de excesso de peso. Comparando-se os dados da PNSN (1989) com os do Estudo Nacional de Despesa Familiar (ENDEF 1974/75), observa-se que no intervalo de quinze anos a proporçăo de adultos obesos quase dobrou $(5,7 \%$ para $9,6 \%)$. Este aumento ocorreu em todos os estratos socioeconômicos, sendo proporcionalmente mais elevado nas famílias de mais baixa renda. Ainda assim, a prevalência de excesso de peso apresenta maior magnitude nos estratos sócio-econômicos mais favorecidos, especialmente entre os homens. Na população feminina a obesidade passa a ser mais prevalente no estrato intermediário de renda, e não mais entre os mais ricos (COITINHO et al. 1991; SICHIERI et al. 1997).

Este rápido aumento na prevalência da obesidade, considerada já uma pandemia, aponta como principal causa as mudanças comportamentais ocorridas no último século. As atividades que requeriam alto gasto energético foram substituidas pelas facilidades proporcionadas pelo desenvolvimento tecnológico $e$ industrial, com isto passou-se a gastar menos energia no trabalho, no transporte, nas atividades domésticas e nas atividades realizadas nos momentos de lazer. Ao baixo gasto energético alia-se a globalização de hábitos alimentares considerados obesogênicos, pela grande difusão de alimentos refinados e processados, ricos em gorduras e açúcares simples, servidos em porçōes cada vez maiores. Este processo de mudança nos padrões de atividade física e de dieta, denominado de "transição nutricional", ocorre simultaneamente ao envelhecimento da população (transição demográfica) e ao aumento da prevalência de doenças crônicas não transmissiveis (transição epidemiológica).

De modo simplista, a obesidade é resultado de um balanço energético positivo, ou seja, uma situação onde o consumo alimentar supera o gasto energético por um período de tempo prolongado. A determinação da obesidade é entretanto mais complexa, envolvendo múltiplos fatores, tais como consumo alimentar, padrão de atividade física, fatores sociais e fatores 
ambientais, além da suscetibilidade individual, determinada por fatores genéticos e biológicos (WORLD HEALTH ORGANIZATION 1997). O estudo destes fatores deve ser realizado em diferentes populaçőes, pois resultados controversos são observados em vários estudos epidemiológicos e experimentais, mostrando que os fatores citados agem de forma diferenciada entre populações e grupos sociais (MONTEIRO e CONDE 1999; MARTORELL et al. 2000; LIEBMAN et al. 2003).

Não restam dúvidas de que o excesso de peso provoca aumento das morbidades e da mortalidade, o que ocorre devido à obesidade freqüentemente se associar a condiçőes tais como diabetes mellitus, dislipidemia e hipertensão arterial, que favorecem a ocorrência de eventos cardiovasculares, particularmente os eventos coronarianos (KANNEL et al. 1967; MANSON et al. 1990; BAIK et al. 2000).

O planejamento e a implementaçăo de serviços para prevençăo e controle da obesidade necessitam fundamentar-se sobre o conhecimento da prevalência, distribuição e fatores determinantes desta doença na população. Neste sentido, os objetivos deste estudo foram estudar a prevalência de sobrepeso e obesidade na populaçāo adulta de Goiânia e investigar a associação entre variáveis relacionadas a condiçōes sóciodemográficas, estilo de vida, atividade física, comportamento alimentar e freqüência de consumo alimentar e o IMC desta população.

\section{MATERIAL E MÉTODOS}

\subsection{Delineamento}

Para o desenvolvimento deste estudo, foram utilizados dados do Estudo da Prevalência e do Conhecimento da Hipertensão Arterial e alguns Fatores de Risco em uma Região do Brasil, projeto aprovado e financiado pelo CNPq e realizado pela equipe da Liga de Hipertensão Arterial da 
Universidade Federal de Goiás, em parceria com a Universidade Federal de Mato Grosso. Trata-se de um estudo com delineamento transversal, de base populacional, realizado nas capitais e em duas cidades do interior dos estados de Goiás e Mato Grosso. No presente estudo, foram analisados apenas os dados relativos a Goiânia, coletados no período de junho a dezembro de 2001.

\subsection{Amostra}

O tamanho da amostra para o município de Goiânia foi calculado considerando-se uma população de 1.004.098 habitantes (IBGE/98), a prevalência de hipertensão arterial no Brasil - $20 \%$ da população adulta (MINISTÉRIO DA SAÚDE 1993), intervalo de confiança de $95 \%$ e erro de estimação de $10 \%$. À amostra obtida $(n=1534)$ foram acrescidos $30 \%$ para cobrir as perdas ( $n=1994)$. A amostra efetivamente estudada constituiu-se de 1.454 indivíduos maiores de 18 anos de ambos os sexos, não institucionalizados e residentes na área urbana (72,9\% da amostra total e $95 \%$ da amostra necessária).

Entre as perdas ( $n=540), 121$ endereços foram classificados como inexistentes (não localizado ou não havia mais residência no endereço sorteado). Os demais domicilios $(n=419)$ foram localizados, mas năo foi realizada a entrevista na grande maioria das vezes por recusa dos moradores. Outras causas menos freqüentes foram domicílio vazio ou moradores não encontrados após três visitas em dias e horários diferentes.

Os domicilios foram selecionados por amostragem probabilística, por conglomerados, em duas etapas. A primeira consistiu na identificação, junto ao IBGE, dos setores censitários utilizados na Pesquisa Nacional por Amostragem de Domicilios (PNAD) de 1998 na zona urbana do município de Goiânia. A segunda etapa constou da seleção dos domicilios. Para esta seleção foram considerados o número de domicilios em cada setor e o tamanho total da amostra. A partir do cálculo do tamanho da amostra por 
setor foram sorteados, de forma aleatória e sistemática, os domicílios de cada setor.

Nos domicílios selecionados, foi entrevistado apenas um morador sorteado entre os moradores maiores de 18 anos, para evitar problemas de interdependéncia de informação entre entrevistados. Foram excluídas do sorteio gestantes e mães de crianças menores de seis meses, para evitar erros na interpretação dos dados. Foram excluídos também moradores que estivessem hospitalizados.

No presente estudo foram analisados 1252 individuos adultos que se encontravam na faixa etária de 20 a 64 anos. Considerando-se, para a região Centro-Oeste, uma prevalência de sobrepeso $22,6 \%$ para os homens e de $26,5 \%$ para as mulheres e de $4,8 \%$ e $11,7 \%$ de obesidade para homens e mulheres, respectivamente (COITINHO et al. 1991) e um intervalo de confiança de $95 \%$, esta amostra permite estimar, para homens e mulheres, a prevalência do sobrepeso e da obesidade com uma margem de erro de $3 \%$ e $2 \%$, respectivamente.

A coleta dos dados foi realizada por entrevistadores previamente treinados, utilizando questionário testado em estudo-piloto. O protocolo foi aprovado pelo Comitê de Ética em Pesquisa Médica Humana e Animal do Hospital das Clínicas /UFG e pelo Comitê de Ética em Pesquisa da Faculdade de Saúde Pública /USP.

\subsection{Variáveis do Estudo}

\section{- Sócio-demográficas}

Sexo; idade (em anos completos, categorizados nas faixas etárias: 2024, 25-34, 35-44, 45-54 e 55-64); paridade (número total de filhos de cada mulher entrevistada); reside com companheiro (sim/não); escolaridade (anos de estudo: 0-3 anos, 4-8 anos e $\geq 9$ anos); renda familiar (renda mensal per capita, em quartis) e informação sobre alimentação saudável no último ano (sim/não). 


\section{- Hábitos de vida}

O tabagismo, o consumo de álcool, e a atividade física foram avaliados tendo como base um grupo de questōes padronizadas pela ORGANIZACIÓN PANAMERICANA DE LA SALUD, em 1997, no protocolo do estudo CARMEN (Conjunto de Ações para a Redução da Morbidade por Enfermidades não Transmissiveis). Com relaçăo ao tabagismo, os participantes foram classificados em três grupos: os que nunca fumaram, os ex-fumantes (aqueles que pararam de fumar há mais de seis meses) e os fumantes (fumam atualmente ou pararam de fumar há menos de seis meses).

O consumo de álcool foi avaliado a partir de questões sobre o consumo de bebidas alcoólicas (sim/não) o tipo de bebida, a freqüência e a quantidade (doses, garrafas, taças ou copos) consumida durante a semana anterior. As quantidades foram convertidas para gramas de etanol por dia: uma garrafa de cerveja $(600 \mathrm{ml})=26,4 \mathrm{~g}$ de etanol; uma taça de vinho $(150 \mathrm{ml})=10,8 \mathrm{~g} \mathrm{e}$ etanol; uma dose de licor $(45 \mathrm{ml})=13,5 \mathrm{~g}$ de etanol; uma dose de cachaça $(60 \mathrm{ml})=24 \mathrm{~g}$ de etanol; uma dose de uísque $(60 \mathrm{ml})=27 \mathrm{~g}$ de etanol (FRANCO 1999).

\section{- Atividade física}

A atividade física ocupacional foi avaliada em quatro categorias de intensidade de esforço: (1) sedentário - corresponde aos indivíduos que trabalham sentados a maior parte do tempo ou que executam apenas atividades do lar de baixa intensidade; (2) leve - caminha bastante enquanto trabalha, mas não tem de levantar ou carregar coisas pesadas; (3) moderado movimenta-se freqüentemente e carrega algum peso; (4) intenso - exerce trabalho extenuante, que requer carregar coisas pesadas. Neste estudo, as categorias 3 e 4 foram combinadas devido ao pequeno número de indivíduos na categoria 4.

Para avaliar a atividade física no deslocamento para o trabalho, os indivíduos informavam se caminhavam ou andavam de bicicleta e quanto tempo dispendiam nesta atividade diariamente. Foram então agrupados nas categorias menos de 15 minutos e de 15 minutos ou mais. 
A atividade física nos momentos de folga ou de lazer foi avaliada em questão com 4 alternativas: (1) sedentário - nenhuma atividade física, apenas atividades como ler e assistir televisão; (2) leve - atividades físicas ocasionais, tais como caminhar, andar de bicicleta e fazer exercícios leves; (3) moderado atividade física regular (correr, ginástica, natação, jogos de equipe); (4) intensa - treinar várias vezes por semana pesadamente ou participar de competições esportivas regularmente. Devido ao pequeno número de indivíduos nesta última categoria, a terceira e a quarta categoria foram agrupadas.

O comportamento sedentário foi avaliado pelo número de horas que o entrevistado referiu assistir televisão diariamente, sendo os indivíduos alocados nas seguintes categorias: (1) menos de 2 horas por dia; (2) de 2 a 4 horas por dia; (3) de 4 a 6 horas por dia; (4) mais de 6 horas por dia. Com base nesta informação, foram formados 2 estratos - menos de 6 horas e 6 horas ou mais por dia.

\section{- Ingestão alimentar}

Para avaliação do consumo de alimentos, foi utilizado um questionário de freqüência de consumo alimentar simples, baseado na freqüência do consumo alimentar no último ano. Os alimentos foram classificados em 8 categorias de consumo: $\left(f_{1}\right)$ nunca; $\left(f_{2}\right)$ menos de 1 vez por mês; $\left(f_{3}\right) 1$ a 3 vezes por mês; $\left(f_{4}\right) 1$ vez por semana; $\left(f_{5}\right) 2$ a 3 vezes por semana; $\left(f_{6}\right) 4$ a 6 vezes por semana; $\left(f_{7}\right) 1$ vez por dia; $\left(f_{8}\right) 2$ ou mais vezes por dia. Para que a freqüência de consumo alimentar durante 0 último ano pudesse ser tratada como variável quantitativa, foi utilizada metodologia descrita em FORNES et al, em 2002. Para cada categoria de consumo $\left(f_{i}\right)$ foi atribuído um peso $\left(S_{f}\right)$, baseado na freqüência de consumo anual. Foi definido como valor de peso máximo $\left(S_{8}=2\right)$ para os alimentos consumidos duas vezes por dia. Os demais pesos foram obtidos por meio da equação:

$$
S n=(1 / 365)[(a+b) / 2]
$$

( $a$ e b representam a freqüência anual de consumo) 
O questionário de freqüência de consumo também incluía questões sobre as seguintes práticas alimentares: uso de adoçantes; retirar a gordura da carne; retirar a pele do frango; fazer as refeiçōes assistindo televisão e o número de refeições por dia.

A lista de alimentos utilizada na pesquisa continha 140 itens, sendo que aqueles com composição semelhante foram agrupados em um mesmo item, totalizando, desta maneira, 68 itens alimentares, distribuidos nos seguintes grupos: leites e produtos derivados; carnes e ovos; gorduras; cereais, pães e tubérculos; verduras e legumes; frutas; leguminosas; bebidas; salgados e preparações; açúcar e doces. A lista de alimentos foi construída tendo como base informações sobre o consumo de alimentos obtidas no município de Goiânia pelo Estudo Multicêntrico de Consumo Alimentar no ano de1996 (GIL et al. 1997).

Para controlar mudanças recentes no padrão alimentar, foi perguntado aos entrevistados "Você mudou sua dieta por motivo de saúde nos últimos 12 meses?" Se a resposta fosse positiva, perguntava-se qual mudança foi feita.

\section{- Antropometria}

Todas as medidas antropométricas foram feitas de acordo com as recomendações de LOHMAN et al. (1988). Para o peso utilizou-se balança eletrônica marca Plenna, modelo Giant Lithium, com capacidade para $150 \mathrm{~kg}$ e precisão de $100 \mathrm{~g}$. Os indivíduos foram pesados descalços e com roupas leves. Para medir a altura, utilizou-se estadiômetro portátil marca Seca, com precisão de $0,1 \mathrm{~cm}$. A medida da circunferência da cintura $(\mathrm{CC})$ foi realizada com fita métrica inextensivel, no nivel natural da cintura ou no ponto médio entre a crista iliaca anterior superior e a última costela. Uma CC entre $80 \mathrm{~cm}$ e $88 \mathrm{~cm}$ para as mulheres e entre $94 \mathrm{~cm}$ e $102 \mathrm{~cm}$ para os homens foi classificada como adiposidade abdominal aumentada e uma $C C \geq 102 \mathrm{~cm}$ para homens $e \geq 88 \mathrm{~cm}$ para mulheres foi classificada como obesidade abdominal (WORLD HEALTH ORGANIZATION 1997). 


\section{- Variável desfecho}

O desfecho primário neste estudo foi o índice de massa corporal (IMC). O IMC foi calculado pela divisão do peso $(\mathrm{Kg})$ pelo quadrado da altura (m). Para a classificação dos valores de IMC foi utilizada a recomendaçăo da WORLD HEALTH ORGANIZATION, em 1997: < 18,5 kg/m² (baixo peso); 18,5 a $24,9 \mathrm{~kg} / \mathrm{m}^{2}$ (peso normal); 25 a $29,9 \mathrm{~kg} / \mathrm{m}^{2}$ (sobrepeso); e $\geq 30 \mathrm{~kg} / \mathrm{m}^{2}$ (obesidade). Para as análises univariada e múltipla utilizou-se o IMC como variável contínua.

\subsection{Análise Estatistica}

Os dados relativos a homens e mulheres foram analisados separadamente. Inicialmente, os resultados foram expressos em porcentagens, médias e intervalos de confiança (IC 95\%). Foi calculada a frequeência de indivíduos nas diferentes categorias de IMC (baixo peso, normal, sobrepeso e obesidade). Para avaliar a associaçăo entre as variáveis em estudo e a variável dependente IMC, foram realizadas análises de regressão linear simples e de correlação de Spearman, sendo esta última utilizada especificamente para o consumo de alimentos. Para estimar o efeito independente das variáveis de controle sobre o desfecho (IMC), foi utilizada análise de regressão linear múltipla hierarquizada. As variáveis que apresentaram $p<0,30$ na análise univariada foram incluídas na análise múltipla (VICTORA et al. 1997).

O modelo teórico dos determinantes da obesidade da OMS (WORLD HEALTH ORGANIZATION 1997), adaptado para este estudo, guiou a estruturação dos blocos de variáveis e, conseqüentemente, a ordem em que estes blocos entraram no modelo (Figura 1.1). No modelo hierarquizado, as variáveis de um bloco são ajustadas pelas variáveis dos blocos situados nos niveis que o precedem.

Para análise dos dados, utilizou-se o STATA (versão 7.0). As análises estatísticas foram corrigidas pelo delineamento complexo da amostra, por meio da utilização do conjunto de comandos SVY, que consideram a 
estrutura complexa da amostra, incorporando nas análises os pesos amostrais associados a cada conglomerado da amostra e o efeito do desenho amostral. Foi utilizado o nivel de significância de $5 \%$.

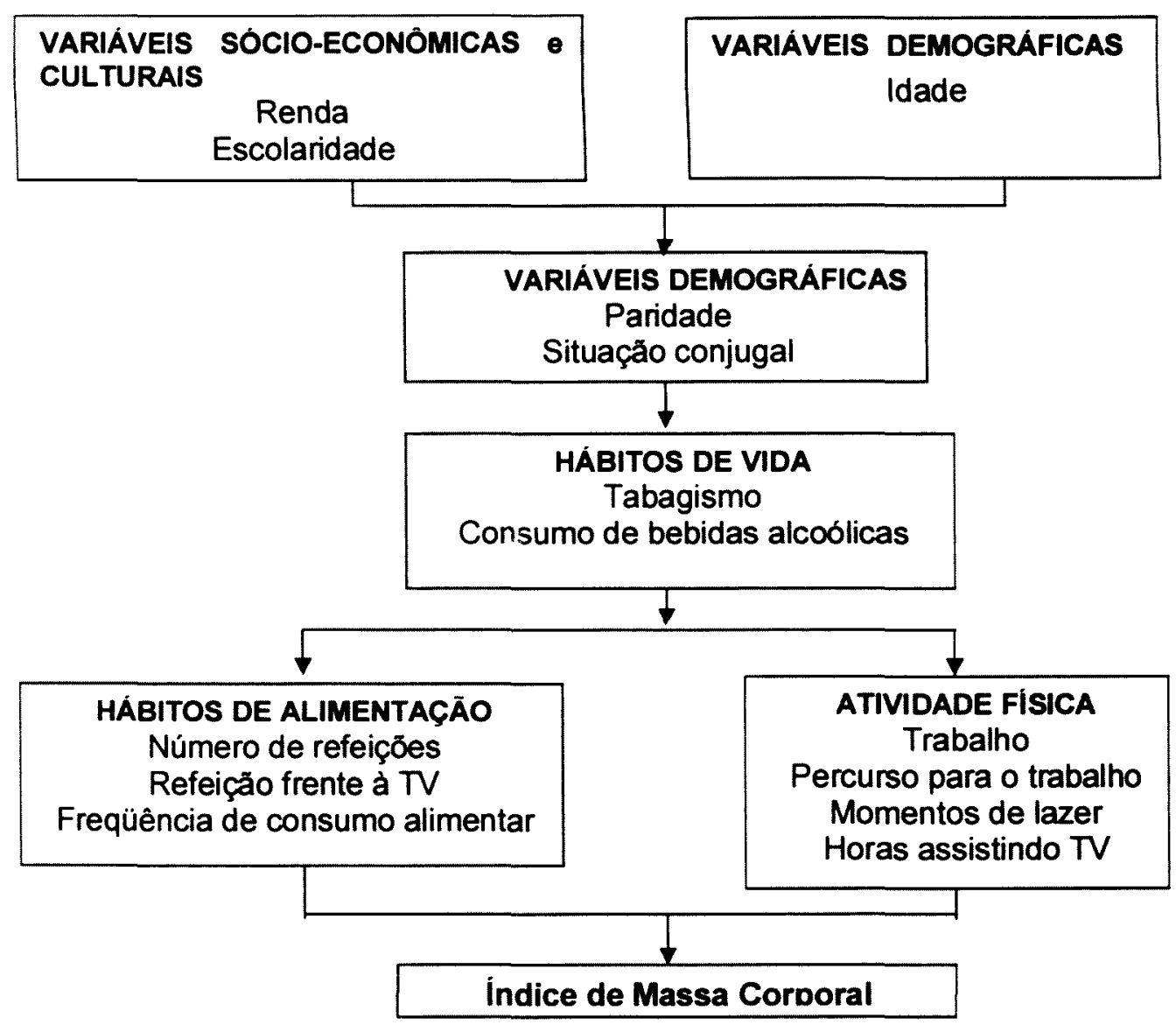

Figura 1.1- Modelo causal do Índice de Massa Corporal.

\section{RESULTADOS}

Dos 1252 indivíduos estudados, 35\% eram homens ( $n=433)$ e $65 \%$ eram mulheres $(n=819)$. Homens e mulheres não apresentaram diferença significativa para escolaridade, renda, idade e IMC (Tabela 1.1). 
Tabela 1.1 - Médias e intervalos de confiança (IC-95\%) de variáveis selecionadas para homens e homens. Goiânia-GO, Brasil, 2001.

\begin{tabular}{lrcrrc}
\hline \multirow{2}{*}{ Variáveis } & \multicolumn{2}{c}{ Homens $(\mathrm{n}=433)$} & \multicolumn{2}{c}{ Mulheres $(\mathrm{n}=819)$} \\
\cline { 2 - 5 } & Média & IC $(95 \%)$ & Média & IC $(95 \%)$ \\
\hline Escolaridade (anos) & 7,9 & {$[6,8 ; 8,9]$} & 7,5 & {$[6,5 ; 8,5]$} \\
Renda (per capita) & 361,2 & {$[262,2 ; 460,3]$} & 293,5 & {$[220,4 ; 366,5]$} \\
Idade (anos) & 38,4 & {$[37,3 ; 39,5]$} & 38,1 & {$[37,0 ; 39,1]$} \\
Peso (kg) & 70,7 & {$[68,0 ; 73,3]$} & 61,3 & {$[60,0 ; 62,5]$} \\
Altura (m) & 169,6 & {$[168,8 ; 170,4]$} & 157,4 & {$[156,8 ; 157,9]$} \\
IMC (kg/m $\left.{ }^{2}\right)$ & 24,6 & {$[23,8 ; 25,3]$} & 24,8 & {$[24,3 ; 25,3]$} \\
Circunferência da cintura (cm) & 86,3 & {$[84,0 ; 88,6]$} & 78,6 & {$[77,7 ; 79,5]$} \\
\hline
\end{tabular}

Aproximadamente $42 \%$ dos homens apresentavam excesso de peso ( $31,2 \%$ de sobrepeso e $10,7 \%$ de obesidade). No entanto, apenas $26 \%$ tinham a adiposidade abdominal acima do adequado. Já para as mulheres, cerca de $43 \%$ apresentavam tanto excesso de peso $(29,2 \%$ de sobrepeso e $13,9 \%$ de obesidade) quanto a adiposidade abdominal aumentada (Tabela 1.2).

Tabela 1.2 - Distribuição de homens e mulheres segundo o índice de massa corpórea (IMC) e a circunferência da cintura (CC). Goiânia-GO, Brasil, 2001.

\begin{tabular}{lcccccc}
\hline Variáveis & \multicolumn{3}{c}{ Homens } & \multicolumn{3}{c}{ Mulheres } \\
\cline { 2 - 7 } & $\mathrm{N}$ & $\%$ & $\mathrm{IC} 95 \%$ & $\mathrm{~N}$ & $\%$ & $\mathrm{IC} \mathrm{95 \%}$ \\
\hline \multicolumn{1}{c}{ IMC } & 13 & 3,9 & {$[1,5 ; 6,2]$} & 49 & 6,5 & {$[3,8 ; 9,2]$} \\
Baixo peso & 221 & 54,2 & {$[45,8 ; 62,6]$} & 409 & 50,3 & {$[47,6 ; 53,1]$} \\
Normal & 144 & 31,2 & {$[23,9 ; 38,3]$} & 235 & 29,2 & {$[26,8 ; 31,7]$} \\
Sobrepeso & 55 & 10,4 & {$[7,6 ; 13,8]$} & 126 & 13,8 & {$[10,5 ; 17,4]$} \\
Obesidade & & & & & & \\
\multicolumn{1}{c}{ CC* } & & & & & & \\
Adequada & 312 & 73,6 & {$[65,9 ; 81,4]$} & 459 & 56,8 & {$[53,6 ; 60,0]$} \\
Aumentada & $73-$ & 16,6 & {$[12,2 ; 21,0]$} & 183 & 23,4 & {$[21,0 ; 25,7]$} \\
Muito aumentada & 47 & 9,4 & {$[5,2 ; 13,6]$} & 173 & 19,6 & {$[17,0 ; 22,2]$}
\end{tabular}


As médias do IMC por categoria das variáveis estudadas são mostradas nas tabelas 1.3 e 1.4. Estas tabelas mostram também os coeficientes de regressão linear simples entre as variáveis sóciodemográficas, estilo de vida, atividade física e práticas alimentares e a variável dependente IMC. Observa-se que, para os homens, o IMC apresentou associação positiva com a idade, a presença de companheira e renda. Para as mulheres, houve associação positiva com a idade e a paridade e associação negativa com a escolaridade.

Detectou-se também associação entre tabagismo e IMC. Os exfumantes apresentaram média maior de IMC do que os que fumam atualmente ou aqueles que nunca fumaram, em ambos os sexos. Para 0 consumo de bebidas alcoólicas, houve associação apenas para as mulheres, sendo que aquelas que consumiam bebidas alcoólicas apresentavam média de IMC menor (Tabela 1.3). A associação entre o consumo de bebidas alcoólicas e $\circ$ IMC foi independente da quantidade de etanol consumida.

Para os homens, os quartis de renda, em salários mínimos (SM), corresponderam a: $1^{\circ}$ quartil $(<0,8 \mathrm{SM}) ; 2^{\circ}$ quartil $(0,8$ a $1,4 \mathrm{SM}) ; 3^{\circ}$ quartil (>1,4 a 2,8 SM); $4^{\circ}$ quartil (>2,8 SM). Para as mulheres correspondeu a: $1^{\circ}$ quartil (< 0,7 SM); $2^{\circ}$ quartil (0,7 a 1,2 SM); $3^{\circ}$ quartil (>1,2 a 2,2 SM); $4^{\circ}$ quartil (>2,2 SM). Um SM correspondia a R $\$ 180,00$. 
Tabela 1.3 - Influência de características sócio-demográficas e de estilo de vida sobre o IMC - média e coeficiente de regressão linear em homens e mulheres. Goiânia-GO, Brasil, 2001.

\begin{tabular}{|c|c|c|c|c|c|c|c|c|}
\hline \multirow{3}{*}{ Variáveis } & \multicolumn{4}{|c|}{ Homens } & \multicolumn{4}{|c|}{ Mulheres } \\
\hline & \multirow[t]{2}{*}{$\mathbf{N}$} & \multirow{2}{*}{$\begin{array}{c}\text { IMC médio } \\
\left(\mathrm{Kg} / \mathrm{m}^{2}\right)\end{array}$} & \multicolumn{2}{|c|}{$\begin{array}{l}\text { Regressão linear } \\
\text { simples }\end{array}$} & \multirow[t]{2}{*}{$\mathbf{N}$} & \multirow{2}{*}{$\begin{array}{c}\text { IMC médio } \\
\left(\mathrm{Kg} / \mathrm{m}^{2}\right)\end{array}$} & \multicolumn{2}{|c|}{$\begin{array}{c}\text { Regressăo linear } \\
\text { simples }\end{array}$} \\
\hline & & & $\beta$ & IC (95\%) & & & $\beta$ & IC (95\%) \\
\hline $\begin{array}{r}\text { Idade (anos) } \\
20-24 \\
25-34 \\
35-44 \\
45-54 \\
55-64\end{array}$ & $\begin{array}{l}72 \\
113 \\
100 \\
91 \\
57\end{array}$ & $\begin{array}{c}22,3 \\
24,1 \\
25,0 \\
26,0 \\
25,2 \\
p^{1}<0,01 \\
\end{array}$ & $\begin{array}{c}- \\
1,79 \\
2,73 \\
3,74 \\
2,96\end{array}$ & $\begin{array}{c}- \\
{[0,53 ; 3,06]} \\
{[1,54 ; 3,92]} \\
{[3,00 ; 4,47]} \\
{[1,89 ; 4,02]}\end{array}$ & $\begin{array}{l}120 \\
227 \\
202 \\
156 \\
114\end{array}$ & $\begin{array}{c}22,5 \\
23,4 \\
25,0 \\
26,2 \\
28,1 \\
p^{4}<0,01 \\
\end{array}$ & $\begin{array}{l}- \\
0.90 \\
2.55 \\
3.73 \\
5.57\end{array}$ & $\begin{array}{l}{[0.23 ; 1.58]} \\
{[1.76 ; 3.35]} \\
{[2.96 ; 4.49]} \\
{[4.11 ; 7.03]}\end{array}$ \\
\hline $\begin{array}{l}\text { Renda } \\
1^{\circ} \text { Quartil } \\
2^{\circ} \text { Quartil } \\
3^{\circ} \text { Quartil } \\
4^{\circ} \text { Quartil }\end{array}$ & $\begin{array}{l}85 \\
106 \\
120 \\
122\end{array}$ & $\begin{array}{c}24,0 \\
23,9 \\
25,0 \\
25,8 \\
p^{1}<0,01 \\
\end{array}$ & $\begin{array}{l}- \\
0.35 \\
0.58 \\
1.97\end{array}$ & $\begin{array}{l}- \\
{[-1,06 ; 1,77]} \\
{[-0,72 ; 1,88]} \\
{[0,57 ; 3,36]}\end{array}$ & $\begin{array}{l}228 \\
207 \\
197 \\
187\end{array}$ & $\begin{array}{c}24,6 \\
24,5 \\
25,1 \\
24,9 \\
p^{1}=0,68 \\
\end{array}$ & $\begin{array}{l}- \\
0,15 \\
0,67 \\
0,56\end{array}$ & $\begin{array}{l}{[-0,81 ; 1,05]} \\
{[-0,40 ; 1,96]} \\
{[-1,10 ; 1,95]}\end{array}$ \\
\hline $\begin{array}{c}\text { Escolaridade } \\
0 \text { a } 3 \text { anos } \\
4 \text { a } 8 \text { anos } \\
\geq 9 \text { anos }\end{array}$ & $\begin{array}{c}57 \\
168 \\
208\end{array}$ & $\begin{array}{c}24,8 \\
24,7 \\
24,3 \\
p^{\dagger}=0,51\end{array}$ & $\begin{array}{c}- \\
- \\
0,14 \\
- \\
0,55\end{array}$ & $\begin{array}{l}{[-1,23 ; 0,94]} \\
{[-1,55 ; 0,45]}\end{array}$ & $\begin{array}{l}119 \\
323 \\
377\end{array}$ & $\begin{array}{c}25,9 \\
24,9 \\
24,1 \\
p^{1}<0,01\end{array}$ & $\begin{array}{c}- \\
- \\
0,97 \\
\overline{1,95}\end{array}$ & $\begin{array}{c}- \\
{[-1,76 ;-0,18]} \\
{[-2,97 ;-0,74]}\end{array}$ \\
\hline $\begin{array}{c}\text { Inf. alimentação } \\
\text { Não } \\
\text { Sim }\end{array}$ & $\begin{array}{l}212 \\
222\end{array}$ & $\begin{array}{c}24,3 \\
24,8 \\
p^{2}=0,19\end{array}$ & $\overline{0,51}$ & {$[-0,96 ; 1,10]$} & $\begin{array}{l}344 \\
475\end{array}$ & $\begin{array}{c}24,4 \\
25,1 \\
p^{2}=0,05\end{array}$ & 0,69 & {$[-0,85 ; 2,24]$} \\
\hline $\begin{array}{l}\text { Sit. conjugal } \\
\text { Sem companheiro } \\
\text { Com companheiro }\end{array}$ & $\begin{array}{l}164 \\
269\end{array}$ & $\begin{array}{c}23,6 \\
25,2 \\
p^{2}<0,01 \\
\end{array}$ & $\overline{1,61}$ & {$[0,64 ; 2,59]$} & $\begin{array}{l}318 \\
501\end{array}$ & $\begin{array}{c}24,5 \\
24,9 \\
p^{2}=0,32 \\
\end{array}$ & $\overline{0,36}$ & {$[-0,69 ; 1,42]$} \\
\hline $\begin{array}{c}\text { Paridade } \\
\text { nenhum } \\
1 \\
2 \\
3 \\
4 \text { ou mais }\end{array}$ & & & & & $\begin{array}{l}136 \\
120 \\
262 \\
153 \\
148\end{array}$ & $\begin{array}{c}23,1 \\
23,9 \\
25,6 \\
25,6 \\
26,2 \\
p^{1}<0,01 \\
\end{array}$ & $\begin{array}{c}- \\
0,81 \\
1,47 \\
2,45 \\
3,06\end{array}$ & $\begin{array}{l}{[-0,13 ; 1,75]} \\
{[0,11 ; 2,82]} \\
{[0,98 ; 3,91]} \\
{[1,65 ; 4,48]}\end{array}$ \\
\hline $\begin{array}{c}\text { Tabagismo } \\
\text { Năo-fumante } \\
\text { fumante } \\
\text { Ex-fumante }\end{array}$ & $\begin{array}{l}205 \\
114 \\
114\end{array}$ & $\begin{array}{c}24,3 \\
23,8 \\
25,9 \\
p^{3}<0,01 \\
\end{array}$ & $\begin{array}{r}- \\
-0,49 \\
1,65\end{array}$ & $\begin{array}{l}{[-1,25 ; 0,25]} \\
{[0,74 ; 2,55]}\end{array}$ & $\begin{array}{l}524 \\
141 \\
154\end{array}$ & $\begin{array}{r}24,6 \\
23,8 \\
26,3 \\
p^{3}<0,01 \\
\end{array}$ & $\begin{array}{r}- \\
-0,74 \\
1,73\end{array}$ & $\begin{array}{c}- \\
{[-1,89 ; 0,42]} \\
{[0,66 ; 2,80]}\end{array}$ \\
\hline $\begin{array}{l}\text { Bebidas } \\
\text { alcoólicas } \\
\text { Năo } \\
\text { Sim }\end{array}$ & $\begin{array}{l}168 \\
265\end{array}$ & $\begin{array}{r}25,0 \\
24,3 \\
p^{2}=0,06 \\
\end{array}$ & $-0, \overline{74}$ & {$[-1,74 ; 0,26]$} & $\begin{array}{l}507 \\
312\end{array}$ & $\begin{array}{r}25,1 \\
24,2 \\
p^{2}=0,01 \\
\end{array}$ & -0.89 & {$[-1,65 ;-0,14]$} \\
\hline
\end{tabular}

Os homens que desenvolviam atividades físicas moderadas ou intensas nos momentos de lazer $(20,4 \%)$ tinham uma média de IMC menor 
do que aqueles que desenvolviam atividades sedentárias ou leves. Os homens que usualmente caminhavam ou iam de bicicleta para o trabalho apresentaram média de IMC inferior ao dos que usavam meios de transporte motorizados ou caminhavam por poucos minutos no deslocamento para 0 trabalho. Ao contrário dos homens, para as mulheres não houve associação entre os valores do IMC e as atividades físicas desenvolvidas no deslocamento para o trabalho e nos momentos de lazer (Tabela 1.4).

Das práticas alimentares, 0 uso regular de adoçantes apresentou associação positiva com o IMC, apenas para as mulheres. Estas também referiram ter alterado seu padrão alimentar no último ano (Tabela 1.4).

A associação entre o IMC e a freqüência de consumo dos diversos grupos de alimentos foi analisada por meio do coeficiente de correlação de Spearman (Tabela 1.5). Para cs homens, apenas o consumo de carnes estava associado positivamente, enquanto as leguminosas se apresentaram associadas negativamente ao IMC. Entre as mulheres, o consumo de carnes (vaca, frango e porco) apresentou associação positiva com o IMC, enquanto - consumo de ovos, gorduras, cereais, frutas e doces apresentou associação negativa. Isto é, as mulheres com média de IMC maior tenderam a reportar comer relativamente mais carnes, mas menos ovos, gorduras e doces. 
Tabela 1.4 - Influência da atividade física e das práticas alimentares sobre o IMC - média e coeficiente de regressão linear em homens e mulheres. Goiânia-GO, Brasil, 2001.

\begin{tabular}{|c|c|c|c|c|c|c|c|c|}
\hline \multirow{3}{*}{ Variáveis } & & \multicolumn{3}{|c|}{ Homens } & \multicolumn{4}{|c|}{ Mulheres } \\
\hline & & \multirow{2}{*}{$\begin{array}{c}\text { IMC } \\
\text { médio } \\
\left(\mathrm{Kg} / \mathrm{m}^{2}\right)\end{array}$} & \multicolumn{2}{|c|}{$\begin{array}{c}\text { Regressão linear } \\
\text { simples }\end{array}$} & \multirow[t]{2}{*}{$\mathbf{N}$} & \multirow{2}{*}{$\begin{array}{c}\text { IMC } \\
\text { medio } \\
\left(\mathrm{Kg} / \mathrm{m}^{2}\right)\end{array}$} & \multicolumn{2}{|c|}{$\begin{array}{l}\text { Regressăo linear } \\
\text { simples }\end{array}$} \\
\hline & & & $\beta \mathbf{i}$ & IC $(95 \%)$ & & & $\beta \mathbf{t}$ & IC $(95 \%)$ \\
\hline $\begin{array}{c}\text { Horas de TV } \\
<6 \text { horas } \\
6 \text { horas ou mais }\end{array}$ & $\begin{array}{c}418 \\
15\end{array}$ & $\begin{array}{c}24,5 \\
25,0 \\
p^{2}=0,62\end{array}$ & 0,49 & {$[-1,39 ; 2,38]$} & $\begin{array}{c}783 \\
36\end{array}$ & $\begin{array}{c}24,7 \\
26,9 \\
p^{2}<0,01\end{array}$ & $\overline{2,29}$ & {$[-0,33 ; 4,90]$} \\
\hline $\begin{array}{c}\text { AF no lazer } \\
\text { Sedentário } \\
\text { Leve } \\
\text { Moderada }\end{array}$ & $\begin{array}{c}220 \\
129 \\
84\end{array}$ & $\begin{array}{c}24,8 \\
25,2 \\
22,9 \\
p^{4}<0,01\end{array}$ & $\begin{array}{r}- \\
0,38 \\
-1,90\end{array}$ & $\begin{array}{c}- \\
{[-0,69 ; 1,46]} \\
{[-2,77 ;-1,02]}\end{array}$ & $\begin{array}{c}558 \\
216 \\
44\end{array}$ & $\begin{array}{c}24,6 \\
25,4 \\
24,4 \\
p^{1}=0,12\end{array}$ & $\begin{array}{c}- \\
0,84 \\
-0,12\end{array}$ & $\begin{array}{c}- \\
{[-0,45 ; 2,14]} \\
{[-2,25 ; 2,01]}\end{array}$ \\
\hline $\begin{array}{c}\text { AF no transporte } \\
<15 \text { minutos } \\
\geq 15 \text { minutos }\end{array}$ & $\begin{array}{l}313 \\
120\end{array}$ & $\begin{array}{c}24,9 \\
23,4 \\
\mathrm{p}^{2}<0,01 \\
\end{array}$ & $-1,48$ & {$[-2,17 ;-0,79]$} & $\begin{array}{l}653 \\
166\end{array}$ & $\begin{array}{c}24,7 \\
24,9 \\
p^{2}=0,78 \\
\end{array}$ & $\overline{0,13}$ & {$[-0,60 ; 0,87]$} \\
\hline $\begin{array}{c}\text { AF no trabalho } \\
\text { Sedentário } \\
\text { Leve/Moderado } \\
\text { Intensa }\end{array}$ & $\begin{array}{l}237 \\
133 \\
63\end{array}$ & $\begin{array}{c}24,8 \\
24,3 \\
24,1 \\
p^{3}=0,34\end{array}$ & $\begin{array}{l}- \\
-0,45 \\
-0,73\end{array}$ & $\begin{array}{c}- \\
{[-1,60 ; 0,70]} \\
{[-1,63 ; 0,17]}\end{array}$ & $\begin{array}{c}601 \\
204 \\
14\end{array}$ & $\begin{array}{c}24,8 \\
24,6 \\
27,2 \\
p^{3}=0,23\end{array}$ & $\begin{array}{c}- \\
-0,22 \\
2,42\end{array}$ & $\begin{array}{c}{[-1,02 ; 0,57]} \\
{[0,45 ; 4,39]}\end{array}$ \\
\hline $\begin{array}{c}\text { Mudou a dieta } \\
\text { Năo } \\
\text { Sim }\end{array}$ & $\begin{array}{l}231 \\
202\end{array}$ & $\begin{array}{c}24,3 \\
24,9 \\
p^{2}=0,09 \\
\end{array}$ & $\overline{0,66}$ & {$[-0,28 ; 1,60]$} & $\begin{array}{l}364 \\
455\end{array}$ & $\begin{array}{c}24,0 \\
25,5 \\
p^{2}<0,01 \\
\end{array}$ & $1, \overline{52}$ & {$[0,86 ; 2,19]$} \\
\hline $\begin{array}{c}\text { Retira a gordura } \\
\text { da carne }{ }^{\star} \\
\text { Nåo } \\
\text { Sim }\end{array}$ & $\begin{array}{l}210 \\
220\end{array}$ & $\begin{array}{c}24,6 \\
24,5 \\
p^{2}=0,84 \\
\end{array}$ & $-\overline{0.07}$ & {$[-0,58 ; 0.43]$} & $\begin{array}{l}222 \\
595\end{array}$ & $\begin{array}{r}24,9 \\
24,7 \\
p^{2}=0,58 \\
\end{array}$ & $-\overline{0,22}$ & {$[-0,89 ; 0,45]$} \\
\hline $\begin{array}{l}\text { Retira a pele do } \\
\text { frango* } \\
\text { Não } \\
\text { Sim }\end{array}$ & $\begin{array}{l}158 \\
274\end{array}$ & $\begin{array}{c}24,6 \\
24,5 \\
p^{2}=0,87\end{array}$ & $-\overline{0,06}$ & {$[-0,98 ; 0,86]$} & $\begin{array}{l}149 \\
667\end{array}$ & $\begin{array}{c}24,9 \\
24,7 \\
p^{2}=0,74\end{array}$ & $-\overline{0,16}$ & {$[-0,89 ; 0,58 ;]$} \\
\hline $\begin{array}{c}\text { Uso de adoçante } \\
\text { Nåo } \\
\text { Sim }\end{array}$ & $\begin{array}{c}350 \\
82\end{array}$ & $\begin{array}{c}24,4 \\
25,2 \\
p^{2}=0,14 \\
\end{array}$ & $0, \overline{76}$ & $(-0,86 ; 2,37)$ & $\begin{array}{l}611 \\
208\end{array}$ & $\begin{array}{c}24,2 \\
26,6 \\
p^{2}<0,01 \\
\end{array}$ & 2,33 & $(1,07 ; 3,58)$ \\
\hline $\begin{array}{c}\text { N. refeiçסes/dia } \\
\text { Menos de } 4 \\
4 \text { ou mais }\end{array}$ & $\begin{array}{l}209 \\
224\end{array}$ & $\begin{array}{c}24,8 \\
24,2 \\
p^{2}=0,12 \\
\end{array}$ & $-0,59$ & {$[-1,36 ; 0,16]$} & $\begin{array}{l}332 \\
487\end{array}$ & $\begin{array}{c}25,0 \\
24,6 \\
p^{2}=0,19 \\
\end{array}$ & -0.47 & {$[-1.07 ; 0.12]$} \\
\hline $\begin{array}{r}\text { Refeiçỏes } \\
\text { frente à TV } \\
\text { Nảo } \\
\text { Sim }\end{array}$ & $\begin{array}{l}142 \\
291\end{array}$ & $\begin{array}{c}25,0 \\
24,3 \\
p^{2}=0,12 \\
\end{array}$ & $-\overline{0,64}$ & {$[-1,32 ; 0,04]$} & $\begin{array}{l}326 \\
493\end{array}$ & $\begin{array}{c}25,0 \\
24,6 \\
p^{2}=0,24 \\
\end{array}$ & $-\overline{-} 42$ & {$[-1,16 ; 0,30]$} \\
\hline
\end{tabular}

Abreviações: AF (atividade física). * $O$ tamanho da amostra ficou reduzido nos casos em que a variável não se aplica; $p^{4}$ (valor do $p$ no teste de tendência); $p^{2}$ (valor do $p$ no teste t de Student); $p^{3}$ (valor do $p$ na ANOVA) 
Tabela 1.5 - Coeficiente de correlação de Spearman entre valor do IMC e freqüência de consumo alimentar segundo sexo. Goiânia-GO, Brasil, 2001.

\begin{tabular}{lcccr}
\hline Grupos de alimentos & \multicolumn{2}{c}{ Homens } & \multicolumn{2}{c}{ Mulheres } \\
\cline { 2 - 5 } & $r_{\mathrm{Sp}}$ & $\mathrm{p}$ & \multicolumn{1}{c}{$\mathrm{r}_{\mathrm{Sp}}$} & $\mathrm{P}$ \\
\hline Leites e produtos derivados & 0,0399 & 0,41 & $-0,0050$ & 0,89 \\
Carnes de vaca, frango e porco & 0,1149 & 0,02 & 0,0781 & 0,02 \\
Peixes frescos e conserva & 0,0279 & 0,56 & $-0,0091$ & 0,79 \\
Ovos & $-0,0474$ & 0,32 & $-0,0715$ & 0,04 \\
Gorduras & $-0,0557$ & 0,25 & $-0,0741$ & 0,03 \\
Cereais e derivados & $-0,0828$ & 0,08 & $-0,1806$ & $<0,01$ \\
Verduras & 0,0091 & 0,85 & $-0,0139$ & 0,69 \\
Frutas & $-0,0415$ & 0,39 & $-0,0950$ & 0,01 \\
Leguminosas & $-0,0973$ & 0,04 & $-0,0381$ & 0,27 \\
Refrigerantes & $-0,0154$ & 0,75 & 0,0143 & 0,68 \\
Açúcar e doces & $-0,0660$ & 0,17 & $-0,1339$ & $<0,01$ \\
\hline
\end{tabular}

Abreviaçס̃es: $r_{s p}$ (coeficiente da correlaçăo de Spearman)

As tabelas 1.6 e 1.7 mostram os coeficientes do modelo de regressão linear múltipla hierarquizada que explicitam a influência das variáveis sóciodemográficas, estilo de vida, práticas alimentares e consumo de alimentos exerce sobre o IMC de homens e mulheres. Para os homens, o tabagismo e o consumo de bebidas alcoólicas ficaram como variáveis de ajuste por apresentarem na análise de regressão múltipla um $p<0,20$, assim como a situação conjugal e uso de adoçante na modelagem para as mulheres.

Entre os homens, observa-se que o IMC aumenta com a idade: os homens com maior nível de renda apresentaram média de IMC maior do que aqueles do $1^{\circ}$ quartil. A atividade física no lazer e no trajeto para o trabalho associaram-se negativamente ao IMC. O consumo de 4 ou mais refeições por dia também apresentou associação negativa com o IMC, a freqüência de consumo de leguminosas apresentou leve associação negativa $(p=0,09)$ e o consumo de carnes exibiu associação positiva com o IMC $(p<0,01)(T a b e l a$ 1.6). 
Tabela 1.6 - Fatores associados ao IMC identificados mediante análise de regressão linear múltipla hierarquizada em homens adultos. Goiânia-GO, Brasil, 2001.

\begin{tabular}{|c|c|c|c|}
\hline \multicolumn{4}{|l|}{$\begin{array}{l}\text { Variáveis } \\
\text { Faixa etária (anos) }\end{array}$} \\
\hline $\begin{array}{l}\text { Faixa etária (anos) }^{\mathrm{a}} \\
\qquad \begin{aligned} 20-24 \\
25-34 \\
35-44 \\
45-54 \\
55-64\end{aligned}\end{array}$ & $\begin{array}{l}- \\
1,79 \\
2,73 \\
3,74 \\
2,96\end{array}$ & $\begin{array}{l}- \\
0,53 ; 3,06 \\
1,54 ; 3,91 \\
3,10 ; 4,47 \\
1,89 ; 4,02\end{array}$ & $\begin{array}{r}- \\
0,01 \\
<0,01 \\
<0,01 \\
<0,01\end{array}$ \\
\hline $\begin{array}{l}1^{\circ} \text { Quartil } \\
2^{\circ} \text { Quartil } \\
3^{\circ} \text { Quartil } \\
4^{\circ} \text { Quartil }\end{array}$ & $\begin{array}{l}- \\
0,32 \\
1,29 \\
2,14\end{array}$ & $\begin{array}{r}-0,89 ; 1,53 \\
-0,18 ; 2,76 \\
0,82 ; 3,44\end{array}$ & $\begin{array}{r}0,60 \\
0,08 \\
<0,01\end{array}$ \\
\hline $\begin{array}{c}\text { Atividade física no lazer } \\
\text { Sedentário } \\
\text { Leve } \\
\text { Moderada }\end{array}$ & $\begin{array}{c}- \\
0,54 \\
-1,18\end{array}$ & $\begin{array}{l}- \\
-0,38 ; 1,47 \\
-1,92 ;-0,45\end{array}$ & $\begin{array}{l}0,- \\
0,25 \\
<0,01\end{array}$ \\
\hline $\begin{array}{c}\text { AF no trajeto para o trabalho }{ }^{c} \\
<15 \text { minutos } \\
\geq 15\end{array}$ & $-1,14$ & $-2,01 ;-0,27$ & $\overline{0,01}$ \\
\hline $\begin{array}{c}\text { Atividade física no trabalho }{ }^{c} \\
\text { Leve/Moderada } \\
\text { Intenso/muito intenso }\end{array}$ & $-\overline{0}, 68$ & $-1,47 ; 0,12$ & $\overline{0,09}$ \\
\hline $\begin{array}{l}\text { Número de refeições ao dia } \\
\text { Menos de } 4 \\
4 \text { ou mais } \\
\text { Carnes }^{d} \quad \\
\text { Leguminosas }^{d}\end{array}$ & $\begin{array}{r}- \\
-0,86 \\
1,11 \\
-0,59\end{array}$ & $\begin{array}{c}- \\
-1,50 ;-2,09 \\
0,45 ; 1,78 \\
-1,06 ;-0,09\end{array}$ & $\begin{array}{r}- \\
0,01 \\
<0,01 \\
0,09\end{array}$ \\
\hline $\begin{array}{l}\text { Modelo 1: faixa etária } \\
\text { " Modelo 2: modelo } 1+\text { renda } \\
\text { c Modelo 3: modelo } 2 \text { + tabagismo, } \\
\text { deslocamento para o trabalho e no t }\end{array}$ & & & $\mathrm{n}$ \\
\hline
\end{tabular}

Verifica-se que, para as mulheres, o IMC aumenta de forma progressiva e acentuada com o avanço da idade, a altura associa-se de forma negativa ao IMC, as ex-fumantes apresentaram média de IMC superior às não-fumantes, o comportamento sedentário de assistir televisão mais de 6 horas por dia favoreceu o aumento do IMC, a freqüência de consumo de cereais apresentou associação negativa e o consumo de carnes exibiu associação positiva com o IMC (Tabela 1.7). 
Tabela 1.7 - Fatores associados ao IMC identificados mediante análise de regressão linear múltipla hierarquizada em mulheres adultas. Goiânia-GO, Brasil, 2001.

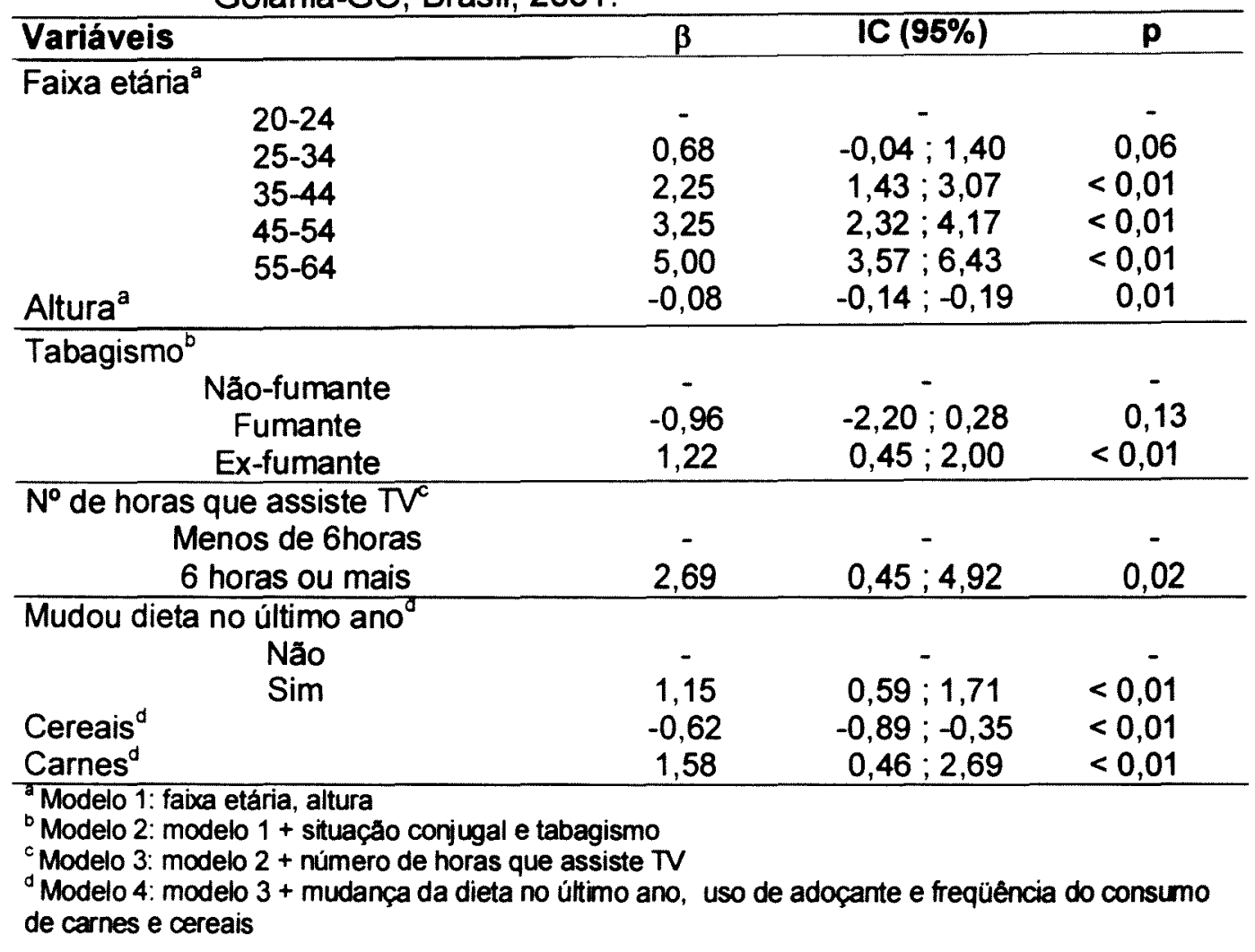

\section{DISCUSSÃO}

O objetivo deste estudo foi pesquisar a associação de variáveis relacionadas a condições sócio-demográficas, estilo de vida, atividade física, comportamento alimentar e freqüência de consumo alimentar e o IMC de indivíduos adultos da cidade de Goiânia (GO).

Vale enfatizar que mesmo existindo uma maior proporção de mulheres na amostra pesquisada, a comparação da distribuição da população estudada por faixa etária e anos de estudo, com os dados do IBGE (2000) mostrou que, considerando-se a faixa etária e anos de estudo, a amostra pode ser considerada representativa da população adulta de Goiânia (Figura 1.2). 
Homens

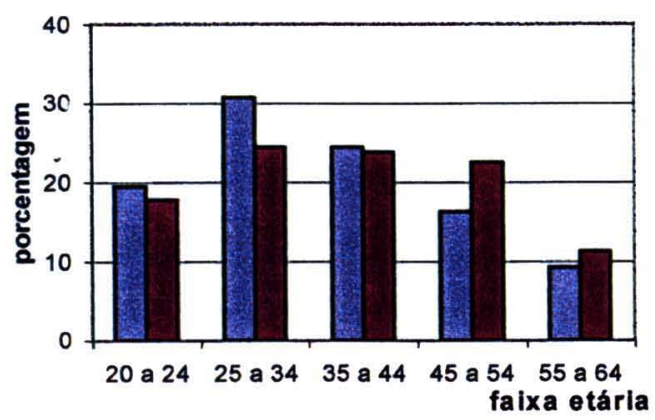

Homens

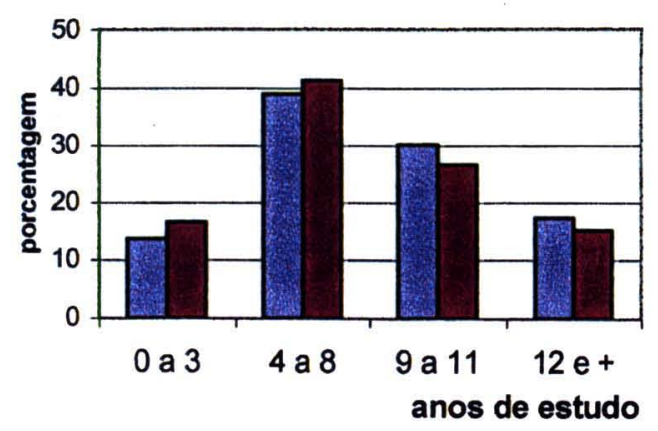

Mulheres

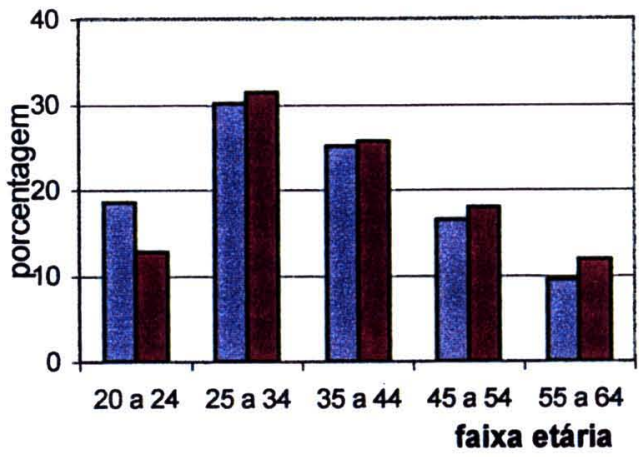

Mulheres

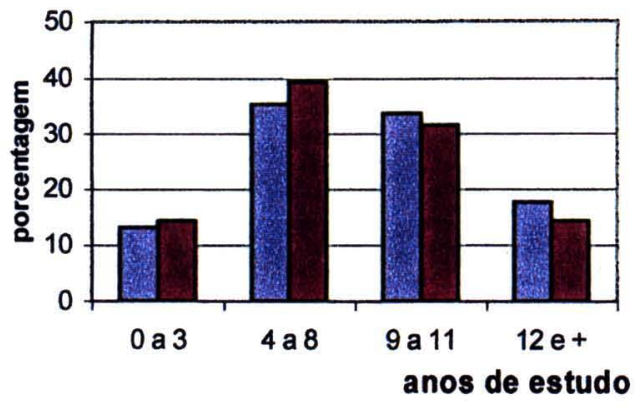

\section{IBGE ESTUDO}

Figura 1.2 - Distribuição de homens e mulheres por faixa etária e anos de estudo segundo os dados do IBGE (Censo 2000) e do presente estudo. Goiânia-GO, Brasil, 2001.

O questionário de freqüência alimentar simples utilizado nesta pesquisa foi constituído por 2 componentes: uma lista de alimentos e preparações e a freqüência com que os alimentos e preparações são ingeridos. A utilização deste tipo de questionário permite conhecer a freqüência de consumo de alimentos ou grupos de alimentos, sem categorizar os indivíduos de acordo com o consumo de nutrientes ou de energia (WILLET 1998). Os 140 alimentos contidos na lista contemplam os hábitos alimentares da área estudada, visto que foram retirados de um levantamento sobre o consumo alimentar da população de Goiânia no ano de 1996 (GIL et al. 1997). 
A inclusão do tamanho da porção de cada item alimentar permite a estimativa do teor de nutrientes em questionários de freqüência alimentar (QFA). Porém esta não é uma tarefa simples, pois o tamanho das porçōes deve ser pesquisado na população de estudo, uma vez que as porções alimentares padronizadas representam medidas de conveniência e aproximação que geralmente não correspondem às quantidades que habitualmente são consumidas. Assim, para a utilização de QFA quantitativos ou semiquantitativos, são necessários estudos prévios de reprodutibilidade e validação do instrumento na população de interesse (WILLET 1998). Neste contexto, para que esta pesquisa fosse economicamente viável e metodologicamente adequada, optou-se por estudar apenas a freqüência de consumo alimentar, utilizando para isto a metodologia de análise adequada a este tipo de questionário de freqüência alimentar (FORNES et al. 2002).

A maior limitação deste estudo é o seu delineamento transversal, que não permite estabelecer com segurança a precedência no tempo entre as variáveis pesquisadas e o desfecho. No entanto, mostra a prevalência e a distribuição das variáveis de interesse e permite testar hipóteses já estabelecidas e propor outras para serem testadas posteriormente, em estudos com delineamentos mais apropriados.

Merece destaque neste estudo a forma hierarquizada utilizada na análise de regressão múltipla, sendo atualmente a metodologia estatística mais apropriada para testar o efeito de fatores segundo a precedência de sua atuação sobre o desfecho. Outro ponto positivo é ser uma pesquisa com amostra representativa da área urbana do município de Goiânia, com coleta de dados realizada no domicílio dos entrevistados por entrevistadores bem treinados.

Na falta de dados anteriores específicos para Goiânia, a comparação com os dados da PNSN, 1989 (COITINHO et al. 1991) para a região CentroOeste mostra que a prevalência de sobrepeso e de obesidade aumentou para ambos sexos, porém de forma muito mais acentuada para os homens. Para eles, a prevalência de sobrepeso passou de $22,6 \%$ para $31,2 \%$ e a 
obesidade foi de $4,8 \%$ para $10,7 \%$. Já para as mulheres, a prevalência de sobrepeso passou de $26,5 \%$ para $29,2 \%$ e a obesidade foi de $11,7 \%$ para $13,8 \%$. A maior prevalência de sobrepeso, mas năo de obesidade, para os homens do que para as mulheres é semelhante aos resultados de estudos realizados nos Estados Unidos (MOKDAD et al. 2001; LIEBMAN et al. 2003) e na Finlândia (LAHTI-KOSKI et al. 2002). Vale destacar, no entanto que a prevalência da obesidade nestes paises è mais do que 0 dobro da prevalência observada na população pesquisada.

A OMS (WORLD HEALTH ORGANIZATION 1997) recomenda, para áreas em desenvolvimento, um IMC médio de $23 \mathrm{~kg} / \mathrm{m}^{2}$ e, para as áreas desenvolvidas, um IMC médio de $21 \mathrm{Kg} / \mathrm{m}^{2}$. De modo geral, observa-se que a média de IMC encontra-se elevada em ambos os sexos, em todos os niveis de escolaridade e de renda, em todas as faixas etárias, com exceção dos mais jovens, o que ressalta a importância da obesidade como problema de saúde pública e remete à necessidade de se conhecer quais fatores sociais e comportamentais estão relacionados ao excesso de peso.

Para as variáveis sócio-demográficas, observou-se aumento do IMC concomitante ao aumento da renda somente para os homens, o que está em concordância com os resultados da PNSN -1989 (SICHIERI et al. 1994). Alguns estudos mostram que o sobrepeso e a obesidade estão inversamente associados ao nivel sócio-econômico em paises desenvolvidos (WAMALA et al. 1997; LAHTI-KOSKI et al. 2002; LIEBMAN et al. 2003), particularmente entre as mulheres, mas estăo positivamente relacionados ao nível sócio-econômico em populaçőes de países em desenvolvimento (MARTOREL et al. 2000; MOLARIUS et al. 2000).

Vale destacar estudo de MONTEIRO et al. (2004) que mostra a distribuição social da obesidade em mulheres (20-49 anos) de 37 paises em desenvolvimento $(n=148579)$ e constata que fazer parte do menor estrato sócio-econômico confere uma forte proteção contra a obesidade em paises com baixo produto interno bruto (PIB < US\$ 745 per capita), mas é forte fator de risco para as regiões com economias mais desenvolvidas (PIB $\geq$ US $\$$ 
2995 per capita). É importante mencionar que o aumento da prevalência da obesidade, entre as mulheres de mais baixa renda, já havia sido identificado também nas áreas urbanas da região economicamente mais desenvolvida do Brasil, região Sudeste (MONTEIRO et al. 1999).

Para ambos os sexos, não houve associação entre o IMC e a escolaridade. Ao contrário do esperado, os indivíduos com maior nível de escolaridade não controlaram melhor seu peso do que os demais, em função de um suposto maior grau de conhecimento sobre saúde e alimentação saudável.

As evidências de estudos realizados em paises desenvolvidos (RISSANEN et al. 1991; GUTIÉRREZ-FISAC et al. 1996; MOKDAD et al. 2001) e os resultados observados por MONTEIRO e CONDE, 1999 e MONTEIRO et al. (2000) para mulheres da região Sudeste do Brasil mostram que há uma tendência secular, inicialmente entre as mulheres, para uma associação negativa entre escolaridade e IMC. As evidências mostram que esta influência é dependente do grau de desenvolvimento da população (GUTIÉRREZ-FISAC et al. 1996; MARTORELL et al. 2000; MOLARIUS et al. 2000), sendo que no Brasil a heterogeneidade social e econômica pode promover a existência de situações diferenciadas, entre risco e proteção.

Assim como em outros estudos (GIGANTE et al. 1997; KRUGER et al. 2000), não foi observada associação entre IMC e paridade. O IMC aumentou de forma significativa com o aumento do número de filhos, porém sua influência perdeu significância estatística após controle pela idade.

A presença do companheiro no domicilio pode levar a mudança nos padrões de dieta e atividade física, favorecendo o ganho de peso (WOO et al 1999; HU G et al. 2002). No presente estudo, a situação conjugal mostrou associação com a obesidade na análise univariada, somente entre os homens. No entanto, o efeito desta variável perdeu significância estatística na análise múltipla, após ajuste pelas variáveis sócio-econômicas.

$\mathrm{Na}$ análise univariada, observou-se uma associação negativa entre consumo de bebidas alcoólicas e IMC, independente da quantidade, tanto entre homens como entre mulheres, porém a associação não se manteve 
significativa na análise múltipla. Ao contrário dos alcoólatras, os consumidores moderados de bebidas alcoólicas tendem a consumir mais energia do que os não consumidores (WESTERPER-PLATENGA e VERWEGEN 1999). Porém, os estudos epidemiológicos mostram resultados controversos sobre a associação entre consumo de álcool e IMC. Os resultados do Nurses' Health Study (COLDITZ et al. 1991) e de outros estudos (LIEBMAN et al. 2003; LAHTI-KOSKI et al. 2002) mostram uma relação inversa entre ingestão de álcool e IMC para as mulheres, o que também foi observado para os homens (MOKDAD et al. 2001). Entretanto, no Profissionals Health Study (COLDITZ et al. 1991), não houve associação entre consumo de álcool e IMC para homens.

Não foi encontrada diferença de IMC entre fumantes e não-fumantes, para homens e mulheres. A associação entre IMC e tabagismo é um tema polêmico nos estudos epidemiológicos, pois alguns têm observado associação inversa (ECK et al. 1992; HU G et al. 2002), enquanto outros não têm observado associação (COLDITZ et al. 1991) ou mesmo encontrado uma associação positiva (MARTI et al. 1989). Esta diferença de resultados pode ser parcialmente explicada pelos resultados de um estudo do Projeto MONICA (MOLARIUS et al. 1997), que analisou a magnitude e a consistência da associação entre tabagismo e IMC em 42 populações. Os homens e mulheres que fumavam geralmente pesavam menos do que os que nunca fumaram (as diferenças variaram de $-2,4$ a $0,5 \mathrm{~kg} / \mathrm{m}^{2}$ para homens e de $-2,9$ a $-0,1 \mathrm{~kg} / \mathrm{m}^{2}$ para mulheres), sendo esta associação menos aparente em populações com proporção relativamente baixa de fumantes e alta proporção de ex-fumantes. Estes resultados sugerem que a associação inversa "clássica" entre IMC e tabagismo, com o tempo, pode perder força em populações com extensas campanhas antitabagismo (Estudos Unidos, Finlândia e Austrália) ou em grupos de fumantes que apresentam um conjunto de hábitos não saudáveis associados ao ganho de peso, tais como sedentarismo e maior consumo de gorduras.

No presente estudo, os ex-fumantes mostraram-se mais pesados do que aqueles que nunca haviam fumado ou fumavam no período do estudo, 
para ambos os sexos. Esta associação, entretanto, manteve-se significativa na análise múltipla apenas para as mulheres. Este achado é coerente com os resultados de estudos longitudinais que indicam que as mulheres que param de fumar ganham mais peso do que os homens (WILLIANSON et al. 1991), porém sua contribuição para o aumento da obesidade tem sido pequena ou mesmo nula (ARTALEJO et al. 2002).

O método utilizado para avaliar a atividade física neste estudo não permitiu uma análise mais precisa do gasto energético, principalmente por não considerar quantas horas por dia são gastas com cada tipo de atividade física e também por não levar em conta as atividades físicas desenvolvidas no domicilio. Apesar destas limitações, foi observada associação inversa entre atividade física nos momentos de lazer e IMC para homens, mas não para mulheres. O resultado para os homens está de acordo com outros estudos (KING et al. 2000; LAHTI-KOSKI et al. 2002; MADDAH et al. 2003). Já a falta de associação observada para as mulheres, apesar de não ser o esperado, visto que a atividade física é um importante determinante do gasto energético, foi também observada em outros estudos (SLATERRY et al. 1992; WAMALA et al. 1997; MADDAH et al. 2003).

Com relação à atividade física no trabalho, não foi observada associação entre IMC e atividade física ocupacional para ambos os sexos, semelhante ao observado em outros estudos (ARTALEJO et al. 2002; LAHTI-KOSKI et al. 2002). No entanto, KING et al. (2000), analisando os dados do NHANES III, observaram que a atividade física ocupacional intensa pode reduzir pela metade a probabilidade de obesidade, especialmente para aqueles que praticam pouca ou nenhuma atividade física no seu tempo livre. Na presente pesquisa observou-se que as atividades físicas realizadas no trabalho são predominantemente de baixo gasto energético, principalmente para as mulheres. Ressalta-se que uma limitação do instrumento utilizado foi considerar em uma mesma categoria (inativo) os indivíduos com atividade leve e aqueles que referiram não terem trabalhado fora no último ano. 
Nesta pesquisa, os homens que usavam veículos motorizados como meio de transporte para o trabalho apresentaram média de IMC superior ao daqueles que se locomoviam a pé ou de bicicleta. Em um estudo realizado em Taijin (uma das maiores cidades da China), homens e mulheres que iam caminhando ou de bicicleta para o trabalho apresentaram uma probabilidade $50 \%$ menor de excesso de peso em análise ajustada pelas variáveis sóciodemográficas, estilo de vida, consumo alimentar e atividades físicas no lazer e no trabalho (HU G et al. 2002).

Dentre os vários comportamentos sedentários, assistir televisão por tempo prolongado tem mostrado ser o fator que representa maior risco para o desenvolvimento de obesidade e diabetes em estudos de coorte (HU FB et al. 2003; LIEBMAN et al. 2003). Para cada aumento de 2 horas no tempo gasto assistindo televisão, havia um aumento de 23\% (IC95\%, 17-30\%) no risco de obesidade (HU FB et al. 2003). Neste estudo, a análise múltipla mostrou que, para as mulheres, assistir televisão por tempo prolongado eleva significativamente o IMC. As mulheres que gastavam mais tempo assistindo televisão praticavam menos atividades físicas nos momentos de lazer e consumiam frutas e verduras com menor freqüência do que as mais ativas ( $p<0,001$ - dados não mostrados).

Foi observada, na análise de correlação de Spearman, uma associação positiva do IMC com a freqüência do consumo de carne e uma associação negativa com o consumo de ovos, gorduras, cereais, frutas e doces para as mulheres. Para os homens, as carnes apresentaram associação positiva e as leguminosas, associação negativa. Vale ressaltar, no entanto, a ausência de ajuste pela idade nesta etapa da análise. Já na análise múltipla, para as mulheres permaneceu significativo apenas 0 consumo de cereais (associação negativa) e de carnes (associação positiva). Para os homens, manteve-se a associação observada na correlação de Spearman. Resultados semelhantes para a ingestão de cereais (principal fonte de carboidratos da dieta), de leguminosas (fonte de proteínas e fibras) e de carnes (importante fonte de gorduras e proteinas) 
foram observados em outros estudos transversais (SLATERRY et al. 1992; HU G et al. 2002; LAHTI-KOSKI et al. 2002).

A falta de associação entre a freqüência do consumo de doces e o IMC pode refletir modificações na dieta dos indivíduos com o IMC elevado, com o objetivo de redução de peso, mas também pode ser resultado da omissão ou da diminuição na freqüência com que informam consumir estes alimentos, reconhecidamente calóricos. Além disso, outra explicação possível é que a quantidade de doces consumida e não a freqüência seja 0 diferencial entre os indivíduos eutróficos e obesos estudados. No sentido oposto ao dos doces, pode ter havido uma superestimação na freqüência do consumo de alimentos de baixa densidade energética, como frutas e verduras, por ser uma conduta socialmente desejável. Portanto, a falta de associação entre variáveis comportamentais e IMC pode sofrer tanto influência do desenho do estudo quanto de um viés de informação (ROMIEU et al. 1988; HEBERT et al. 1995).

Além do excesso calórico, o número de refeições diárias parece afetar a regulação do peso corpóreo e a lipogênese, visto que os indivíduos obesos freqüentemente tendem a comer muitos dos alimentos em uma única refeição, geralmente no final da tarde ou à noite. Porém, nem todos os estudos têm observado associação entre o número de refeições e a obesidade (WIHELMINE et al. 1993; GIGANTE et al. 1995). No presente estudo, o hábito de fazer 4 ou mais de refeições por dia foi um fator de proteção contra o excesso de peso entre os homens, resultado que reforça a premissa de que o padrão alimentar associado à obesidade é irregular e/ou desorganizado (BLUNDELL e GILLET 2001). Já o hábito de fazer uma ou mais refeições em frente à televisão não interferiu no IMC para ambos sexos.

Este estudo apresenta a prevalência do excesso de peso na população adulta de Goiânia-GO, além de identificar os fatores que se associam de forma independente ao IMC. Observou-se alta prevalência de excesso de peso, sendo de $41,9 \%$ para os homens $(31,2 \%$ de sobrepeso e 
$10,7 \%$ de obesidade) e de $43,0 \%$ para as mulheres $(29,2 \%$ de sobrepeso e $13,8 \%$ de obesidade). Esta prevalência aumenta com a idade, para homens e mulheres, e com a renda, apenas para os homens. Observou-se também que um estilo de vida ativo, juntamente com a ingestão de mais cereais $e$ menos carnes, parece oferecer maior proteção contra a elevação do IMC.

\section{REFERÊNCIAS BIBLIOGRÁFICAS}

1. Artalejo FR, Garcia EL, Gutiérrez-Fisac JL, Banegas JRB, Urdinguio PJL, Rojas VD. Changes in the Prevalence of overweight and obesity and their factors in Spain, 1987-1997. Preventive Medicine 2002: 34; 72-81.

2. Baik I, Ascherio A, Rimm EB, Giovannucci E, Spiegelman D, Stampfer MJ, Willet WC. Adiposity and mortality in men. American Journal of Epidemiology 2000;152(3): 264-70.

3. Blundell JE, Gillet A. control of food intake in the obese. Obes Res 2001; 9(Suppl 4): 263S-270S.

4. Colditz GA, Giovannucci E, Rimm EB, Stampfer MJ, Rosner B, Speizer FE, Gordis $E$, Willett W. Alcohol intake in relation to diet and obesity in women and men. Am J Clin Nutr 1991; 54: 49-55.

5. Coitinho DC, Leão MM, Recine $E$, Sichieri R. Condiçőes nutricionais da população brasileira: adultos e idosos:Pesquisa Nacional sobre Saúde e Nutrição. Brasilia : INAN/Instituto Nacional de Alimentação e Nutrição; 1991.

6. Eck LH, Hackett-Renner C, Klesges. Impact of diabetic status, dietary intake, physical activity, and smoking status on body mass index in NHANES II. Am J Clin Nutr 1992; 56: 329-33.

7. Fornés NS, Martins IS, Velásquez-Meléndez G, Latorre MRDO. Escores de consumo alimentar e niveis lipêmicos em população de São Paulo, Brasil. Rev Saúde Pública 2002; 36(1): 12-18. 
8. Franco G. Tabela de Composição Química dos Alimentos. 9a ed. Rio de Janeiro: Atheneu, 1999. 307p.

9. Gigante DP, Barros FC, Post CLA, Olinto MTA. Prevalência de obesidade em adultos e seus fatores de risco. Rev. Saúde Pública 1997; 31(3): 236-46.

10. Gil MF, Braga VLN, Cunha DTO, Monego ET, Reis MAC, Moreira MA, Antunes MJC, Bonfim S, Souza MCHS, Borges CD. Freqüência alimentar, estado nutricional, atividade física e renda familiar em Goiânia - dados preliminares.In: Congresso Brasileiro de Saúde Coletiva, 5, 1997, águas de Lindóia. Anais. Águas de Lindóia: ABRASCO, 1997. p.317.

11. Gutiérrez-Fisac JF, Regidos E, Rodriguez C. Trends in obesity differences by educational level in Spain. J Clin Epidemiol. 1996; 49: 351-354.

12. Hebert JR, Clemow L, Pbert L, Ockene IS, Ockene J. Social desirability bias in dietary self-report may compromise the vality of dietary intake measures. International Joumal of Epidemiology 1995; 24(2): 389-398.

13. Hu FB, Li TY, Colditz GA, Willet WC, Manson JE. Television watching and other sedentary behaviors in relation to risk of obesity and type 2 diabetes mellitus in women. JAMA 2003; 289 (14):1785-1791.

14. Hu G, Pekkarinen H, Hänninen, Tian H Jin R. Comparison of dietary and non-dietary risk factors in overweight and normalweight Chinese adults. British Journal of Nutrition 2002; 88: 91 97.

15. Fundação IBGE. Censo demográfico 2000 [2000]. Disponível em URL:http::/hww ibge.gov.brl. 
16. Instituto Nacional de Alimentação e Nutrição/IPEAIBGE. Pesquisa Nacional sobre Saúde e Nutrição: condiçōes nutricionais da população brasileira - adultos e idosos. Brasília, 1991.

17. Kannel WB, Brand, Skinner JJ, Drawber TR, Mcnamara M. The relation of obesity to blood pressure and development of hypertension: The Framingham Study. Ann Inter Med 1967; 67: 48-59.

18. King GA, Fitzhugh EC, Basset Jr DR, McLaughlin JE, Strath SJ, Swartz AM, Thompson DL. Relationship of leisure-time physical activity and occupational activity to the prevalence of obesity. International Journal of Obesity $2000 ; 25$ : 606-612.

19. Kruger HS, Venter CS, Voster HH, Margetts BM. Physical inactivity is the major determinant of obesity in black women in the North West Province, South Africa: The THUSA Study. Nutrition 2000; 18: $422-427$.

20. Lahti-Koski M, Pietnen P, Heliovaara M, Vartiainen E. Associations of body mass indes and obesity with physical activity, alcohol intake, and smoking in the 1982-1997 FINRISK studies. Am J Clin Nutr 2002; 75: 809-817.

21. Liebman M, Pelican S, Moore SA, Holmes B, Wardlaw MK, Melcher LM, Liddil AC, Paul LC, Dunnagan T, Haynes GW. Dietary intake, eating behavior, and physical activity-related determinants of high body mass index in rural communities in Wyoming, and Idaho. International Journal of Obesity 2003; 27: 684-692.

22. Lohman TG, Roche AF, Martorel R. Anthropometric standardization reference manual. Illinois: Human Kinetics Books, 1988.

23. Maddah M, Eshraghian MR, Djazayery A, Mirdamadi R. Association of body mass index with educational level in Iranian 
men and woman. European journal of Clinical Nutrition 2003; 57: 819-823.

24. Manson JE, Colditz GA, Stampfer MJ, Willet WC, Rosner B, Monson RB, Speizer FE, Hennnekens $\mathrm{CH}$. A prospective study of obesity and risk of coronary heart disease in women. The Now England Journal of Medicine 1990; 322(13): 882-889.

25. Marti B, Tuomilehto J, Korhonen HJ, Kartovaara L, Vartiainen E, Pietinen P, Puska P. Smoking and leanness: evidence for change in Finland. BMJ 1989; 298:1287-1290.

26. Martorell R, Khan LK, Hughes MI, Grummer-Strawn. Obesity in women from developing countries. European Journal of Clinical Nutrition. 2000; 54: 247-252.

27. Ministério da Saúde. Controle da hipertensão arterial: uma proposta de integração ensino-serviço. Rio de Janeiro: CDCV/NUTES, 1993. 233p.

28. Mokdad AH, Bowman BA, Ford ES, Vinicor F, Marks JS, Koplan $J P$. The continuing epidemics of obesity and diabetes in the United States. JAMA 2001; 286: 1195-1200.

29. Molarius A, Seidell Jc, Sans S, Tuomilehto J, Kuulasmaa K. Educational level, relative body weight, and changes in their association over 10 years: an international perspective from the WHO MONICA Project. Am. J. Public Health 2000;90:1260-1268.

30. Molarius A, Seidell, Kuulasmaa K, Dobson AJ, Sans S. Smoking and relative body weight : na international perspective from the WHO Mônica Project. Journal of Epidemiology an Community Health 1997; 51: 252-260.

31. Monteiro CA, Benício MHA, Popkin BM. Economic and culturaleducational predictors of overweight in urban and rural Brazilian women. Rev Bras Nutr Clin 2000; 15: 253-260. 
32. Monteiro CA, Conde WL, Lu B, Popkin BM. Obesity and inequities in health in the developing world. International Journal of Obesity 2004:1-6.

33. Monteiro CA, Conde WL. A tendência secular da obesidade segundo estratos sociais: Nordeste e Sudeste do Brasil, 19751989-1997. Arq Bras Endocrinol Metab 1999; 43(3): 186-94.

34. Monteiro CA. Epidemiologia da obesidade. In: Halpern A, Matos AFG, Suplicy HL, Mancini MC, Zanella MT. Obesidade. São Paulo: Lemos Editorial; 1998. p. 15-30.

35. Monteiro CA, Conde WL, Lu B, Popkin BM. Obesity and inequities in health in the developing world. International Journal of Obesity 2004. p.1-6.

36. Organización Panamericana de la Salud. Protocolo y directrices: Conjunto de Ações para la Reducción Multifactorial de Enfermedades no Transmisibles (CARMEN/CINDI). OPAS; 1997.

37. Rissanen AM, Heliövaara $M$, Knekt $P$, Reunanen A, Aromaa A. Determinants of weight and overweight in adult Finns. European Joural of Clinical Nutrition 1991; 45: 419-430.

38. Romieu I, Willet WC, Stampfer MJ, Colditz GA, Sampson L, Rosner $B$, Hennekens $\mathrm{CH}$, Speizer FE. Energy intake and other determinants of relative weight. Am J Clin Nutr 1988; 47: 406-12.

39. Slaterry ML, McDonald, Bild DE, Caan BJ, Hilner JE, Jacobs DR, Liu Kiang. Associations of body fat and its distribution with dietary intake, physical, alcohol, and smoking in blacks and whites. Am J Clin Nut 1992; 55: 943-949.

40. Sichieri R, Coitinho DC, Leão MM, Recine E, Everhart JE. High temporal, geographic, and income variation in body mass index among adults in Brazil. Am J Publlic Health 1994; 84: 793-798.

41. Victora CG, Huttly S, Fuchs SC, Olinto MT. The role of conceptual frameworks in epidemiological analysis: ahierarchical approach. 
International Journal of Epidemiology 1997; 26: 224-7.

42. Wamala SP, Wolk A, Orth-Gomér. Determinants of obesity in relation to socioeconomic status among middle-aged swedish women. Preventive Medicine 1997; 26: 734-744.

43. Westerterper-Plantenga MS, Verwegen CRT. The appetizing of na apéritif in overweight and normal-weight humans. Am $\mathrm{J}$ Clin Nutr 1999; 69: 205-212.

44. Wilhelmine PHG, Verboeket VDV, Westerterp KR, Kester ADM. Effect of the pattern of food intake on human energy metabolism. British Joumal of Nutrition 1993; 70: 103-115.

45. Willet W. Nutritional Epidemiology. $2^{\text {th }}$ edition; Oxford University Press. New York, 1998.

46. Willianson DF, Madans J, Anda RF, Klieinman JC, Giovino GA, Byers $T$. smoking cessation and severity of weight gain in a national cohort. N Engl J Med 1991; 324: 739-745.

47. Woo J, Leung SSF, Ho SC, Sham A, Lam TH, Janus ED. Influence of educational level and marital status on dietary intake, obesity and other cardiovascular risk factors in a Hong Kong Chinese population. European Journal of Clinical Nutrition 1999:53:461467.

48. World Health Organization. Obesity: Preventing and Managing the Global Epidemic. Report. Geneva; 1997. 
ARTIGO 2

CIRCUNFERÊNCIA DA CINTURA E ÍNDICE DE MASSA CORPORAL COMO PREDITORES DA HIPERTENSÃO ARTERIAL

WAIST CIRCUNFERENCE AND BODY MASS INDEX AS PREDICTORS OF HYPERTENSION 


\section{RESUMO}

Objetivos: Avaliar a associação entre os indices antropométricos, índice de massa corporal (IMC) e circunferência da cintura (CC), e a hipertensão arterial (HA) e avaliar a capacidade preditiva dos pontos de corte recomendados para estes índices antropométricos na identificaçăo da HA da população adulta do Município de Goiânia. Métodos: Este é um estudo transversal de base populacional realizado em Goiânia (GO), em 2001, com uma amostra de 1238 individuos entre 20 e 64 anos de idade. Foi definido como obesidade total o IMC $\geq 30 \mathrm{kgm}^{2}$, como obesidade abdominal a CC no nível 2 ( $C C \geq 88 \mathrm{~cm}$ para mulheres e $\geq 102 \mathrm{~cm}$ para homens) e como $\mathrm{HA}$ valores de pressão sistólica $\geq 140 \mathrm{mmHg}$ ou pressão diastólica $\geq 90 \mathrm{mmHg}$ ou, ainda, uso de medicamentos hipotensores. As associaçōes entre os índices antropométricos (IMC e CC) e a HA foram obtidas por meio de análise de regressão logística múltipla ajustada por fatores de confusăo. A curva ROC foi utilizada para avaliar a sensibilidade e a especificidade dos pontos de corte do IMC ( $\geq 30)$ e do nivel 2 da CC na predição da HA e para determinar o ponto de corte para a $\mathrm{CC}$ e para o IMC que identifica o maior número de indivíduos com ou sem o risco de HA. Resultados: A CC apresentou associaçăo com a HA em ambos sexos; já o IMC apresentou associação apenas para as mulheres. Porém os pontos de corte da CC no nivel 2 apresentaram baixa sensibilidade (12,5\% para homens e $33,6 \%$ para mulheres) em identificar a HA, o que também foi observado para o IMC $\geq 30$ $\mathrm{kg} / \mathrm{m}^{2}$. Os pontos de corte com melhor capacidade preditiva de $\mathrm{HA}$ coincidiram com o nivel $1 \mathrm{da} C \mathrm{C}$ e $\circ \mathrm{IMC} \geq 25 \mathrm{kgm}^{2}$, para as mulheres, e foram inferiores a estes valores para os homens. Conclusão: Os pontos de corte utilizados para classificação da obesidade, nivel 2 da CC e o IMC $\geq$ $30 \mathrm{kgm}^{2}$, não são adequados para identificar os grupos de maior risco para a HA, uma vez que este risco já se eleva com pequenos aumentos na adiposidade.

Palavras-chave: circunferência da cintura, índice de massa corporal, hipertensão 


\section{ABSTRACT}

Objective: The aim of this study was to examine the association between two anthropometric indexes - body mass index (BMI) and waist circumference (WC) - and hypertension and to assess the predictive value of the cut-off points recommended for these indexes, for the purpose of identifying high blood pressure in the adult population of Goiannia. Methods: This cross-sectional study of the population of Goiania (GO) was carried out in 2001, and consisted of a sample of 1238 individuals aged $20-64$ years. A BMI of $\geq 30 \mathrm{kgm} 2$ was defined as total obesity and abdominal obesity was defined as a level 2 WC W $\mathrm{C} \geq 88 \mathrm{~cm}$ for women and $\geq 102 \mathrm{~cm}$ for men). Systolic values of $\geq 140 \mathrm{mmHg}$ or $\geq 90 \mathrm{mmHg}$ diastolic were defined as hypertension. Another marker was the use of hypotensive medication. Multiple logistic regression analysis adjusted for confusion factors was used to obtain the association between the anthropometric indexes (BMI and $\mathrm{W}$ ) and hypertension. The analyses of the ROC curve was used to examine the sensitivity and specificity of the cut-off points for BMI $(\geq 30)$ and of level 2 WC in predicting hypertension, and determining the cut-off points for the WC and BMI values that could identify the highest number of individuals at risk of developing hypertension, as opposed to those who wouldn't be at risk. Results: WC showed a significant relationship to hypertension for both men and women, while for BMI this association applies for women only. However the sensitivity of the cut-off points for level 2 WC was low $(12,5 \%$ for men and $33,6 \%$ for women), for the purpose of identifying hypertension. A similar observation had already been made for the $\mathrm{BMI} \geq 30$ $\mathrm{kg} / \mathrm{m} 2$. There was risk of hypertension for WC values below the recommended levels for level 2 WC. Conclusion: The cut-off points for BMI ( $\left.\geq 30 \mathrm{~kg} / \mathrm{m}^{2}\right)$ and of level 2 WC, are not adequate in identifyingy the highest number of individuals at risk of hypertension, since this risk increases with a small adiposity enlarging.

Key-words: waist circumference, body mass index, hypertension 


\section{INTRODUÇÃO}

A obesidade é definida como um excesso de gordura corporal, resultante do desequilíbrio crônico entre consumo alimentar e gasto energético. Entre os prejuizos causados pela obesidade, destaca-se o fato dela ser um fator de risco independente para o desenvolvimento das doenças cardiovasculares e alguns tipos de cânceres. Além de estar fortemente associada a outros fatores de risco cardiovasculares (hipertensão, diabetes e dislipidemias), elevando a magnitude da morbimortalidade pelas doenças cardiovasculares (HUBERT et al 1983; MANSON et al. 1990; WILLETT et al. 1995; OKOSUN et al 2000a ORGANIZATION 1997).

Para o diagnóstico da obesidade, existem vários métodos indiretos que permitem estimar com precisão a quantidade total de gordura corpórea, assim como sua distribuição. Entre estes métodos destacam-se a tomografia computadorizada, a absorciometria por raios- $X$ de dupla energia (DEXA) e a ressonância magnética. Para a realização de estudos epidemiológicos, entretanto, considerando-se a simplicidade e os custos dos diversos métodos, tem sido recomendada a utilização de indices antropométricos: o índice de massa corporal (IMC), a relação cintura-quadril (RCQ) ou apenas a circunferência da cintura (CC) e as dobras cutâneas (DC) (BRAY 1988; WORLD HEALTH ORGANIZATION 1997).

Apesar de não medir a composição corporal, o IMC possui bom potencial como indicador do estado nutricional em estudos epidemiológicos. Sua utilizaçăo baseia-se nos resultados de estudos populacionais que mostram que o IMC é pouco correlacionado com a altura e altamente correlacionado com a massa de gordura absoluta e na associação existente entre IMC elevado e morbi-mortalidade por doenças cardiovasculares, diabetes mellitus, câncer de cólon e doenças das vias biliares (GARROW 1988; REXROADE et al. 1997, STEVENS 2000, CALLE et al., 1999).

A relação entre $I M C$ e risco de morbidades, no entanto, pode ser 
afetada pela distribuição da gordura corpórea, visto que as principais complicações da obesidade, que incluem doenças cardiovasculares, diabetes mellitus, hipertensão e hiperlipidemia, estão associadas ao maior acúmulo de gordura abdominal, independente do peso corpóreo (DESPRÉS et al. 1985; TAYLOR et al 1988; HAUNER et al. 1994).

A comparação das medidas antropométricas com exames de diagnóstico por imagens, como a ressonância magnética e a tomografia computadorizada, mostra que a circunferência da cintura foi a variável antropométrica que apresentou melhor correlação com 0 tecido adiposo visceral (POULIOT et al. 1994). Desta maneira, uma medida mais sensível para avaliar a gordura abdominal pode ser mais útil do que o IMC para identificar fatores de risco associados à obesidade.

Os pontos de corte atualmente utilizados para a classificação da CC foram definidos por LEAN et al. (1995) em um estudo transversal com uma amostra de 904 homens e 1014 mulheres entre 25 e 74 anos de idade da população do norte de Glasgow. Foram identificados os pontos de corte da CC que se associavam ao IMC $25 \mathrm{~kg} / \mathrm{m}^{2}$ e $30 \mathrm{~kg} / \mathrm{m}^{2}$ e/ou a $R C Q \geq 0,95$ para os homens e $\geq 0,80$ para as mulheres. Para facilitar sua utilização, tanto no uso clínico como em programas de promoção de saúde, estes pontos de corte foram descritos como niveis de ação: no nível 1 de ação (CC $\geq 80 \mathrm{~cm}$ em mulheres e $\mathrm{CC} \geq 94 \mathrm{~cm}$ em homens), o indivíduo apresenta risco aumentado para morbidades associadas à obesidade e deve ser aconselhado a parar de ganhar peso e adotar um estilo de vida saudável; no nível 2 ( $\geq 88$ em mulheres e $\geq 102$ em homens), o indivíduo apresenta risco muito aumentado para as morbidades associadas à obesidade e deve procurar ajuda, urgente, de um profissional de saúde para perda de peso e pesquisa de outros fatores de risco.

Questiona-se, no entanto, o uso universal dos pontos de corte definidos por LEAN et al (1995), visto que a sensibilidade destes na identificação dos fatores de risco associados à obesidade pode variar entre as diversas 
populaçōes e os grupos etários (KO et al. 1996; FOUCAN et al. 2000, OKOSUM et al 2000b; ZHU et al 2002), o que torna necessário avaliar estes pontos de corte nas diferentes faixas etárias das diversas populações para, então, definir os pontos de corte adequados para identificar riscos de saúde associados à obesidade.

A possibilidade da utilizaçăo de uma medida simples, barata, de fácil interpretação e, principalmente, que pode ser realizada pela própria população como forma de triagem em programas de promoção da saúde e prevenção dos fatores de risco cardiovasculares, estimulou a realização deste estudo, cujos objetivos foram avaliar a associação entre os índices antropométricos IMC e CC com a hipertensão arterial, sua capacidade preditiva global, o desempenho dos pontos de corte recomendados e os pontos de corte com maior capacidade preditiva para estes índices antropométricos na identificação do risco de hipertensão arterial da população adulta do município de Goiânia.

\section{MATERIAL E MÉTODOS}

\subsection{Delineamento}

Para o desenvolvimento deste estudo, foram utilizados dados do Estudo da Prevalência e do Conhecimento da Hipertensão Arterial e alguns Fatores de Risco em uma Região do Brasil, projeto aprovado e financiado pelo CNPq e realizado pela equipe da Liga de Hipertensão Arterial da Universidade Federal de Goiás, em parceria com a Universidade Federal de Mato Grosso. Trata-se de um estudo com delineamento transversal, de base populacional, realizado nas capitais e em duas cidades do interior dos estados de Goiás e Mato Grosso. No presente estudo, foram analisados apenas os dados relativos a Goiânia, coletados no período de junho a dezembro de 2001. 
O tamanho da amostra para o município de Goiânia foi calculado considerando-se uma população de 1.004 .098 habitantes (IBGE/98), a prevalência de hipertensão arterial no Brasil - $20 \%$ da populaçăo adulta (MINISTÉRIO DA SAÚDE 1993), intervalo de confiança de $95 \%$ e erro de estimaçăo de $10 \%$. À amostra obtida $(n=1534)$ foram acrescidos $30 \%$ para cobrir as perdas $(n=1994)$. A amostra efetivamente estudada constituiu-se de 1.454 individuos maiores de 18 anos de ambos os sexos, não institucionalizados e residentes na área urbana $(72,9 \%$ da amostra total e 95\% da amostra necessária).

Entre as perdas ( $n=540), 121$ endereços foram classificados como inexistentes (não localizado ou năo havia mais residência no endereço sorteado). Os demais domicilios $(n=419)$ foram localizados, mas não foi realizada a entrevista na grande maioria das vezes por recusa dos moradores. Outras causas menos freqüentes foram domicilio vazio ou moradores não encontrados após três visitas em dias e horários diferentes.

Os domicilios foram selecionados por amostragem probabilistica, por conglomerados, em duas etapas. A primeira consistiu na identificação, junto ao IBGE, dos setores censitários utilizados na Pesquisa Nacional por Amostragem de Domicilios (PNAD) de 1998 na zona urbana do município de Goiânia. A segunda etapa constou da seleção dos domicilios. Para esta seleção foram considerados o número de domicílios em cada setor e o tamanho total da amostra. A partir do cálculo do tamanho da amostra por setor foram sorteados, de forma aleatória e sistemática, os domicilios de cada setor.

Nos domicilios selecionados, foi entrevistado apenas um morador sorteado entre os moradores maiores de 18 anos, para evitar problemas de interdependência de informaçāo entre entrevistados. Foram excluídas do sorteio gestantes e mães de crianças menores de seis meses, para evitar erros na interpretaçăo dos dados. Foram excluídos também moradores que estivessem hospitalizados. 
No estudo original, a amostra de 20 a 64 anos correspondeu a 1252 individuos, 433 homens e 819 mulheres. Destes, foram excluídos 2 homens ( 1 não apresentava a medida da CC e o outro apresentava uma CC com valor biologicamente não plausivel) e 13 mulheres ( 9 não apresentavam os valores da pressão arterial e 4 não apresentavam os valores da pressão arterial e da (C), sendo a amostra final deste estudo composta por 1237 pessoas.

A coleta de dados foi realizada por entrevistadores treinados que preencheram um questionário padronizado que incluia questð̋es sobre as condições sócio-demográficas, a dieta, as atividades físicas, o consumo de álcool, o tabagismo e o uso de medicação hipotensora, além das medidas da pressão arterial, peso, altura e CC. A entrevista foi realizada após a assinatura do termo de consentimento, cujo protocolo foi aprovado pelo Comitê de Ética em Pesquisa Médica Humana e Animal do Hospital das Clínicas da Universidade Federal de Goiás e pelo Comitê de Ética em Pesquisa - COEP - da Faculdade de Saúde Pública da Universidade de São Paulo.

\subsection{Variáveis do Estudo}

As medidas antropométricas foram feitas de acordo com as recomendações de LOHMAN et al. (1988). Os indivíduos foram pesados e medidos descalços e com roupas leves, utilizando balança eletrônica da marca Plenna, modelo Giant Lithium, com capacidade para $150 \mathrm{~kg}$ e precisão de $100 \mathrm{~g}$ e estadiômetro portátil (Seca), com precisão de $0,1 \mathrm{~cm}$.

O IMC foi calculado pela divisão do peso $(\mathrm{Kg})$ pelo quadrado da altura (m). Para a classificaçãc dos valores de IMC foi utilizada a recomendação da OMS (1995): < 18,5 kg/m² (baixo peso); 18,5 a 24,9 kg/m² (normal); 25 a $29,9 \mathrm{~kg} / \mathrm{m}^{2}$ (sobrepeso); e $\geq 30 \mathrm{~kg} / \mathrm{m}^{2}$ (obesidade, neste artigo denominada obesidade total). 
A medida da $\mathrm{CC}$ foi realizada com fita métrica inextensível, no nível natural da cintura, ponto médio entre a crista iliaca anterior superior e a última costela, com precisão de $0,1 \mathrm{~cm}$. $O$ acúmulo de gordura na cintura, ou obesidade abdominal, foi classificado em dois niveis. $O$ nivel 1 correspondeu aos valores de CC entre 80,0 e $87,9 \mathrm{~cm}$ para as mulheres e entre 94,0 e $101,9 \mathrm{~cm}$ para os homens; o nível 2 correspondeu a uma $\mathrm{CC} \geq 88,0 \mathrm{~cm}$ e $\geq$ $102,0 \mathrm{~cm}$ para mulheres e homens, respectivamente. Valores abaixo de 80,0 $\mathrm{cm}$ para as mulheres e $94,0 \mathrm{~cm}$ para os homens foram classificados como adequados (WORLD HEALTH ORGANIZATION 1997).

Para a medida da pressão arterial (PA) foi utilizado aparelho semiautomático (marca OMRON - HEM $705 \mathrm{CP}$ ). Este aparelho foi escolhido por diminuir a influência do entrevistador na coleta da pressão arterial e por já ter sido validado (ARTIGAO et al., 2000), sendo seus dados comparáveis aos obtidos por meio das medidas com coluna de mercúrio (padrão ouro). Foram realizadas duas aferições da pressão arterial, com intervalo mínimo de 5 minutos entre elas. A medição foi realizada no braço esquerdo seguindo as recomendações propostas pelo Programa Nacional de Controle de Hipertensão Arterial (MINISTÉRIO DA SAÚDE 1993). Para fins de análise, considerou-se a segunda medida. Foram considerados como hipertensos os indivíduos com pressão arterial sistólica (PAS) $\geq 140 \mathrm{mmHg}$ e/ou pressão arterial diastólica (PAD) $\geq 90 \mathrm{mmHg}$, ou em uso atual de medicação hipotensora (SOCIEDADE BRASILEIRA DE HIPERTENSÃO 2002).

Foram utilizadas como variáveis de controle o sexo; a idade (em anos completos: $20-24 ; 25-34 ; 35-44 ; 45-54 ; 55-64$ ); a paridade (número total de filhos de cada mulher entrevistada); a escolaridade (anos de estudo: 0-3 anos, 4-8 anos e $\geq 9$ anos); a renda familiar mensal per capita (expressa em quartis); o tabagismo (fumante, ex-fumante e nunca fumou); o consumo de bebidas alcoólicas na última semana (categorizada de acordo com a ingestão diária de gramas de etanol: $<30 \mathrm{~g}$ ou $\geq 30 \mathrm{~g}$ em homens e $<15 \mathrm{~g}$ ou $\geq 15 \mathrm{~g} \mathrm{em}$ mulheres) e a realização de atividades físicas nos momentos de lazer (sedentário; leve; moderado e intensa). 


\subsection{Análise Estatística}

Após a revisão dos questionários, os dados foram digitados duplamente em bancos elaborados no ACCESS. O procedimento validate (Epi-Info 6.04) foi utilizado para avaliação da qualidade da digitação. Para a análise utilizou-se o STATA (versão 7.0).

As análises foram feitas separadamente para homens e mulheres. Foram apresentados as médias e os intervalos de confiança de $95 \%$ das variáveis estudadas. Foi realizado teste de tendência para avaliar a prevalência da hipertensão nas categorias do IMC e da CC.

O IMC e a CC foram testados separadamente em modelos de regressão logística, ajustados por idade, escolaridade, renda, tabagismo, paridade (em mulheres), consumo de álcool e atividades físicas no lazer. Devido à alta colinearidade entre $\mathrm{IMC}$ e $\mathrm{CC}$, estas medidas não foram colocadas como variáveis independentes no mesmo modelo de regressão, tendo como desfecho a hipertensão arterial.

Análises de curvas receiver operating characteristic (ROC) foram utilizadas para avaliar e comparar a capacidade de identificar a hipertensão pelos índices antropométricos, IMC e CC. As áreas sob a curva ROC fornecem a probabilidade global destes índices classificarem corretamente a presença ou a ausência de hipertensão. Um teste perfeito tem uma área sob a curva ROC igual a 1,0 , já uma área igual a 0,5 significa que a performance do teste não é melhor do que o acaso (HANLEY e MCNEIL 1982).

Foi calculada a sensibilidade e a especificidade do nivel 2 da CC (88 $\mathrm{cm}$ e 102 em mulheres e homens, respectivamente) e do IMC $\geq 30 \mathrm{~kg} / \mathrm{m}^{2}$ na identificação da hipertensão. A sensibilidade foi definida como a proporção de individuos hipertensos corretamente identificados e a especificidade como a proporção de normotensos corretamente identificados. Foram também identificados os pontos de corte da CC e do IMC com melhor 
capacidade preditiva de hipertensão, local onde as curvas de sensibilidade e especificidade se cruzam (ALTMAN e BLAND 1994).

As análises estatísticas foram corrigidas pelo delineamento complexo da amostra, por meio da utilização do conjunto de comandos SVY do STATA, que consideram a estrutura complexa da amostra, utilizando os pesos associados a cada conglomerado da amostra e o efeito do desenho amostral. Em todos os testes, foi considerado o nivel de significância de $5 \%$.

\section{RESULTADOS}

As caracteristicas da população em estudo são mostradas na Tabela 2.1. Os homens apresentaram médias mais altas de peso, altura, CC, PAS e PAD do que as mulheres; as médias de idade e do IMC foram semelhantes.

Tabela 2.1 - Médias e intervalos de 95\% de confiança das principais variáveis, segundo sexo. Goiânia-GO, Brasil, 2001.

\begin{tabular}{lcccc}
\hline \multirow{2}{*}{ Variáveis } & \multicolumn{2}{c}{ Homens $(\mathrm{n}=431)$} & \multicolumn{2}{c}{ Mulheres $(\mathrm{n}=806)$} \\
\cline { 2 - 5 } & Média & $\mathrm{IC}(95 \%)$ & Média & IC $(95 \%)$ \\
\hline Idade (anos) & 38,7 & {$[37,3 ; 39,5]$} & 38,1 & {$[37,1 ; 39,1]$} \\
Peso $(\mathrm{kg})$ & 70,7 & {$[68,0 ; 73,3]$} & 61,2 & {$[60,0 ; 62,4]$} \\
Altura $(\mathrm{m})$ & 169,6 & {$[168,8 ; 170,4]$} & 157,4 & {$[156,8 ; 157,9]$} \\
IMC $\left(\mathrm{kg} / \mathrm{m}^{2}\right)$ & 24,6 & {$[23,8 ; 25,3]$} & 24,7 & {$[24,3 ; 25,2]$} \\
CC $(\mathrm{cm})$ & 86,3 & {$[84,0 ; 88,6]$} & 78,6 & {$[77,7 ; 79,5]$} \\
PAS $(\mathrm{mmHg})$ & 129,9 & {$[126,08 ; 132,9]$} & 117,5 & {$[115,6 ; 119,4]$} \\
PAD $(\mathrm{mmHg})$ & 86,3 & {$[84,0 ; 88,5]$} & 79,0 & {$[77,5 ; 80,5]$} \\
\hline
\end{tabular}

A prevalência da hipertensão arterial foi de $39,7 \%$ em homens e de $29,4 \%$ em mulheres. Já as prevalências de obesidade total (IMC $\geq 30 \mathrm{~kg} / \mathrm{m}^{2}$ ) e obesidade abdominal (nível II da CC) foram, respectivamente, de 10,6\% e $9,3 \%$ para os homens e $13,7 \%$ e $19,6 \%$ para as mulheres (Figura 2.1 ). As prevalências da hipertensão, da obesidade total e da obesidade abdominal aumentaram significativamente com o aumento da idade para ambos sexos 
$(p<0,001$ ), porém de forma mais expressiva no sexo feminino (Figuras 2.2 e 2.3).

Uma pequena parcela da amostra (19 homens e 36 mulheres), com valores normais de pressão arterial, foi classificada como hipertensa devido ao uso de medicação hipotensora.

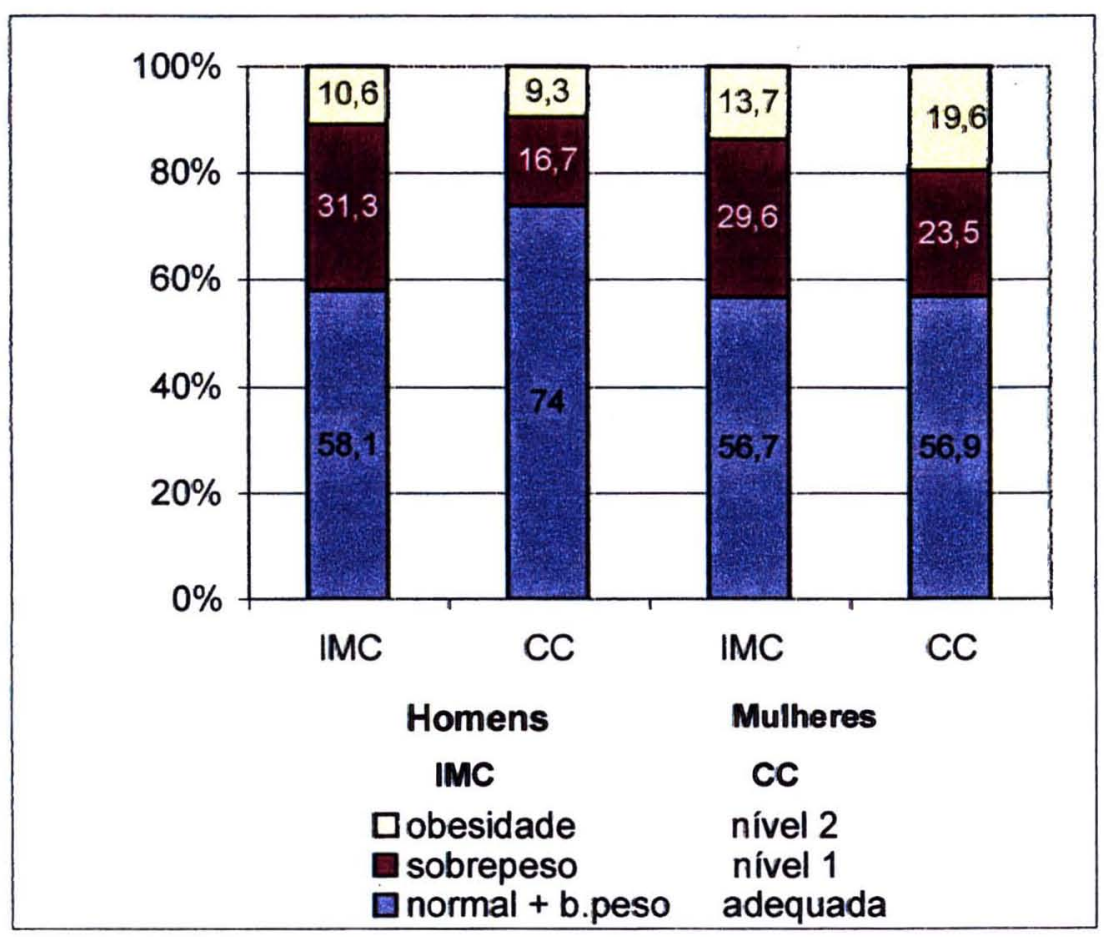

Figura 2.1- Porcentagem de homens e mulheres por categorias de IMC e CC. Goiânia-GO, Brasil, 2001. 


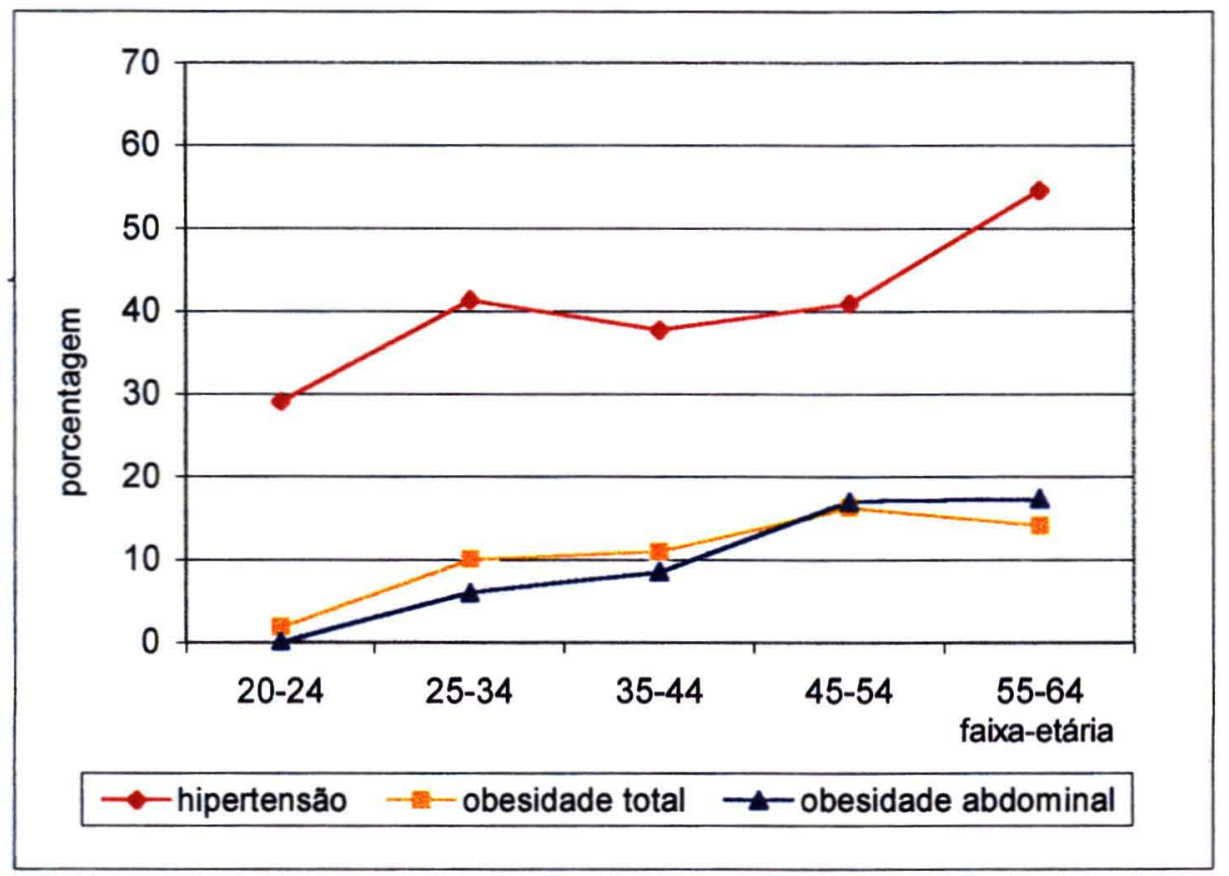

Figura 2.2 - Prevalência (\%) de hipertensão arterial, obesidade total e obesidade abdominal por faixa-etária em homens. GoiâniaGO, Brasil, 2001.

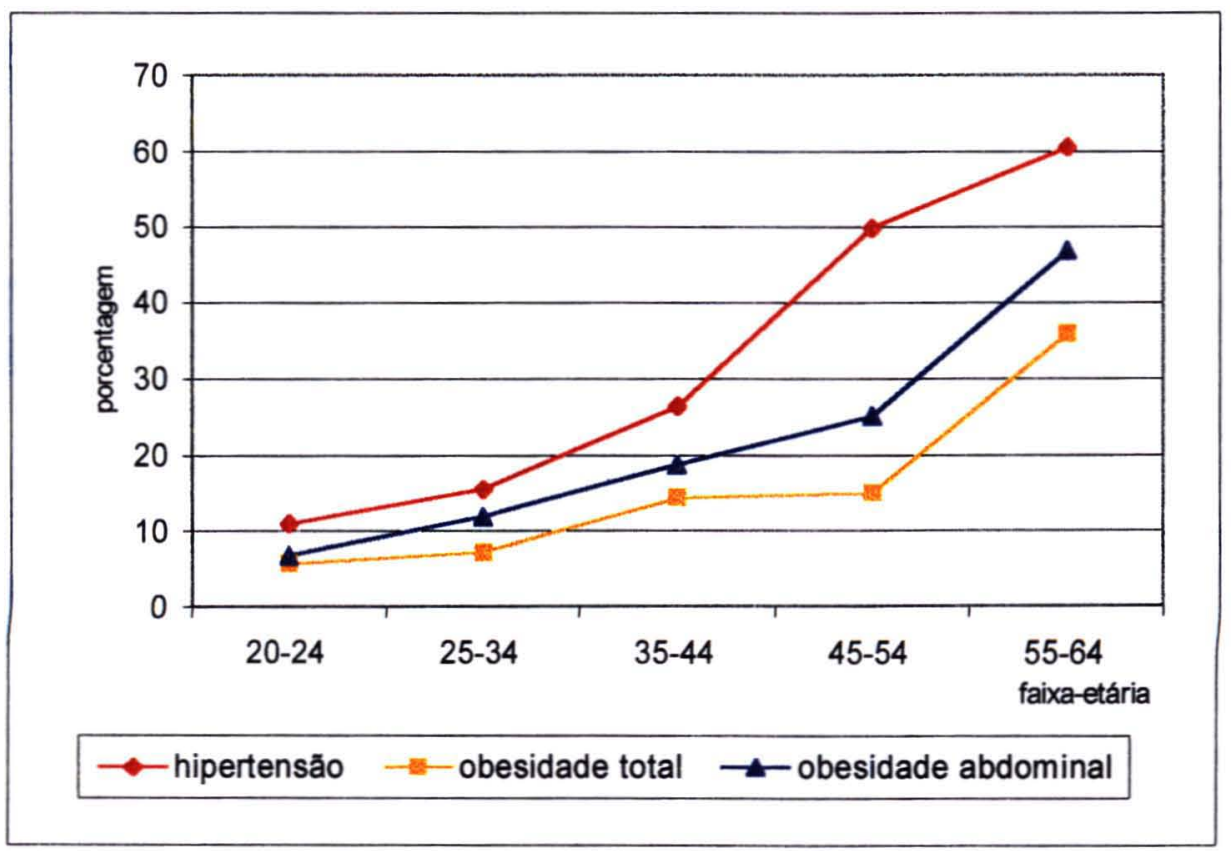

Figura 2.3 - Prevalência (\%) de hipertensão arterial, obesidade total e obesidade abdominal por faixa-etária em mulheres. GoiâniaGO, Brasil, 2001. 
Observa-se que houve aumento significativo da prevalência da hipertensão com o aumento da $\mathrm{CC}$, para o total de homens. Enquanto que para as mulheres, independente da faixa etária, a prevalência da hipertensão aumentou tanto com o aumento do IMC, quanto com o aumento da CC (Tabela 2.2).

Tabela 2.2 - Prevalência (\%) de hipertensão arterial segundo a classificação do IMC e da $\mathrm{CC}$ em homens e mulheres por faixa etária. Goiânia-GO, Brasil, 2001.

\begin{tabular}{lcccccc}
\hline & \multicolumn{5}{c}{ Hipertensão arterial (\%) } \\
\cline { 2 - 7 } \multicolumn{1}{c}{ Indices } & \multicolumn{5}{c}{ Homens } & \multicolumn{3}{c}{ Mulheres } \\
\cline { 2 - 7 } antropométricos & $\begin{array}{c}\text { Total } \\
\text { (n=431) }\end{array}$ & $\begin{array}{c}20-39 \\
(n=239)\end{array}$ & $\begin{array}{c}40-64 \\
(n=192)\end{array}$ & $\begin{array}{c}\text { Total } \\
(n=806)\end{array}$ & $\begin{array}{c}20-39 \\
(n=444)\end{array}$ & $\begin{array}{c}40-64 \\
(n=362)\end{array}$ \\
\hline IMC & & & & & & \\
$<25$ & 38,4 & 34,6 & 46,1 & 17,4 & 11,5 & 30,2 \\
$25-29,9$ & 35,9 & 35,7 & 36,0 & 39,0 & 19,4 & 56,2 \\
$\geq 30$ & 58,5 & 54,0 & 61,9 & 58,4 & 44,7 & 66,1 \\
& $p^{*}=0,06$ & $p^{*}=0,50$ & $p^{*}=0,39$ & $p^{*}<0,01$ & $p^{*}<0,01$ & $p^{*}<0,01$ \\
CC & & & & & & \\
Adequado & 34,8 & 33,0 & 38,0 & 17,3 & 11,3 & 32,3 \\
Nivel 1 & 53,8 & 53,3 & 54,2 & 41,2 & 21,7 & 56,0 \\
Nivel 2 & 54,2 & 59,2 & 51,9 & 50,3 & 37,2 & 57,5 \\
& $p^{*}<0,01$ & $p^{*}=0,07$ & $p^{*}=0,12$ & $p^{*}<0,01$ & $p^{*}<0,01$ & $p^{*}<0,01$ \\
\hline Total & 39,8 & 36,2 & 44,3 & 29,4 & 16,2 & 47,3 \\
\hline
\end{tabular}

" $p$ do teste de tendéncia.

A análise de regressão logística múltipla mostrou que o odds ratio para a hipertensão foi cerca de duas vezes maior para os homens com valores elevados de $\mathrm{CC}(\geq 94 \mathrm{~cm}$ e $\geq 102 \mathrm{~cm})$, em comparação com a categoria de referência $(<94 \mathrm{~cm})$. O IMC elevado não apresentou associação com a hipertensão quando ajustado pelas variáveis de controle, no entanto a magnitude da associação para o $\mathrm{IMC} \geq 30 \mathrm{~kg} / \mathrm{m}^{2}$ foi próximo aos valores observados para os niveis 1 e 2 da CC. Para as mulheres, os valores elevados de IMC e CC apresentaram associaçăo com a hipertensão arterial nos modelos ajustados, sendo que as mulheres com a $C C \geq 88 \mathrm{~cm}$ 
apresentaram um aumento de cerca de 3 vezes no odds ratio e aquelas com - IMC $\geq 30 \mathrm{~kg} / \mathrm{m}^{2}$ um aumento de 4,7 vezes em comparação com as categorias de referência (Tabela 2.3 ). Nestes modelos, foram testadas as interaçóes da idade tanto com a obesidade total como com a obesidade abdominal, as quais não foram estatisticamente significativas.

Tabela 2.3 - Odds ratio (OR) bruto e ajustado para hipertensão segundo índice de massa corporal e circunferência da cintura por sexo. Goiânia-GO, Brasil, 2001.

\begin{tabular}{|c|c|c|c|c|c|}
\hline Variáveis & $N$ & OR bruto & IC $95 \%$ & $\begin{array}{c}\text { OR } \\
\text { ajustad } \\
0^{1}\end{array}$ & IC 95\% \\
\hline $\begin{array}{l}\text { Homens } \\
\text { Indice de massa corporal } \\
<25 \mathrm{~kg} / \mathrm{m}^{2} \\
25 \text { a } 29 \mathrm{~kg} / \mathrm{m}^{2} \\
\geq 30 \mathrm{~kg} / \mathrm{m}^{2}\end{array}$ & $\begin{array}{c}223 \\
144 \\
54\end{array}$ & $\begin{array}{c}1,00 \\
0,90 \\
2,26 \\
p^{*}=0,11\end{array}$ & $\begin{array}{c}- \\
{[0,52 ; 1,57]} \\
{[1,02 ; 4,79]}\end{array}$ & $\begin{array}{c}1,00 \\
0,66 \\
1,78 \\
p^{*}=0,53\end{array}$ & $\begin{array}{c}{[0,33 ; 1,32]} \\
{[0,89 ; 3,58]}\end{array}$ \\
\hline $\begin{array}{l}\text { Circunferência da cintura } \\
<94 \mathrm{~cm} \\
94 \text { a } 102 \mathrm{~cm} \\
\geq 102 \mathrm{~cm}\end{array}$ & $\begin{array}{c}312 \\
73 \\
46\end{array}$ & $\begin{array}{c}1,00 \\
2,18 \\
2,14 \\
p^{*}<0,01\end{array}$ & $\begin{array}{c}- \\
{[1,34 ; 3,54]} \\
{[1,07 ; 4,28]}\end{array}$ & $\begin{array}{c}1,00 \\
2,00 \\
1,87 \\
p^{*}=0,02\end{array}$ & $\begin{array}{l}{[1,04 ; 3,87]} \\
{[0,99 ; 3,62]}\end{array}$ \\
\hline $\begin{array}{l}\text { Mulheres } \\
\text { Indice de massa corporal } \\
<25 \mathrm{~kg} / \mathrm{m}^{2} \\
25 \text { a } 29 \mathrm{~kg} / \mathrm{m}^{2} \\
\geq 30 \mathrm{~kg} / \mathrm{m}^{2}\end{array}$ & $\begin{array}{l}451 \\
233 \\
122\end{array}$ & $\begin{array}{l}1,00 \\
3,04 \\
6,67 \\
p^{*}<0,01\end{array}$ & $\begin{array}{c}- \\
{[2,17 ; 4,25]} \\
{[4,39 ; 10,14]}\end{array}$ & $\begin{array}{c}1,00 \\
2,51 \\
4,67 \\
p^{*}<0,01\end{array}$ & $\begin{array}{c}- \\
{[1,61 ; 3,90]} \\
{[3,21 ; 6,78]}\end{array}$ \\
\hline $\begin{array}{l}\text { Circunferência da cintura } \\
<80 \mathrm{~cm} \\
80 \mathrm{a} 87 \mathrm{~cm} \\
\geq 88 \mathrm{~cm}\end{array}$ & $\begin{array}{l}455 \\
180 \\
171\end{array}$ & $\begin{array}{l}1,00 \\
3,34 \\
4,84 \\
p^{*}<0,01\end{array}$ & $\begin{array}{c}- \\
{[1,71 ; 6,53]} \\
{[3,15 ; 7,44]}\end{array}$ & $\begin{array}{c}1,00 \\
2,47 \\
3,02 \\
p^{*}<0,01\end{array}$ & $\begin{array}{c}- \\
{[1,39 ; 4,80]} \\
{[1,87 ; 4,87]}\end{array}$ \\
\hline
\end{tabular}

Ajustado por idade, escolaridade, renda, tabagismo, consumo de álcool, atividade física no lazer e paridade (mulheres). ${ }^{\star} \mathrm{P}$ de tendência.

As áreas sob a curva ROC para o IMC e a CC são mostradas na Figura 2.4. As áreas observadas mostram que a CC e o IMC apresentam probabilidades semelhantes, em ambos sexos, para classificarem corretamente a presença ou a ausência de hipertensão, sendo esta capacidade um pouco maior entre as mulheres. 
área sob a curva $\mathrm{ROC}=0,71(0,67 ; 0,75)$

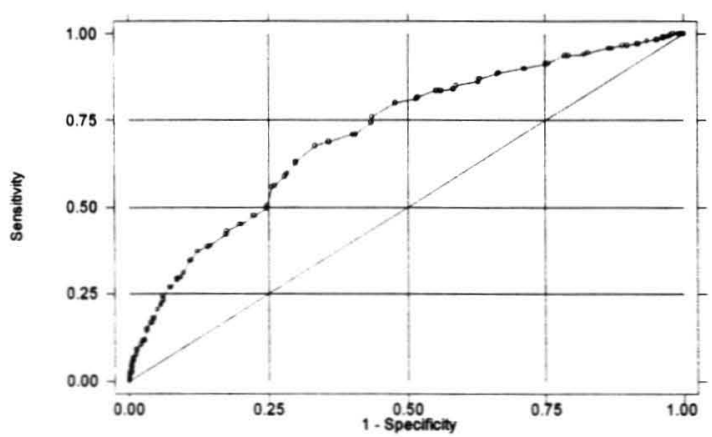

Mulheres 20-65 anos - CC

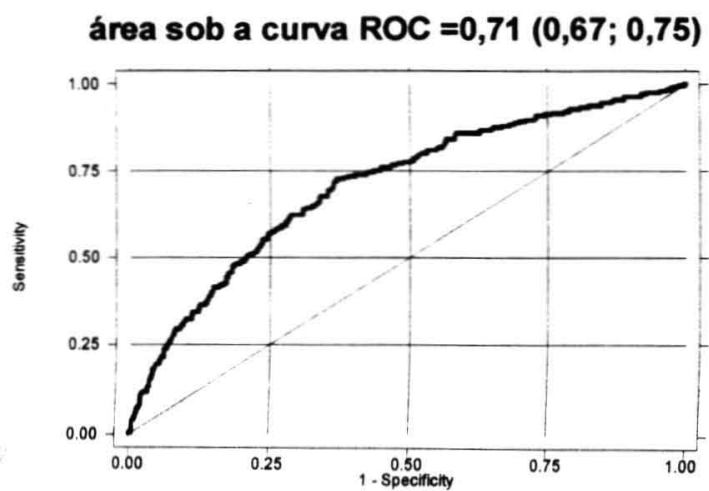

Mulheres 20-65 anos - IMC

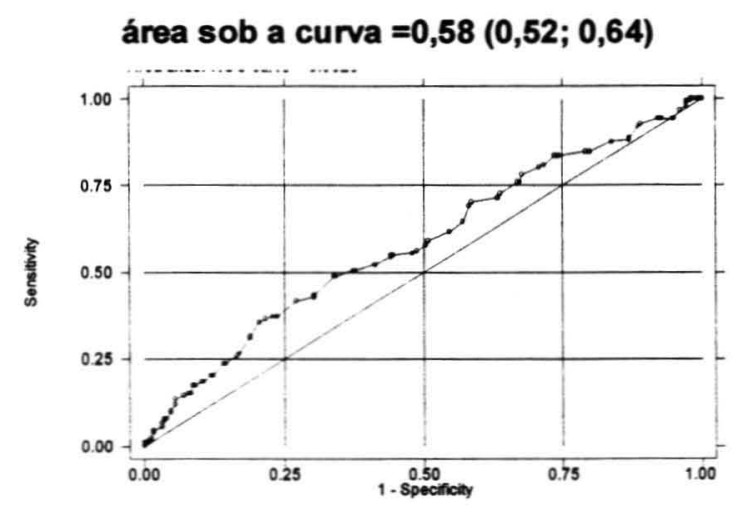

Homens $20-65$ anos $-\mathrm{CC}$

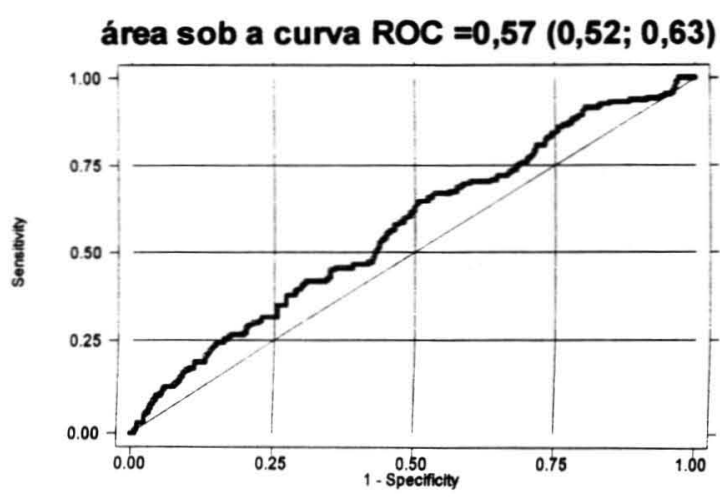

Homens 20-65 anos -IMC

Figura 2.4 - Áreas sob as curvas ROC e IC (95\%) da circunferência da cintura e do índice de massa corporal na predição da hipertensão em mulheres e homens. Goiânia-GO, Brasil, 2001.

O nível 2 da CC e o IMC $\geq 30 \mathrm{~kg} / \mathrm{m}^{2}$ apresentaram baixa sensibilidade na predição da hipertensão, sendo que os maiores valores foram observados para homens e mulheres de 40 a 65 anos de idade. Já a especificidade mostrou-se elevada, em ambos sexos (Tabelas 2.4 e 2.5). 
Tabela 2.4 - Capacidade preditiva do nível 2 da circunferência da cintura (CC) para a detecção do risco de hipertensão, segundo sexo e faixa etária. Goiânia-GO, Brasil, 2001.

\begin{tabular}{|c|c|c|c|}
\hline Faixa etária & $\mathbf{N}$ & Sensibilidade & Especificidade \\
\hline \multicolumn{4}{|l|}{ Homens } \\
\hline 20-39 anos & 239 & $5,6(2,0 ; 12,9)$ & $97,8(94,3 ; 99,6)$ \\
\hline $40-65$ anos & 192 & $19,5(12,1 ; 30,1)$ & $85,8(77,9 ; 91,9)$ \\
\hline Total & 431 & $12,5(7,8 ; 18,2)$ & $92,8(88,8 ; 95,5)$ \\
\hline \multicolumn{4}{|l|}{ Mulheres } \\
\hline 20-39 anos & 444 & $27,6(17,9 ; 39,6)$ & $91,0(87,8 ; 93,8)$ \\
\hline $40-65$ anos & 362 & $36,3(29,1 ; 43,9)$ & $75,9(69,2 ; 81,8)$ \\
\hline Total & 806 & $33,6(28,0 ; 40,2)$ & $86,2(83,2 ; 89,0)$ \\
\hline
\end{tabular}

Tabela 2.5 - Capacidade preditiva da obesidade total (IMC $\geq 30 \mathrm{~kg} / \mathrm{m}^{2}$ ) para a detecção do risco de hipertensão, segundo sexo e faixa etária. Goiânia-GO, Brasil, 2001.

\begin{tabular}{llll}
\hline Faixa etária & N & Sensibilidade & Especificidade \\
\hline $\begin{array}{c}\text { Homens } \\
\text { 20-39 anos }\end{array}$ & 239 & $10,3(4,8 ; 18,7)$ & $95,0(89,9 ; 97,7)$ \\
$40-65$ anos & 192 & $21,1(13,1 ; 31,4)$ & $89,4(82,4 ; 94,8)$ \\
$\quad$ Total & 431 & $15,6(10,7 ; 22,1)$ & $92,7(88,8 ; 95,5)$ \\
Mulheres & & & \\
20-39 anos & 444 & $23,7(14,4 ; 35,1)$ & $94,3(91,5 ; 96,5)$ \\
$40-65$ anos & 362 & $28,9(22,0 ; 36,0)$ & $86,7(81,3 ; 91,3)$ \\
Total & 806 & $27,2(21,8 ; 33,6)$ & $91,9(89,4 ; 94,0)$ \\
\hline
\end{tabular}

$\mathrm{Na}$ Tabela 2.6 são apresentados os pontos de corte da CC e do IMC com maior capacidade preditiva de hipertensão. Nestes pontos de corte, os valores de sensibilidade e especificidade são semelhantes, pois correspondem ao local no qual as curvas de sensibilidade e especificidade se cruzam. Para os homens, estes pontos foram de $86 \mathrm{~cm}$ para a $\mathrm{CC}$ e de $24,6 \mathrm{~kg} / \mathrm{m}^{2}$ para o IMC, enquanto que para as mulheres, foram de $80 \mathrm{~cm}$ para a CC e de $25,0 \mathrm{~kg} / \mathrm{m}^{2}$ para o IMC. Estes valores variaram com a idade, 
sendo inferiores para os individuos de 20 a 39 anos e superiores para os indivíduos de 40 a 65 anos.

Tabela 2.6 - Pontos de corte da CC e do IMC onde a sensibilidade é igual à especificidade (S - E) na predição da hipertensão, segundo faixa etária em homens e mulheres. Goiânia -GO, Brasil, 2001.

\begin{tabular}{cccccc}
\hline Faixa etária & $\mathbf{N}$ & \multicolumn{2}{c}{ CC } & \multicolumn{2}{c}{ IMC } \\
\cline { 3 - 6 } & & $\begin{array}{c}\text { Ponto de corte } \\
(\mathbf{c m})\end{array}$ & $\mathbf{S}-\mathbf{E}(\%)$ & $\begin{array}{c}\text { Ponto de corte } \\
\left(\mathbf{k g} / \mathbf{m}^{2}\right)\end{array}$ & $\mathbf{S}-\mathbf{E}(\%)$ \\
\hline Homens & & & & & \\
20-39 anos & 239 & 82 & 60,5 & 24,5 & 58,0 \\
40-65 anos & 192 & 88 & 62,8 & 25,6 & 56,0 \\
$\quad$ Total & 431 & 86 & 60,4 & 24,6 & 59,2 \\
Mulheres & & & & & \\
20-39 anos & 444 & 76 & 62,8 & 23,5 & 59,5 \\
40-65 anos & 362 & 83 & 63,2 & 25,6 & 66,5 \\
Total & 806 & 80 & 66,5 & 25,0 & 65,0 \\
\hline
\end{tabular}

* O ponto de corte onde a sensibilidade é igual à especificidade identifica o maior número de individuos com e sem a hipertensăo.

\section{DISCUSSÃo}

Este estudo analisou a associação entre a obesidade avaliada pelos índices antropométricos IMC e CC com a hipertensão e examinou a capacidade preditiva destes índices antropométricos na identificação do risco da hipertensão arterial da população adulta do Município de Goiânia.

A validade externa e a interna deste estudo foram asseguradas pela utilização de uma amostra representativa da população adulta de Goiânia, com informaçōes coletãjas no domicílio, por pessoal treinado, utilizando questionário e instrumentos padronizados e por ter considerado nas análises o efeito do delineamento complexo da amostra. É importante ressaltar que, embora tenham sido efetivamente avaliados $72,9 \%$ da amostra total, a comparação da distribuição da população estudada por faixa etária e escolaridade com os dados do censo de 2000 , do IBGE, não mostrou 
diferenças significativas para ambos os sexos, o que reforça que a amostra estudada é representativa da população adulta de Goiânia. A principal limitação do estudo foi ter um delineamento transversal, o que não permite identificar a precedência no tempo entre a exposição e o desfecho. Outra limitação foi o fato de que a apreciação dos pontos de corte dos índices antropométricos foi realizada exclusivamente com relação à hipertensão. Outras doenças associadas à obesidade, como a dislipidemia e o diabetes, não foram incorporadas neste estudo.

Assim como em outros estudos (TAYLOR et al 1995; LEAN et al. 1995; FOUCAN 2000), foi observada uma alta correlação entre CC e IMC, para ambos sexos. Entretanto, para as mulheres, a prevalência da obesidade variou de acordo com o indicador antropométrico utilizado, sendo que a obesidade central, avaliada pelo nível $2 \mathrm{da} \mathrm{CC} \mathrm{(} \geq 88 \mathrm{~cm}$ para as mulheres e $\geq 102 \mathrm{~cm}$ para os homens), foi mais prevalente do que a obesidade total (IMC $\geq 30 \mathrm{~kg} / \mathrm{m}^{2}$ ). Estes dados sugerem uma diferença entre os sexos na capacidade diagnóstica dos pontos de corte recomendados para a CC.

Considerando-se o ponto de corte de $140 \times 90 \mathrm{mmHg}$ ou o uso de medicação hipotensora para definiçăo de hipertensão, observou-se que cerca de $39,8 \%$ dos homens e $29,4 \%$ das mulheres eram hipertensos. A hipertensão foi observada tanto nos indivíduos com IMC na faixa de normalidade quanto nos obesos, sendo que nos individuos de IMC normal, $38,4 \%$ e $17,4 \%$ dos homens e mulheres, respectivamente, eram hipertensos. Já entre os obesos, a proporçăo de hipertensos aumentou para $59,1 \%$ entre os homens e $58,4 \%$ entre as mulheres. As prevalências de hipertensão, na presença de obesidade abdominal, foram próximas aos valores observados para a obesidade total. De acordo com o observado em outros estudos (GUAGNANO et al. 2001, DOLL et al. 2002), estes resultados mostram que tanto o ganho de peso como o acúmulo de gordura abdominal aumenta a probabilidade de o indivíduo tornarse hipertenso.

$\mathrm{Na}$ análise de regressão logística múltipla, os níveis 1 e 2 da $\mathrm{CC}$ apresentaram associação com o risco de hipertensão para ambos os sexos. 
Já o sobrepeso e a obesidade total apresentaram associação com a hipertensão apenas para as mulheres. Apesar da obesidade total não ter apresentado associação significativa com a hipertensão entre os homens, a magnitude da associação foi próxima aos valores observados para a CC e a falta de significância estatística pode ter ocorrido devido ao menor tamanho da amostra de homens.

O excesso de tecido adiposo é um dos principais fatores de risco associados à hipertensão tanto nos estudos prospectivos quanto nos transversais em diversas populações, independente da idade (HAN et al 1995; STAMLER et al. 1997; KROKE et al.1998; GUAGNAMO et al. 2001; DOLL et al. 2002).

Em estudos prospectivos, o ganho de peso a médio e longo prazo aumentou consideravelmente a incidência de hipertensão e a perda de peso reduziu esta incidência. Estimativas do estudo de Framingham sugerem que cerca de $70 \%$ dos casos novos de HA poderiam ser atribuidos à obesidade ou ao ganho de peso (HUBERT et al. 1983). Já no National Heart Foundation of Austrália Risk Factor Prevalence Survey, aproximadamente um terço dos casos de hipertensão foram atribuidos à obesidade em homens e mulheres dos 25 aos 64 anos de idade. Em homens mais jovens, entre 25 e 44 anos, dois terços da hipertensão foi atribuída à obesidade (CASSANO et al. 1990). No Nurses' Health Study, um aumento no IMC de $1 \mathrm{~kg} / \mathrm{m}^{2}$ foi associado a um aumento de $12 \%$ no risco de hipertensão (HUANG et al. 1988).

Em estudos populacionais transversais realizados no Brasil, observou-se que, em Porto Alegre, a hipertensão foi igualmente associada com o IMC, O RCQ e a CC para as mulheres, enquanto para os homens apenas o IMC apresentou associação (GUS et al. 1998). Na Pesquisa Nutrição e Saúde, realizada no Municipio do Rio de Janeiro, a relação cintura-quadril apresentou maior capacidade preditiva de hipertensão $e$ menor correlação com o IMC do que a CC (PEREIRA et al. 1999). Em estudo realizado em São Paulo, a relação cintura-quadril e a CC 
associaram-se de forma semelhante com a hipertensão (MARTINS e MARINHO 2003). MELÉNDEZ-VELASQUEZ et al. (2002), em uma amostra de mulheres de um centro de saúde de Belo Horizonte, observou que a CC associou-se significativamente com a $\mathrm{HA}$, porém os pontos de corte avaliados, $80 \mathrm{~cm}$ e $88 \mathrm{~cm}$, mostraram moderada $(63,8 \%)$ e baixa $(42,8 \%)$ sensibilidade para hipertensão, respectivamente.

Já no único estudo longitudinal brasileiro $(5,6 \pm 1,1$ ano de seguimento) de base populacional, que explorou a associação entre diferentes índices de obesidade com a incidência de hipertensão, GUS et al. (2004) observaram que a razão de risco para o nivel 2 da CC foi de $1,78(0,76 ; 4,09)$ para os homens e de $1,72(1,09 ; 2,73)$ para as mulheres, enquanto que para o IMC $\geq 30 \mathrm{~kg} / \mathrm{m}^{2}$ foi de $1,08(0,52 ; 2,24)$ para os homens e de $1,74(0,93 ; 3,26)$ para as mulheres. Concluíram que o risco de incidência de hipertensão foi mais consistente quando a obesidade foi definida pelo nível 2 da $\mathrm{CC}$ do que pelo $I M C \geq 30 \mathrm{Kg} / \mathrm{m}^{2}$, em ambos os sexos.

Estes estudos confirmam a importância do excesso de peso total e do acúmulo da gordura visceral na prevalência da hipertensão. No entanto, os indices antropométricos mais utilizados nos estudos epidemiológicos (IMC, $\mathrm{CC}$ e RCQ) não refletem a mesma quantidade de gordura em diferentes populações. Já é bem estabelecido que existem diferenças na relação entre a gordura corpórea e o IMC e/ou CC, isso ocorre, em parte, devido às diferenças genéticas na composição corpórea, bem como pelas diferenças na ingestão alimentar e no padrão de atividade física (SLATTERY et al. 1992; HAUNER et al. 1994). Estas diferenças modulam o grau de associação entre os indicadores antropométricos e os fatores de risco cardiovasculares.

A patogênese da hipertensão, associada à obesidade, é altamente complexa, envolvendo vários fatores que agem conjuntamente para promover a vasoconstricção e a retenção de sódio, fatores proximais na gênese da hipertensão. As evidências mostram que a leptina, os ácidos graxos livres e a insulina, que estão aumentados na obesidade, podem agir 
individualmente ou sinergicamente na promoção da vasoconstriç̧ão, por meio da estimulação do sistema nervoso simpático. A disfunção endotelial e a resistência à insulina, induzidas, principalmente, pela obesidade abdominal, podem também aumentar diretamente a vasoconstricção. Por sua vez, o aumento da reabsorção tubular de sódio pode ser causado pelo aumento da atividade do nervo simpático renal, pelo efeito direto da insulina, pela hiperatividade do sistema renina-angiotensina e possivelmente pela alteração na força física intra-renal (MONTANI et al. 2002).

Os valores observados para a área sob a curva ROC mostram que as medidas do IMC e da CC têm poder semelhante na avaliação do risco de hipertensão, o que foi também observado para dislipidemia e diabetes por LEDOUX et al. (1997).

Os pontos de corte recomendados para o nível 2 da CC apresentaram baixa sensibilidade, para ambos os sexos, para identificar o risco de hipertensão, o que também foi observado para o $I M C \geq 30 \mathrm{~kg} / \mathrm{m}^{2}$. A alta especificidade observada, confere aos pontos de corte utilizados a capacidade de classificar poucos individuos normotensos como hipertensos; em contrapartida, a baixa sensibilidade faz com que muitos hipertensos sejam classificados como normotensos.

Em outros estudos, a sensibilidade observada para estes índices antropométricos foi de baixa a moderada, sendo que as diferenças tanto na prevalência dos fatores de risco quanto na composição corpórea produzem sensibilidades diferenciadas na identificação da hipertensão nas diversas populações. No estudo de LEAN et al. (1995), a sensibilidade do nível 2 da CC, na predição da hipertensão, foi de $40,3 \%$ e $56,6 \%$, para homens e mulheres adultos, respectivamente. Em uma amostra de adultos americanos com sobrepeso, a sensibilidade do nivel 2 da CC aumentou com a idade e foi diferente entre as etnias, sendo que, para os homens de 40 a 59 anos, foram observadas sensibilidades de $32,0 \%, 53,8$ e 35,0\% para brancos, negros e hispânicos, respectivamente (OKOSUN et al. 2000b). 
$\mathrm{Na}$ análise da curva ROC foi interessante observar que, para o total das mulheres, os pontos de corte que apresentaram a melhor capacidade preditiva do risco de hipertensão correspondem aos valores atualmente recomendados para o nivel $1 \mathrm{da}$ CC e para o sobrepeso, $80 \mathrm{~cm}$ e $25 \mathrm{~kg} / \mathrm{m}^{2}$, respectivamente. Já para os homens, o ponto de equilibrio entre as curvas de sensibilidade e de especificidade foi observado abaixo dos valores atualmente recomendados para o nivel $1 \mathrm{da} C \mathrm{CC}$ e para o sobrepeso, $86 \mathrm{~cm}$ e $24,6 \mathrm{~kg} / \mathrm{m}^{2}$, respectivamente. Estes pontos de corte foram menores entre os mais jovens e maiores para os indivíduos com 40 anos ou mais, em ambos sexo. Reforçando as evidências de que a relação entre adiposidade e hipertensão é mais forte entre os adultos mais jovens e que o risco para as doenças cardiovasculares são observados a partir de pequenos aumentos na adiposidade total ou abdominal (HUANG et al. 1988)

A utilização universal da CC e do IMC tem sido questionada por vários pesquisadores, principalmente para as populações de origem asiática (KO et al. 1996; VIKRAM et al. 2003). Em uma sub amostra de homens $(n=4388)$ e mulheres $(n=4631)$ brancos participantes da terceira Pesquisa Nacional de Saúde e Nutrição (NHANES III), ZHU et al. (2003) observaram que uma CC $\geq 90 \mathrm{~cm}$ (homens) e $\geq 83 \mathrm{~cm}$ (mulheres) apresentam o mesmo odds ratio para os fatores de risco cardiovascular associados ao $I M C \geq 25 \mathrm{~kg} / \mathrm{m}^{2}$, enquanto uma $C C \geq 100 \mathrm{~cm}$ e $\geq 93 \mathrm{~cm}$ para homens e mulheres, respectivamente, equivale ao odds ratio observado para o $\mathrm{MC} \geq 30 \mathrm{Kg} / \mathrm{m}^{2}$.

Os resultados do presente estudo mostram que, para os homens, 0 impacto da obesidade abdominal sobre a hipertensão arterial foi maior do que o impacto da obesidade total; já para as mulheres, tanto a obesidade abdominal quanto a total associaram-se significativamente com a hipertensão. Os pontos de corte para a obesidade abdominal nível 2 e a obesidade total $I M C \geq 30 \mathrm{Kg} / \mathrm{m}^{2}$ apresentaram baixa sensibilidade para detectar a hipertensão, em ambos os sexos. Para os homens, os pontos de corte mais adequados para a triagem do risco de hipertensão foram inferiores aos valores recomendados para o nivel 1 da CC ( $\geq 94 \mathrm{~cm})$ e para a 
classificação do sobrepeso $\left(\geq 25,0 \mathrm{~kg} / \mathrm{m}^{2}\right)$. Já para as mulheres corresponderam aos pontos de corte recomendados para o nível 1 da CC $(\geq 80 \mathrm{~cm})$ e para a classificação do sobrepeso $\left(\geq 25,0 \mathrm{~kg} / \mathrm{m}^{2}\right)$. Estes resultados reforçam a pertinência de se utilizar estes pontos de corte como parte das estratégias dos programas de saúde pública, tanto para a prevenção e controle do excesso de peso como para alertar sobre a necessidade de se avaliar a presença da hipertensão arterial e também de outros fatores de risco associados ao ganho de peso.

\section{REFERÊNCIAS BIBLIOGRÁFICAS}

1. Altman DG, Bland JM. Diagnostic tests 1: sensitivity and specificity. BMJ 1994; 308: 1552.

2. Artigao LM, Llavador JJ, Puras A, Lopez Abril J, Rubio MM, Torres C, Vidal A, Sanchis C, Divison JA, Nabarro F, Caldevilla D, Fuentes G. Evaluation and validation of Omron Hem $705 \mathrm{CP}$ and Hem 706/711 monitors for self-measumement of blood pressure. Atencion Primaria 2000. 15; 25(2): 96-102.

3. Bray GA. Trad. de Gelman A et al. Obesidade: Conceitos básicos e aplicações clinicas. Clínicas Médicas da América do Norte. Rio de Janeiro: Interlivros; 1989. Classificação e avaliação das obesidades; p. 161-184.

4. Calle EE, Thun MJ, Petrelli JM, Rodriguez C, Weath CW. Body-mass index and mortality in a prospective cohort of U.S. adults. The New England Journal of Medicine 1999; 341(15); 1097-1105.

5. Després J, Allard C, Tremblay A, Talbot J, Bouchard C. Evidence for a regional component of body fatness in the association with serum lipids in men an women. Metabolism 1985; 34(10): 967-73. 
6. Doll S, Paccaud F, Bovet $P$, Burnier M, Wietlisbch. Body mass index, abdominal adiposity and blood pressure: consistency of their association across developing and developed countries. International Joumal of Obesity $2002 ; 26$ : 48-57.

7. Foucan L, Hanley J, Deloumeaux J, Suissa S. Body mass index (BMI) and waist circumference (WC) as screening tools for cardiovascular risk factors in Guadeloupean women. Journal of Clinical Epidemiology 2000; 55: 990-996.

8. Garrow JS. Obesity and related diseases. Edinburg: Churchill Livingstone, 1988.

9. Guagnano MT, Ballone E, Colagrande V, Della Vechia R, Manigrasso $M R$, Merlitti D, Riccioni G, Sensi S. Large waist circumference and risk of hypertension. International of Obesity $2001 ; 25: 1360-1364$.

10. Gus M, Fuchs SC, Moreira LB, Moraes RS, Moraes RS, Wiehe M, Silva AF, Albers F, Fuchs FD. Association between different measurements of obesity and the incidence of hypertension. American Journal of Hypertension 1998; 17 (1): 50-53.

11. Gus M, Moreira LB, Pimentel M Gleisener ALM, Moraes RS, Fuchs FD. Associação entre diferentes indicadores de obesidade e prevalência de hipertensão arterial, Arq Bras Cardiol 1998; 70 (2): 111-114.

12. Han TS, Leer EM, Seidell JC, Lean MEJ. Waist circumference action levels in the identification of cardiovascular risk factors: prevalence study in a random sample. BMJ 1995; 311: 1401-1405.

13. Hanley JA, Mcneil BJ. The meaning and use of the area under a receiver operating characteristic (ROC) curve. Radiology 1982; 143: 29-36.

14. Hauner $H$, Bognar $E$, Blum A. Body fat distribution and its association with metabolic and hormonal risk factors in women with angiographically assessed coronary artery disease: evidence for the 
presence of a metabolic syndrome. Atherosclerosis 1994; 105: 209216.

15. Huang Z, Willet WC, Manson JE, Rosner B, Stampfer MJ, Speizer FE, Colditz GA. Body weight, weight change, and risk for hypertension in women. Annals of Internal Medicine 1988; 128(2): 81-8.

16. Hubert HB, Feinleib $M$, Mcnamara $M$, Castelli $W$. Obesity as an independent risk factor for cardiovascular disease: A 26-year follow-up of participants in the Framingham Heart Study. Circulation 1983; 67(5): 968-76.

17. Ko GTC, Chan JCN, Woo J, Cockram CS. Waist circumference as a screening measurement for overweight or centrally obese Chinese. International Journal of Obesity 1996; 20: 791-792.

18. Kroke A, Bergmann M, Klipstein-Grobusch K, Boeing H. Obesity, body fat distribution and body build: Their relation to blood pressure and prevalence of hypertension. International Journal of Obesity 1998; 22: 1062-1070.

19. Ledoux M, Lambert J, Reedr BA, Despres JP. Correlation between cardiovascular disease risk factors and simple anthropometric measures. CMAJ 1997; 157(Suppl 1): S46-S53.

20. Lean MEJ, Han TS, Morrison CE. Waist circumference as a measure for indicating need for weight mangement. BMJ 1995; 311: 158-161.

21. Lohman TG, Roche AF, Martorel R. Anthropometric standardization reference manual. Illinois: Human Kinetics Books, 1988.

22. Manson JE, Colditz GA, Stampfer MJ, Willet WC, Rosner B, Monson $\mathrm{RB}$, Speizer FE, Hennnekens $\mathrm{CH}$. A prospective study of obesity and risk of coronary heart disease in women. The New England Journal of Medicine 1990; 322(13): 882-9.

23. Martins IS, Marinho SP. O potencial diagnóstico dos indicadores da obesidade centralizada. Rev Saúde Pública 2003; 37(6): 760-767. 
24. Meléndez-Velásquez G, Kac G, Valente JG, Tavares R, Silva CQ, Garcia ES. Evaluation of waist circumference to predict general obesity and arterial hypertension in women in greater Metropolitan Belo Horizonte, Brazil. Cad Saúde Pública 2002; 18(3): 765-771.

25. Ministério da Saúde. Controle da hipertensão arterial: uma proposta de integração ensino-serviço. Rio de Janeiro: CDCV/NUTES, 1993. 233p.

26. Montani JP, Antic V, Yang Z, Dullo A. Pathways from obesity to hipertensión:from the perspective of a vicious triangle. International Journal of Obesity 2002; 26 (Suppl 2): S28-S38.

27. Okosun IS, Liao Y, Rotimi CN, Choi S, Cooper RS. Predictive values of waist circumference for dyslipidemia, type 2 diabetes and hypertension in overweight white, black, and hispanic american adults. Journal of Clinical Epidemiology 2000b; 53: 401-408.

28. Okosun IS, Liao Y, Rotimi CN, Prewitt E, Cooper RS. Abdominal adiposity and clustering of multiple metabolic syndrome in white, black and hispanic americans. Ann Epidemiol 2000a;10: 263-270.

29. Organización Panamericana de la Salud. Protocolo y directrices: Conjunto de Ações para la Reducción Multifactorial de Enfermedades no Transmisibles (CARMEN/CINDI). OPAS; 1997.

30. Pereira RA, Sichieri R, Marins VMR. Razão cintura/quadril como preditor de hipertensão. Cad Saúde Pública 1999; 15(2): 333-344.

31. Pouliot MC, Després JP, Lemieux S, Moorjani S, Bourchard C, Tremblay A, Nadeu A, Lupien PJ. Waist circumference and abdominal sagittal diameter: Best simple anthropometric indexes of abdominal visceral adipose tissue accumulation and related cardiovascular risk in men and woman. Am Journal of Cardiology 1994; 73 : 460-468.

32. Rexroade KM, Hennekens $\mathrm{CH}$, Willet WC, Colditz GA, Stampfer MJ, Rich-Edwards JW, Speizer FE, Manson JE. A prospective study of body mass index, weight change, and risk of stroke in women. JAMA 1997; 
277(19): 1539-45.

33. Slattery ML, McDonald A, Bild DE, Caan BJ, Hilner JE, Jacobs DR, Liu K. Associations of body fat and its distribution with dietary intake, physical activity, alcohol. And smoking in blacks and whites. Am J Clin Nutr 1992; 55: 943-949.

34.Sociedade Brasileira de Hipertensão, Sociedade Brasileira de Cardiologia e Sociedade Brasileira de Nefrologia. IV Diretrizes Brasileiras de Hipertensão Arterial. Campos do Jordão, 2002.

35. Stata Corp. (2001). Stata Statistical Software: Release 7.0. Stata Corporation.

36. Stevens J. Impact of age on associations between weight and mortality.

Nutrition Reviews 2000; 25(5): 129-37.

37. Taylor RW, Keil D, Gold EJ, Williams SM, Goulding A. Body mass index, waist girth, and waist-to-hip ratio as indexes pf total and regional adiposity in women: evaluation using receiver operating characteristic curves. Am J Clin Nutr 1998; 67: 44-49.

38. Vikram NK, Pandey RM, Misra A, Sharma R, Devi JR, Khanna N. Non-obese (body mass index $<25 \mathrm{~kg} / \mathrm{m}^{2}$ ) asian indians with normal waist circumference hava hight cardiovascular risk. Nutrition 2003; 16(6): 503-509

39. Willet WC, Manson JE, Stampfer MJ, Colditz GA, Rosner B, Speizer FE, Hennekens $\mathrm{CH}$. Weight, weight change, and coronary heart disease in women. JAMA 1995; 273(6): 461-5.

40. World Health Organization. Obesity: Preventing and Managing the Global Epidemic. Report. Geneva; 1997.

41. Zhu SK, Wang ZM, Heshka S, Heo M, Faith MS, Heymsfield S. Waist circumference and obesity-associated risk factors amosng whites in the National Health and Nutrition Examination Survey: clinical action thresholds. Am J Clin Nutr 2002; 76: 743-749. 
ARTIGO 3

VALIDADE DO PESO E DA ALTURA REFERIDOS EM ESTUDO EPIDEMIOLÓGICO: O ESTUDO DE GOIÂNIA

VALIDITY OF SELF-REPORTED WEIGHT AND HEIGHT FOR AN EPIDEMIOLOGICAL STUDY: THE GOIÂNIA STUDY 


\section{RESUMO}

Objetivo: Avaliar a validade do peso e altura referidos no diagnóstico da obesidade e identificar quais as características sócio-demográficas e individuais contribuem para um possivel viés de informaçăo da populaçăo adulta de Goiânia. Métodos: Foi analisada uma amostra composta por 1023 individuos, com idade entre 20 e 64 anos, participantes de estudo transversal de base populacional realizado no município de Goiânia $(\mathrm{GO})$ em 2001. Em entrevista domiciliar foram coletadas informações sobre o peso e altura referidos. Na mesma ocasião os indivíduos foram pesados e medidos utilizando procedimentos e instrumentos padronizados. Foram calculadas diferenças de médias, coeficiente de correlaçăo intraclasse entre as medidas referidas e aferidas, segundo categorias de idade, IMC, escolaridade, renda e altura. Foram comparadas as classificaçסes do IMC obtido a partir das medidas aferidas com o IMC obtido pelas medidas referidas. Resultados: As comparaçóes entre os valores referido e aferido de peso e altura mostram que os homens superestimaram a altura em $0,9 \mathrm{~cm}$ ( $p<0,05)$, o que ocorreu de forma mais acentuada nos indivíduos de menor altura; enquanto o peso foi levemente superestimado em $0,44 \mathrm{~kg}(p=0,06)$. As mulheres năo apresentaram diferença para o peso $(-0,03 \mathrm{~kg}, p>0,05)$ e superestimaram a altura em $2,2 \mathrm{~cm} \quad(p<0,05)$, sendo este comportamento influenciado pelo aumento da idade, menor escolaridade, menor altura, baixo peso $e$ obesidade. O IMC obtido a partir dos dados referidos foi subestimado ( $p<0,05$ ) em $0,27 \mathrm{~kg} / \mathrm{m}^{2}$ e $0,67 \mathrm{~kg} / \mathrm{m}^{2}$ para homens e mulheres, respectivamente. $O$ coeficiente de correlação intraclasse entre as medidas aferidas e reportadas mostrou alto grau de concordância, em ambos sexos. A sensibilidade e especificidade do IMC referido foram altas em identificar 0 IMC aferido. Conclusãn: Nesta população os individuos de 20 a 64 anos forneceram informaçōes confiáveis de peso e altura atuais, o que torna viável esta metodologia em estudos epidemiológicos futuros de monitoramento da prevalência de excesso de peso nesta população.

Palavras-chave: peso referido, altura referida, obesidade 


\section{ABSTRACT}

Objective: Assessing the accuracy of self-reported weight and height at the time obesity was diagnosed, and identifying which sociodemographic and individual features contribute to create an information bias in the adult population of Goiannia. Methods: The sample brought to this analysis comprised of 1023 individuals, aged 20-64 years, who participated in a cross-sectional study of the population in the county of Goiania (GO), in 2001. In interviews carried out at home, the agents collected information on weight and height, as informed by the individuals. At the same time, and using standard instruments and procedures, these individuals were weighed and height measurements were taken. The mean differences were then calculated. The intraclass correlation coefficients between the self-reported numbers and those obtained through verification were also calculated, according to age, BMI, schooling, income and height. The BMl class obtained through the verification and the BMI from the self-reported numbers were compared. Results: When comparing self-reported values and those obtained though verification it was possible to see that men overestimate their height in $0.9 \mathrm{~cm}(p<0,05)$, and that shorter individuals have a tendency towards increasing this difference; while weight was underestimated in $0.44 \mathrm{~kg} \quad(p=0,06)$. On the other hand, women underestimated their weight in $0.03 \mathrm{~kg}(p>0,05)$ and overestimated their height in $2.2 \mathrm{~cm}(p<0,05)$. This behavior was influenced by these factors: increased age, less schooling, lower height, low weight and obesity. The BMl obtained from the selfreported data was underestimated $(p<0.05)$ in $0.27 \mathrm{~kg} / \mathrm{m}^{2}$ and $0.67 \mathrm{~kg} / \mathrm{m}^{2}$ for men and women, respectively. The coefficient of intraclass correlation showed a high degree of agreement between the self-reported weight and height figures and those obtained through verification, for both sexes. Both the sensitivity and specificity of the self-reported BMI were high, in terms of identifying the BMI obtained through verification. Conclusion: In this population, the information given by individuals aged 20-34 years, on their current weight and height was found to be reliable. Therefore, this methodology proved to be feasible for future epidemiological studies aiming at monitoring the prevalence of excess weight in this population.

Key-words: self-reported weight, self-reported height, obesity 


\section{INTRODUÇÃO}

A alta prevalência de doenças crônicas não transmissíveis principalmente câncer e doenças cardiovasculares têm aumentado o interesse em estudos nos quais as informaçōes sobre as doenças crônicas e os fatores de risco associados a estas doenças são obtidas por auto-informação da população. Os dados podem ser coletados por meio de entrevistas frente-afrente, envio de questionários pelo correio ou entrevistas por telefone. Estes procedimentos permitem avaliar amostras representativas da população, muitas vezes por um longo periodo de tempo com menor custo e simplificação do trabalho de campo (RIMM et al. 1995; HUANG et al. 1999).

Nestes estudos, entre as variáveis reportadas estão as medidas de peso e altura, que são utilizadas para o cálculo do índice de massa corporal (IMC), índice antropométrico mais utilizado em estudos populacionais. Os resultados de vários estudos (PIRIE et al. 1981; PALTA 1982; ROWLAND 1990; ROBERTS 1995; KUCZMARSKI et al. 2001; SPENCER et al. 2002) mostram que o peso e a altura referidos apresentam alta concordância com os dados obtidos diretamente, sendo, portanto, uma alternativa interessante para medir e monitorar a prevalência da obesidade.

As evidências, no entanto, mostram que o erro na informação não é aleatório, e sim está relacionado a características, tais como obesidade, idade, condição social, fatores culturais e psicológicos. No caso das medidas antropométricas, há uma tendência sistemática na direção de se atingir uma estética corporal socialmente valorizada. Neste sentido, tem-se observado uma maior subestimação de peso entre os indivíduos obesos e uma superestimação da altura, principalmente entre as pessoas de baixa estatura (JALKANEN et al. 1987; STEWART et al. 1987; STEVENS et al. 1990; ROWLAND 1990; KUCZMARSKI et al. 2001). Os indivíduos mais velhos também tendem a superestimar sua altura atual com magnitude maior do que os mais jovens, em parte, devido à perda gradual de altura que ocorre com o envelhecimento (ROWLAND 1990; KUCZMARSKI et al. 2001; SPENCER et al. 2002). 
Como o erro não é aleatório, a alta prevalência de indivíduos que subestimam ou superestimam as medidas de peso e/ou altura, leva a uma classificação enviesada do IMC, com uma redução na prevaléncia dos individuos situados nos extremos da classificação (baixo peso e obesidade). Portanto, antes da utilização das medidas referidas de peso e altura de uma determinada população é pertinente a realização de estudos que permitam conhecer a magnitude do erro associado a estas informaçőes.

Até o momento, foram realizados poucos estudos da validade das medidas de peso e altura referidos no Brasil (SCHMIDT et al. 1993; CHOR et al. 1999; FONSECA et al. 2004). No único estudo de base populacional, realizado na população urbana de Porto Alegre, SCHMIDT et al. (1993) observaram que o peso foi superestimado pelos homens e subestimado pelas mulheres, porém, concluiram que a validade do peso reportado é aceitável em estudos de prevalência de adiposidade.

O objetivo deste estudo foi avaliar a validade do peso e altura referidos no diagnóstico da obesidade e identificar quais as características sócio-demográficas e individuais contribuem para um possível viés de informação da população adulta de Goiânia.

\section{MATERIAL E MÉTODOS}

\subsection{Delineamento}

Para o desenvolvimento deste estudo, foram utilizados dados do Estudo da Prevalência e do Conhecimento da Hipertensão Arterial e alguns Fatores de Risco em uma Região do Brasil, projeto aprovado e financiado pelo $\mathrm{CNPq}$ e realizado pela equipe da Liga de Hipertensão Arterial da Universidade Federal de Goiás, em parceria com a Universidade Federal de Mato Grosso. Trata-se de um estudo com delineamento transversal, de base populacional, realizado nas capitais e em duas cidades do interior dos estados de Goiás e Mato Grosso. No presente estudo, foram analisados 
apenas os dados relativos a Goiânia, coletados no período de junho a dezembro de 2001.

O tamanho da amostra para o município de Goiânia foi calculado considerando-se uma população de 1.004.098 habitantes (IBGE/98), a prevalência de hipertensão arterial no Brasil - $20 \%$ da população adulta (MINISTÉRIO DA SAÚDE 1993), intervalo de confiança de $95 \%$ e erro de estimação de $10 \%$. À amostra obtida $(n=1534)$ foram acrescidos $30 \%$ para cobrir as perdas ( $n=1994)$. A amostra efetivamente estudada constituiu-se de 1.454 indivíduos maiores de 18 anos de ambos os sexos, não institucionalizados e residentes na área urbana $(72,9 \%$ da amostra total e $95 \%$ da amostra necessária).

Entre as perdas $(n=540), 121$ endereços foram classificados como inexistentes (não localizado ou não havia mais residência no endereço sorteado). Os demais domicílios $(n=419)$ foram localizados, mas não foi realizada a entrevista na grande maioria das vezes por recusa dos moradores. Outras causas menos freqüentes foram domicílio vazio ou moradores não encontrados após três visitas em dias e horários diferentes.

Os domicilios foram selecionados por amostragem probabilistica, por conglomerados, em duas etapas. A primeira consistiu na identificação, junto ao IBGE, dos setores censitários utilizados na Pesquisa Nacional por Amostragem de Domicílios (PNAD) de 1998 na zona urbana do município de Goiânia. A segunda etapa constou da seleção dos domicílios. Para esta seleção foram considerados o número de domicilios em cada setor e o tamanho total da amostra. A partir do cálculo do tamanho da amostra por setor foram sorteados, de forma aleatória e sistemática, os domicílios de cada setor.

Nos domicílios selecionados, foi entrevistado apenas um morador sorteado entre os moradores maiores de 18 anos, para evitar problemas de interdependência de informação entre entrevistados. Foram excluídas do sorteio gestantes e mães de crianças menores de seis meses, para evitar 
erros na interpretação dos dados. Foram excluídos também moradores que estivessem hospitalizados.

De uma amostra inicial de 1454 individuos, foram elegiveis os 1252 individuos (433 homens e 819 mulheres) com idade de 20 a 64 anos. Destes, foram excluídos aqueles sem informação sobre a altura referida (10 homens e 113 mulheres), o peso referido (22 homens e 39 mulheres) e aqueles sem informação de ambos (6 homens e 39 mulheres). Portanto, foram excluídos $229(18,3 \%)$ individuos, 38 (8,8\%) homens e $191(23,3 \%)$ mulheres, sendo a amostra final composta por 1023 individuos.

A entrevista foi realizada após a assinatura do termo de consentimento, cujo protocolo foi aprovado pelo Comitê de Ética em Pesquisa Médica Humana e Animal do Hospital das Clínicas da Universidade Federal de Goiás e pelo Comitê de Ética em Pesquisa - COEP - da Faculdade de Saúde Pública da Universidade de Săo Paulo.

\subsection{Variáveis do Estudo}

A coleta de dados foi realizada por entrevistadores treinados que preencheram um questionário padronizado que incluía questōes sobre as condições sócio-demográficas, estilo de vida (dieta, atividade física, consumo de álcool e tabagismo) e mensuração da pressão arterial, peso, altura e circunferência da cintura. Antes da realização das medidas antropométricas, os indivíduos informavam qual era o seu peso e altura atuais, sendo que durante a leitura do termo de consentimento os entrevistados foram informados que as medidas de peso e altura seriam realizadas após responderem ao questionário da entrevista.

As medidas antropométricas foram feitas de acordo com as recomendaçōes de LOHMAN et al. (1988). Os indivíduos foram pesados e medidos descalços e com roupas leves. Para a medida do peso utilizou-se balança eletrônica da marca Plenna, modelo Giant Lithium, com capacidade para $150 \mathrm{~kg}$ e precisão de $100 \mathrm{~g}$. Para a medida da altura utilizou-se estadiômetro portátil (Seca), com precisão de $0,1 \mathrm{~cm}$. 
O IMC foi calculado pela divisão do peso $(\mathrm{Kg})$ pelo quadrado da altura (m). Para a classificação dos valores de IMC foi utilizada a recomendação da OMS (1997): < 18,5 kg/m² (baixo peso); 18,5 a $24,99 \mathrm{~kg} / \mathrm{m}^{2}$ (peso normal); 25 a $29,99 \mathrm{~kg} / \mathrm{m}^{2}$ (sobrepeso) e $\geq 30 \mathrm{~kg} / \mathrm{m}^{2}$ (obesidade).

\subsection{Análise Estatistica}

Após a revisão dos questionários, os dados foram digitados duplamente em bancos elaborados no ACCESS. O procedimento validate (Epi-Info 6.04) foi utilizado para avaliação da qualidade da digitação. Para a análise utilizou-se o STATA (versão 7.0).

Os dados dos homens e das mulheres foram analisados em separado. Os erros na informação da altura, do peso e do IMC foram obtidos pela diferença entre os valores referidos e aferidos. Valores negativos significavam subestimação do valor referido e valores positivos representavam superestimação do valor referido.

Utilizou-se teste $t$ de Student pareado para avaliar as diferenças entre as médias das medidas referidas e aferidas. A análise de variância foi utilizada para avaliar as diferenças entre as medidas referidas e aferidas segundo as categorias de idade $(20-24 ; 25-34 ; 35-44 ; 45-54 ; 55-64)$, escolaridade ( $<9$ anos e $\geq 9$ anos); IMC (<18,5; 18,5-24; 25-29; $\geq 30)$; renda familiar (quartil de renda per capita) e altura (quartil). Para determinar quais destas variáveis apresentavam associação independente com o erro da informação do peso e altura, foi realizada análise de regressão linear múltipla.

Para avaliação da concordância entre as medidas aferidas e referidas de peso e altura foi calculado o coeficiente de correlação intraclasse ( $\mathrm{CCl}$ ). Optou-se por este coeficiente, pois o $\mathrm{CCl}$, além de avaliar a correlaçăo entre grupos de valores, como fazem os coeficientes tradicionalmente mais utilizados (Pearson e Spearman), é também uma boa medida de concordância (reprodutibilidade), uma vez que considera a variabilidade entre indivíduos, ou 
seja, a tendência sistemática de subestimação ou superestimação dos valores (SZKLO e JAVIER NIETO 2000).

Para a análise da validade do IMC obtido a partir das medidas referidas de peso e altura, foram calculadas a sensibilidade e a especificidade para classificar corretamente o IMC.

As análises estatísticas foram corrigidas pelo delineamento complexo da amostra, por meio da utilização do conjunto de comandos SVY do STATA, que consideram a estrutura complexa da amostra, utilizando os pesos associados a cada conglomerado da amostra e o efeito do desenho amostral. Foi considerado o nível de significância de $5 \%$.

\section{RESULTADOS}

A amostra estudada foi composta por 1023 indivíduos, sendo 628 $(61,4 \%)$ mulheres e $395(38,6 \%)$ homens. Homens e mulheres não apresentaram diferença significativa para idade, renda, escolaridade e IMC (Tabela 3.1). A comparação dos indivíduos excluídos com os estudados não apresentou diferença segundo categorias de idade e IMC (dados não mostrados).

Tabela 3.1 - Médias e IC (95\%) de variáveis selecionadas para mulheres e homens. Goiânia-GO, Brasil, 2001.

\begin{tabular}{|c|c|c|c|c|}
\hline \multirow[t]{2}{*}{ Variáveis } & \multicolumn{2}{|c|}{ Homens ( $n=395)$} & \multicolumn{2}{|c|}{ Mulheres $(n=628)$} \\
\hline & Média & IC (95\%) & Média & IC (95\%) \\
\hline Idade (anos) & 37,8 & {$[36,2 ; 39,4]$} & 37,6 & {$[36,6 ; 38,5]$} \\
\hline Escolaridade (anos) & 8,0 & {$[7,1 ; 9,0]$} & 7,9 & {$[6,9 ; 8,9]$} \\
\hline Renda (per capita em SM) & 2,1 & {$[1,6 ; 2,6]$} & 1,8 & {$[1,3 ; 2,2]$} \\
\hline Peso (kg) & 70,6 & {$[67,7 ; 73,6]$} & 61,3 & {$[59,8 ; 62,7]$} \\
\hline Altura (m) & 169,6 & {$[168,8 ; 170,5]$} & 157,6 & {$[156,9 ; 158,2]$} \\
\hline $\operatorname{IMC}\left(\mathrm{kg} / \mathrm{m}^{2}\right)$ & 24,5 & {$[23,6 ; 25,4]$} & 24,7 & {$[24,2 ; 25,2]$} \\
\hline
\end{tabular}


As médias das diferenças entre o peso, altura e IMC referidos e aferidos segundo faixa-etária, variáveis sócio-econômicas e antropometria para homens e mulheres são apresentadas nas Tabelas 3.2 e 3.3, respectivamente.

\section{Peso}

Os homens apresentaram uma tendência a superestimar o peso em média $0,44 \mathrm{~kg}(p=0,06)$. A superestimação de peso foi significativa para os homens mais jovens (até 34 anos), para os de maior escolaridade e para aqueles situados no $3^{\circ}$ quartil de renda e de altura. A diferença com maior magnitude foi observada para os homens de baixo peso (IMC $<18,5 \mathrm{~kg} / \mathrm{m} 2$ ), os quais superestimaram o peso em média cerca de $3 \mathrm{~kg}$. Por outro lado, os obesos informaram o peso abaixo do aferido com diferencial médio de $-1,4 \mathrm{~kg}$ $(p<0,01)$. A análise de variância mostrou que as diferenças entre as medidas referidas $e$ aferidas de peso variaram significativamente com a idade $(p=0,04)$, escolaridade $(p=0,03)$ e IMC $(p<0,01)$ (Tabela 3.2, Figura 3.1).

As mulheres tenderam a subestimar o peso, achado que não alcançou significância estatística. A análise das diferenças, segundo as categorias das variáveis estudadas, mostra que a subestimação do peso foi significativa apenas para as mulheres de 35 a 44 anos, para aquelas situadas no $3^{\circ}$ quartil de renda e entre as obesas $(p<0,01)$. Já as mulheres de baixo peso e eutróficas superestimaram o peso em média $0,81 \mathrm{~kg}$ e 0,27 $\mathrm{kg}(p<0,01)$, respectivamente. As diferenças entre as medidas referidas $\mathrm{e}$ aferidas de peso variaram significativamente com a idade $(p<0,01)$ e IMC $(p<0,01)$ (Tabela 3.3, Figura 3.2).

$\mathrm{Na}$ regressão linear múltipla apenas o IMC apresentou associação independente com o erro na informação do peso, para ambos os sexos. Para cada $1 \mathrm{~kg} / \mathrm{m}^{2}$ a diferença na informação do peso foi de $0,28 \mathrm{~kg}$ menor $(p<0,01)$ para os homens e $0,1 \mathrm{~kg}(p<0,01)$ menor para as mulheres. Isto ocorreu em função dos indivíduos de baixo peso terem informado o peso com maior diferencial em relação aos indivíduos com excesso de peso. 
Os coeficientes de correlação intraclasse entre as medidas reportadas e aferidas do peso foram de 0,96 e 0,97, para homens e mulheres, respectivamente. Um elevado grau de concordância foi também observado para todas as categorias das variáveis analisadas, em ambos os sexos.

A distribuição das diferenças entre peso referido e aferido mostra que $95 \%$ dos valores referidos pelos homens ficaram entre $-7,9 \mathrm{~kg}$ e $8,0 \mathrm{~kg} \mathrm{e}$ para as mulheres entre $-5,7 \mathrm{~kg} \mathrm{e} 5,4 \mathrm{~kg}$ (Figura 3.3). O peso foi informado com uma diferença $\geq 2 \mathrm{~kg}$ ( $\leq-2$ ou $\geq+2 \mathrm{~kg}$ ) por $45 \%$ dos homens e por $31 \%$ das mulheres. Somente $10,5 \%$ das mulheres informaram o peso com um erro $\geq 4 \mathrm{~kg}$, para os homens este valor foi de $20,3 \%$.

\section{Altura}

Os homens superestimaram sua altura em média $0,91 \mathrm{~cm}(p<0,01)$, sendo que a maior magnitude foi observada para os homens de 55 a 64 anos $(1,57 \mathrm{~cm})$ e naqueles de menor estatura $(2,11 \mathrm{~cm})$. As diferenças entre as medidas referidas e aferidas de altura variaram significativamente com o IMC $(p<0,01)$ e altura $(p<0,01)$ (Tabela 3.2).

Para as mulheres, a altura foi superestimada em $2,2 \mathrm{~cm}(p<0,01)$. A altura foi significativamente superestimada em todas as categorias das variáveis pesquisadas (faixa-etária, escolaridade, renda, IMC e altura), sendo que as maiores magnitudes foram observadas para as mais velhas $(3$, $33 \mathrm{~cm})$, para as de menor escolaridade $(2,63 \mathrm{~cm})$ e menor altura $(3,16 \mathrm{~cm})$ e para aquelas situadas nos extremos da classificação do IMC, baixo peso $(3,66 \mathrm{~cm})$ e obesas $(3,40 \mathrm{~cm})$ (Tabela 3.3$)$. As diferenças entre as medidas referidas e aferidas de altura variaram significativamente com a idade, escolaridade, IMC e altura $(p<0,01)$

Para os homens, a associação independente com o erro na informação da altura foi observada para o IMC e a altura, já para as mulheres o erro se associou de forma independente com a escolaridade e a altura. No modelo para os homens, cada $1 \mathrm{~kg} / \mathrm{m}^{2}$ aumenta a diferença na informaçăo da altura em $0,12 \mathrm{~cm} \quad(p<0,01)$ e para cada centímetro de altura reduz a diferença em $0,1 \mathrm{~cm}(p<0,01)$. No modelo para as mulheres, cada ano de estudo reduz o 
erro na informação da altura em $0,05 \mathrm{~cm}(p=0,03)$ e cada centímetro na altura reduz o erro em $0,1 \mathrm{~cm}(p=0,03)$.

Os coeficientes de correlação intraclasse entre as medidas reportadas e aferidas da altura foram de 0,92 e 0,83, para homens e mulheres, respectivamente. Estes valores foram menores do que os coeficientes observados para o peso; mostrando que a altura referida foi menos válida do que o peso, principalmente entre as mulheres.

A distribuição das diferenças entre altura referida e aferida mostra que $95 \%$ dos valores referidos pelos homens ficaram entre $-6,0 \mathrm{~cm} \mathrm{e} 7,6 \mathrm{~cm}$ e para as mulheres entre $-5,0 \mathrm{~cm}$ e $11,1 \mathrm{~cm}$ (Figura 3.3). Cerca de $55 \%$ dos homens e $57 \%$ das mulheres informaram a altura com uma diferença $\geq 2 \mathrm{~cm}$, sendo que $9,3 \%$ dos homens e $23,4 \%$ das mulheres superestimaram a altura em $5 \mathrm{~cm}$ ou mais.

IMC

A média do IMC obtido a partir das medidas referidas de peso e altura foi menor do que a média do IMC calculado a partir das medidas aferidas $(p<0,01)$, de maneira mais acentuada entre as mulheres. As maiores subestimações foram observadas para os mais velhos, para os obesos e para os de menor altura, em ambos os sexos. As diferenças entre as medidas referidas e aferidas do IMC variaram significativamente com o IMC e altura $(p<0,01)$ para os homens e com a idade, escolaridade, IMC e altura para as mulheres $(p<0,01)$. Apesar destas diferenças, foi observada alta correlação $(0,97)$ entre IMC referido e IMC aferido para homens e mulheres (Tabelas 3.2 e 3.3 ).

Considerando o IMC aferido como padrão, observa-se que $25,1 \%$ dos homens e $3,2 \%$ das mulheres de baixo peso foram classificados como eutróficos utilizando-se o IMC referido. No outro extremo, 10,2\% dos homens obesos e $28,3 \%$ das mulheres obesas foram classificados como sobrepeso. Com isto, observa-se que, para os homens, a sensibilidade na identificação do sobrepeso e obesidade foi de $82,0 \%$ e $89,8 \%$, respectivamente, sendo um pouco mais baixa $(74,9 \%)$ na identificação do baixo peso. Para as mulheres, 
as menores sensibilidades foram observadas na identificação do sobrepeso e obesidade, $77,2 \%$ e $71,7 \%$, respectivamente (Figuras 3.4 e 3.5 ). Foram observadas altas especificidades do IMC obtido a partir das medidas referidas de peso e altura, para todas as categorias da classificaçăo do IMC aferido, em ambos os sexos. A menor especificidade foi observada na classificação da normalidade (eutrofia), sendo de $88,6 \%$ para os homens e de $84,5 \%$ para as mulheres (dados não mostrados).

Tabela 3.2 - Diferença ${ }^{1}$ e coeficiente de correlação intraclasse $\left(r_{i c c}\right)$ entre as medidas referidas e aferidas de peso, altura e IMC em homens segundo idade, variáveis sócio-econômicas e antropometria. Goiânia-GO, Brasil, 2001.

\begin{tabular}{|c|c|c|c|c|c|c|c|}
\hline \multirow[t]{2}{*}{ Variáveis } & \multirow[t]{2}{*}{$\mathbf{N}$} & \multicolumn{2}{|c|}{ Diferença no peso } & \multicolumn{2}{|c|}{ Diferença na altura } & \multicolumn{2}{|c|}{ Diferença no IMC } \\
\hline & & Media (dp) & $r_{\text {ice }}$ & Média (dp) & rice & Media (dp) & $r_{\text {ice }}$ \\
\hline $\begin{array}{l}\text { Total } \\
\text { Faixa etária }\end{array}$ & 395 & $0,44(3,4)$ & 0,96 & $0,91(3,2)^{*}$ & 0,92 & $-0,27(0,9)^{*}$ & 0,97 \\
\hline $20-24$ & 66 & $1,07(3,3)^{* a}$ & 0,93 & $0,27(3,0)$ & 0,91 & $-0,07(0,8)$ & 0,97 \\
\hline $25-34$ & 107 & $0,77(2,9)^{\star}$ & 0,97 & $1,20(3,4)^{*}$ & 0,90 & $-0,34(0,9)^{*}$ & 0,97 \\
\hline $35-44$ & 93 & $0,12(3,7)$ & 0,96 & $1,13(2,7)^{\star}$ & 0,94 & $-0,36(0,8)^{*}$ & 0,98 \\
\hline $45-54$ & 79 & $0,51(3,2)$ & 0,98 & $0,48(3,1)$ & 0,94 & $-0,17(0,9)$ & 0,97 \\
\hline \multicolumn{8}{|c|}{ Escolaridade } \\
\hline$<9$ anos & 200 & $0,11(3,6)^{a}$ & 0,96 & $0,74(3,6)$ & 0,90 & $-0,23(1,1)$ & 0,97 \\
\hline$>=9$ anos & 195 & $0,89(3,1)^{\star}$ & 0,97 & $1,12(2,4)^{\star}$ & 0,95 & $-0,32(0,7)^{\star}$ & 0,98 \\
\hline \multicolumn{8}{|l|}{ Renda } \\
\hline 1 quartil & 102 & $0,24(3,8)$ & 0,94 & $0,73(3,8)$ & 0,86 & $-0,26(1,2)$ & 0,95 \\
\hline 2 quartil & 101 & $0,61(4,1)$ & 0,94 & $0,85(3,0)$ & 0,92 & $-0,23(0,8)$ & 0,98 \\
\hline 3 quartil & 94 & $0,71(2,5)^{*}$ & 0,98 & $1,21(3,0)^{*}$ & 0,95 & $-0,34(0,8)^{*}$ & 0,98 \\
\hline 4 quartil & 98 & $0,23(3,0)$ & 0,99 & $0,89(2,1)^{\star}$ & 0,95 & $-0,26(0,6)^{*}$ & 0,99 \\
\hline \multicolumn{8}{|c|}{$0,00(2,1)$} \\
\hline$<18,5$ & 11 & $3,23(2,1)^{\star a, b}$ & 0,88 & $-1,08(2,4)^{a}$ & 0,90 & $0,23(0,5)^{\mathrm{a}}$ & 0,69 \\
\hline $18,5-24$ & 202 & $0,95(3,2)^{\star c, d}$ & 0,91 & $0,62(3,3)$ & 0,90 & $-0,15(0,9)^{\mathrm{b}}$ & 0,88 \\
\hline $25-29$ & 132 & $-0,20(3,3)^{a, c}$ & 0,94 & $1,40(3,1)^{\star}$ & 0,95 & $-0,43(1,0)^{*}$ & 0,79 \\
\hline$>=30$ & 50 & $-1,38(4,2)^{* b, d}$ & 0,94 & $0,67(2,5)^{\star a}$ & 0,94 & $-0,65(0,9)^{\star}$ & 0,94 \\
\hline Altura & & & & & & & \\
\hline 1 quartil & 108 & & 0,95 & $2,11(3,3)^{*}$ a.b.c. & 0,67 & $\begin{array}{l}-0,63(1,0)^{a} \\
-021(09)^{a}\end{array}$ & 0,97 \\
\hline 2 quartil & 102 & $\begin{array}{l}0,19(3,4) \\
0,71(3,4)^{*}\end{array}$ & 0,95 & $0,62(2,9)^{\mathrm{a}}$ & 0,38 & $\begin{array}{l}-0,21(0,9) \\
-0,15(0.9)^{0}\end{array}$ & 0,98 \\
\hline 3 quartil & 94 & & 0,97 & $0,51(3,1)^{0}$ & 0,43 & $0.02(0,8)^{c}$ & 0,98 \\
\hline 4 quartil & 91 & & 0,96 & $-0,02(2,8)^{c}$ & 0,88 & & 0,98 \\
\hline
\end{tabular}

${ }^{1}$ Diferenca $=$ valor referido menos valor aferido ; ${ }^{*} p<0,05$ no teste $t$ de Student pareado; médias de diferenças, nas colunas, seguidas por letras iguais apresentam $p<0,05$ na análise de variáncia. 
Tabela 3.3 - Diferença ${ }^{1}$ e coeficiente de correlação intraclasse $\left(r_{\text {icc }}\right)$ entre as medidas referidas e aferidas de peso, altura e IMC em mulheres segundo idade, variáveis sócio-econômicas e antropometria. Goiânia-GO, Brasil, 2001.

\begin{tabular}{|c|c|c|c|c|c|c|c|}
\hline \multirow[t]{2}{*}{ Variáveis } & & \multicolumn{2}{|c|}{ Diferença no peso } & \multicolumn{2}{|c|}{ Diferença na altura } & \multicolumn{2}{|c|}{ Diferença no IMC } \\
\hline & & Média & $r_{\text {Icc }}$ & Média & $r_{i c c}$ & Média & $r_{\text {ice }}$ \\
\hline Total & 628 & $-0,03(2,6)$ & 0,97 & $2,22(3,8) *$ & 0,83 & $-0,67(1,2)^{*}$ & 0,97 \\
\hline \multicolumn{8}{|c|}{ Faixa etária } \\
\hline $20-24$ & 97 & $0,67(2,8)^{a}$ & 0,97 & $1,41(3,6) * a$ & 0,81 & $-0,35(0,9) * a, b$ & 0,97 \\
\hline $25-34$ & 184 & $-0,08(2,6)$ & 0,97 & $2,11(3,8) *$ & 0,84 & $-0,57(1,0) * c$ & 0,97 \\
\hline $35-44$ & 150 & $-0,63(2,4) \star^{a}$ & 0,98 & $1,94(3,6) *$ & 0,86 & $-0,61(1,2) \star d$ & 0,98 \\
\hline $45-54$ & 115 & $0,18(2,4)$ & 0,98 & $2,74(3,8)^{\star}$ & 0,81 & $-0,87(1,2)$ & 0,96 \\
\hline $55-64$ & 82 & $0,51(0,5)$ & 0,98 & $3,33(3,3)^{\star a}$ & 0,74 & $-1,18(1,2)^{\star b, c, d}$ & 0,97 \\
\hline \multicolumn{8}{|c|}{ Escolaridade } \\
\hline$<9$ anos & 308 & $0,02(2,5)$ & 0,98 & $2,63(4,3)^{\star a}$ & 0,80 & $-0,78(1,3)^{\star a}$ & 0,96 \\
\hline$>=9$ anos & 320 & $-0,09(2,7)$ & 0,98 & $1,67(3,0)^{\star a}$ & 0,89 & $-0,53(1,0) * a$ & 0,98 \\
\hline \multicolumn{8}{|l|}{ Renda } \\
\hline 1 quartil & 157 & $0,01(2,9)$ & 0,97 & $2,40(4,3) *$ & 0,77 & $-0,68(1,3) *$ & 0,97 \\
\hline 2 quartil & 159 & $0,27(2,4)$ & 0,98 & $2,01(3,4)$ * & 0,86 & $-0,64(1,1)$ & 0,97 \\
\hline 3 quartil & 156 & $-0,44(2,5)^{\star}$ & 0,98 & $2,42(3,7)$ * & 0,87 & $-0,74(1,2)$ & 0,97 \\
\hline 4 quartil & 156 & $-0,02(2,2)$ & 0,98 & $1,87(3,5)^{\star}$ & 0,85 & $-0,61(1,1)$ & 0,97 \\
\hline \multicolumn{8}{|l|}{ IMC } \\
\hline$<18,5$ & 39 & $0,81(1,9)^{* a, b}$ & 0,90 & $3,66(4,6)$ *a & 0,68 & $-0,72(0,9) *$ & 0,77 \\
\hline $18,5-24$ & 331 & $0,27(2,5)^{\star c, d}$ & 0,92 & $1,71(3,8) * a, b$ & 0,83 & $-0,44(1,1) * b, c$ & 0,83 \\
\hline $25,-29$ & 171 & $-0,51(2,5)^{* a, c}$ & 0,91 & $2,28(3,3)$ * & 0,88 & $-0,73(1,1)^{* b, d}$ & 0,78 \\
\hline$>=30$ & 87 & $-0,52(3,2)^{b, d}$ & 0,96 & $3,40(3,8)$ * & 0,78 & $-1,40(1,6)^{* a, c, d}$ & 0,92 \\
\hline \multicolumn{8}{|l|}{ Altura } \\
\hline 1 quartil & 157 & $-0,03(2,3)$ & 0,98 & $3,16(4,4) * a, b$ & 0,52 & $-1,06(1,5)^{\star a, b, c}$ & 0,96 \\
\hline 2 quartil & 160 & $\begin{array}{r}0,08(2,8) \\
-013(27)\end{array}$ & 0,97 & $2,18(3,9)^{\star}$ & 0,42 & $-0,66(1,2)^{*}$ & 0,97 \\
\hline 3 quartil & 169 & $\begin{array}{l}-0,13(2,7) \\
-0,21(2,6)\end{array}$ & 0,97 & $1,79(3,4))^{* a}$ & 0,39 & $-0,49(0,9) * 0$ & 0,98 \\
\hline 4 quartil & 142 & $-0,21(2,6)$ & 0,97 & $1,66(3,2) * b$ & 0,62 & $-0,44(0,9)^{\star c}$ & 0,97 \\
\hline
\end{tabular}

${ }^{1}$ Diferença = valor referido menos valor aferido ; ${ }^{a} \mathrm{p}<0,05$ no teste $t$ de Student pareado; ${ }^{a, b, c, d}$ médias de diferenças seguidas por letras iguais apresentam $p<0,05$ na análise de variância. 


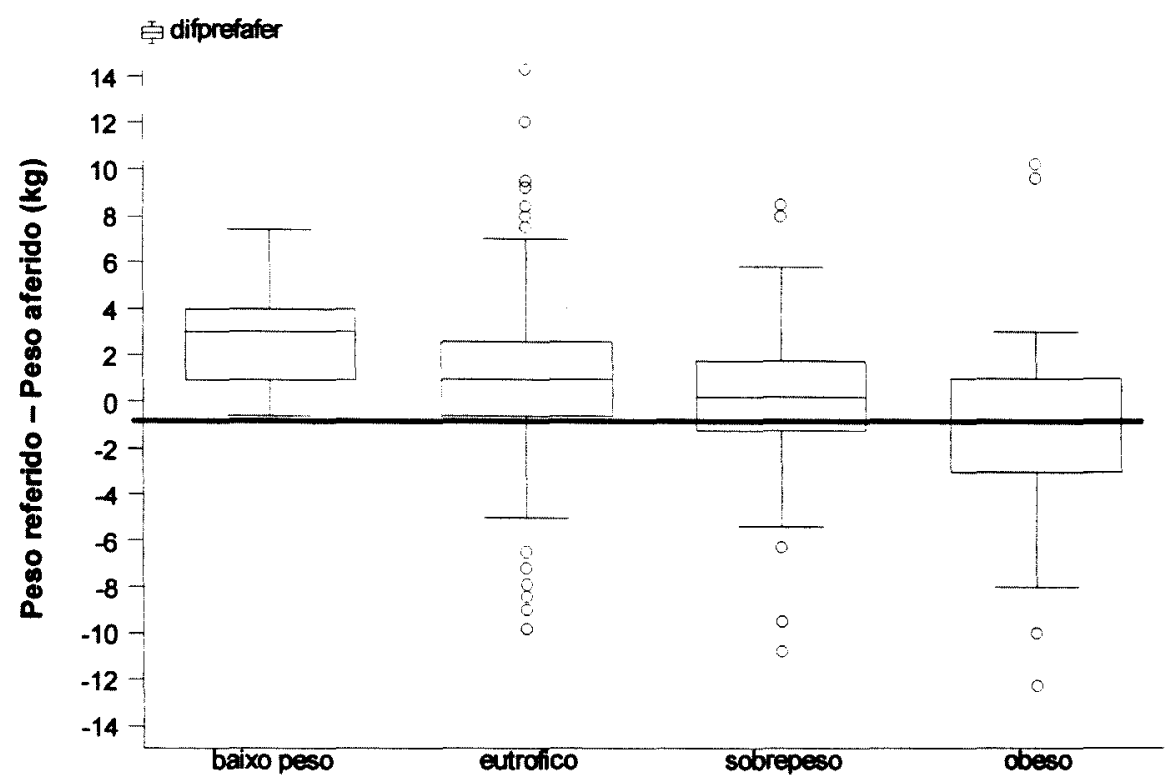

Figura 3.1 - Distribuição da diferença entre peso referido e peso aferido segundo categorias de IMC para homens de 20 a 64 anos. Goiânia-GO, Brasil, 2001.

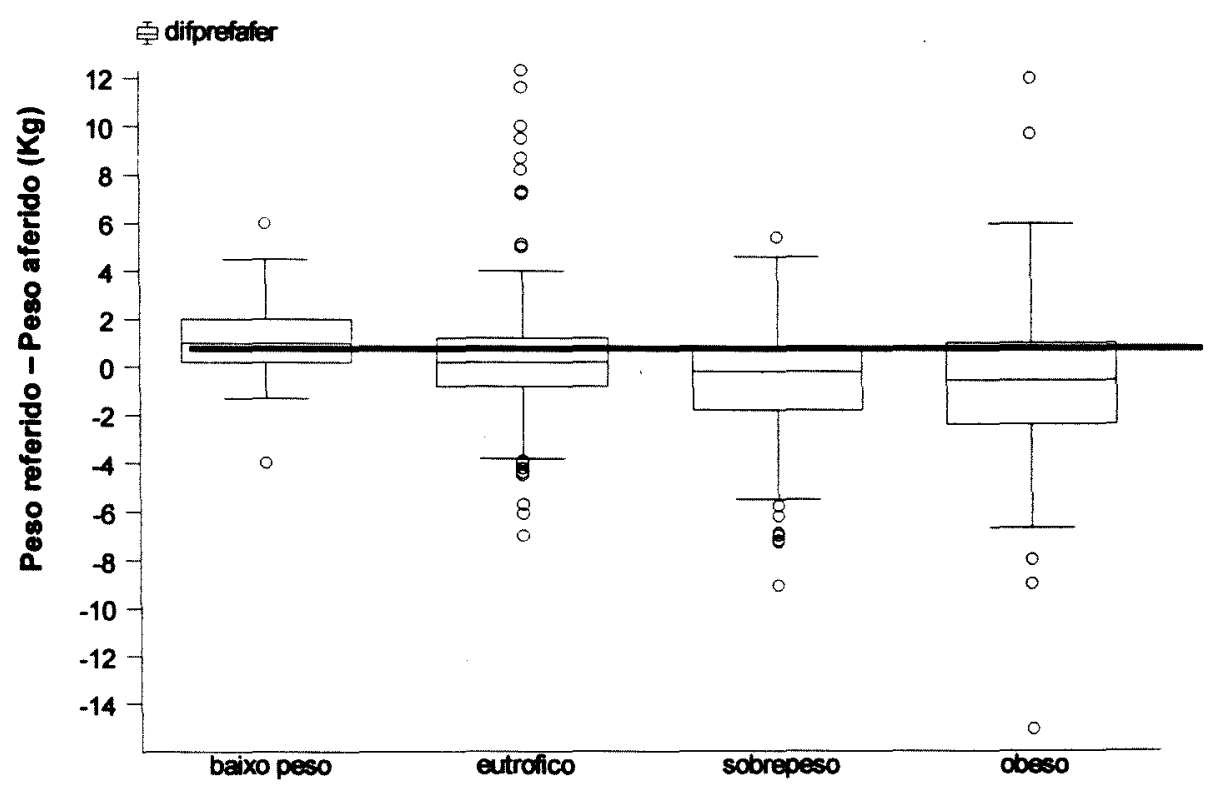

Figura 3.2 - Distribuição da diferença entre peso referido e peso aferido segundo categorias de IMC para mulheres de 20 a 64 anos. Goiânia-GO, Brasil, 2001. 
3

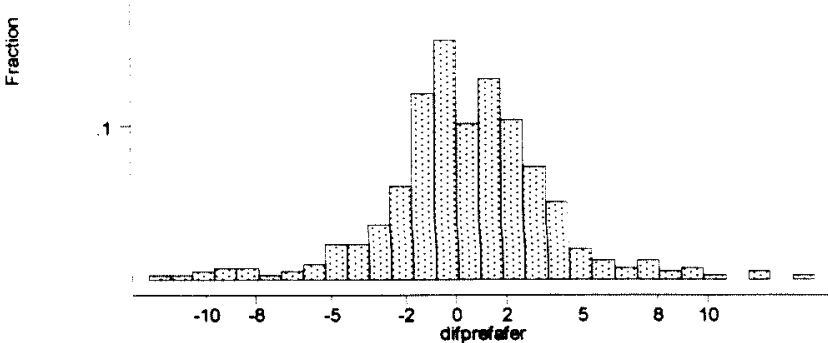

Homens (peso referido - peso aferido)

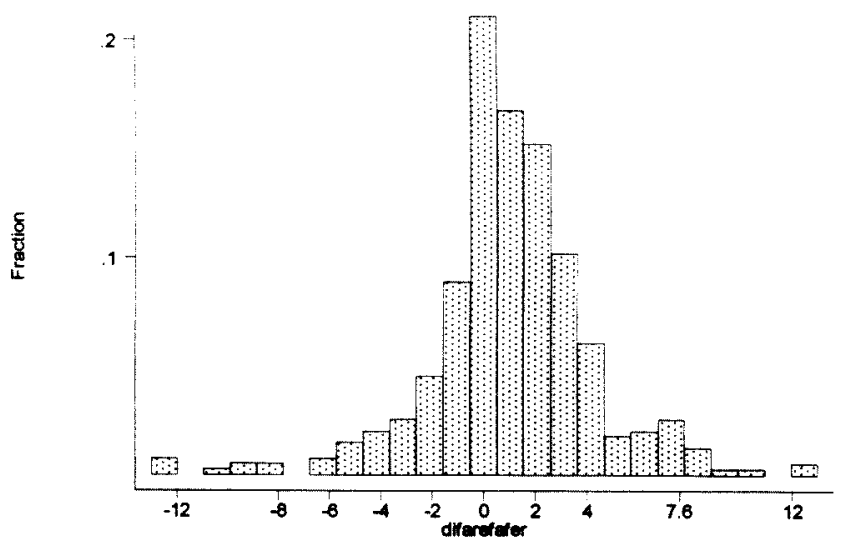

Homens (altura referida - altura aferida)

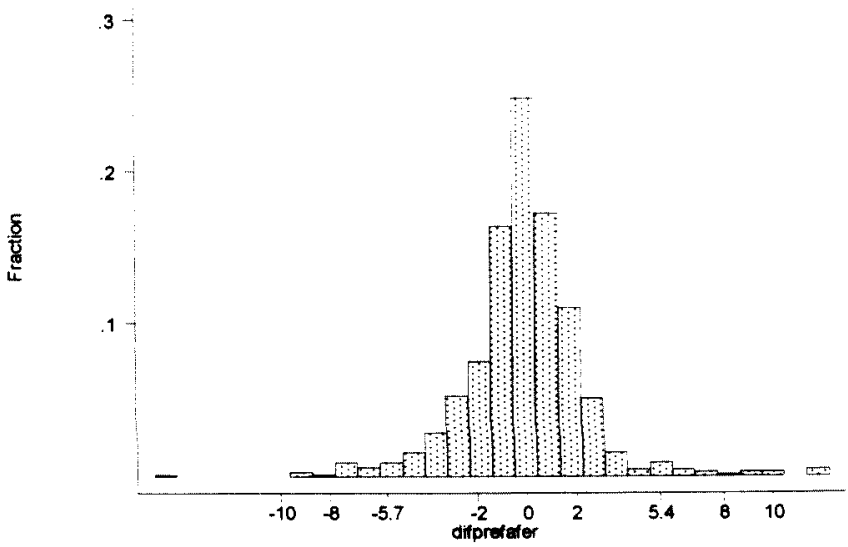

Mulheres (peso referido - peso aferido)

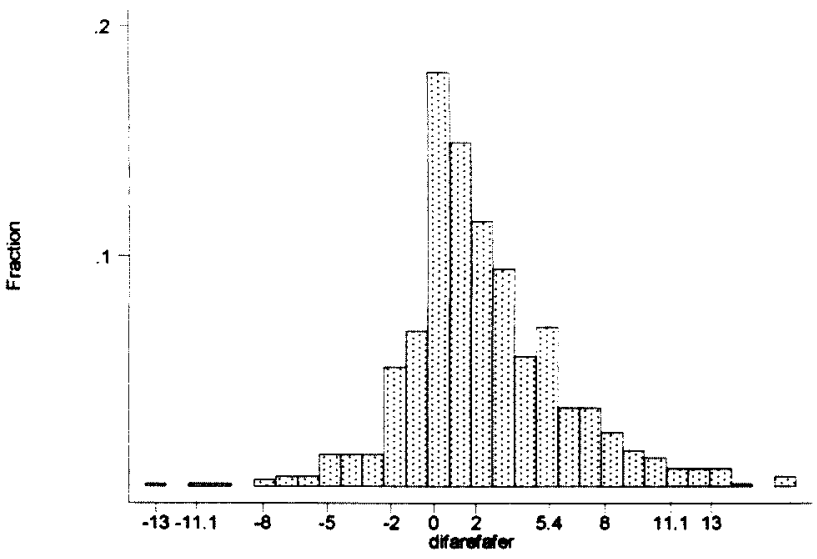

Mulheres (altura referida - altura aferida)

Figura 3.3 - Distribuição da diferença entre valores referidos e aferidos do peso e altura em homens e mulheres de 20 a 64 anos. Goiânia-GO, Brasil, 2001 


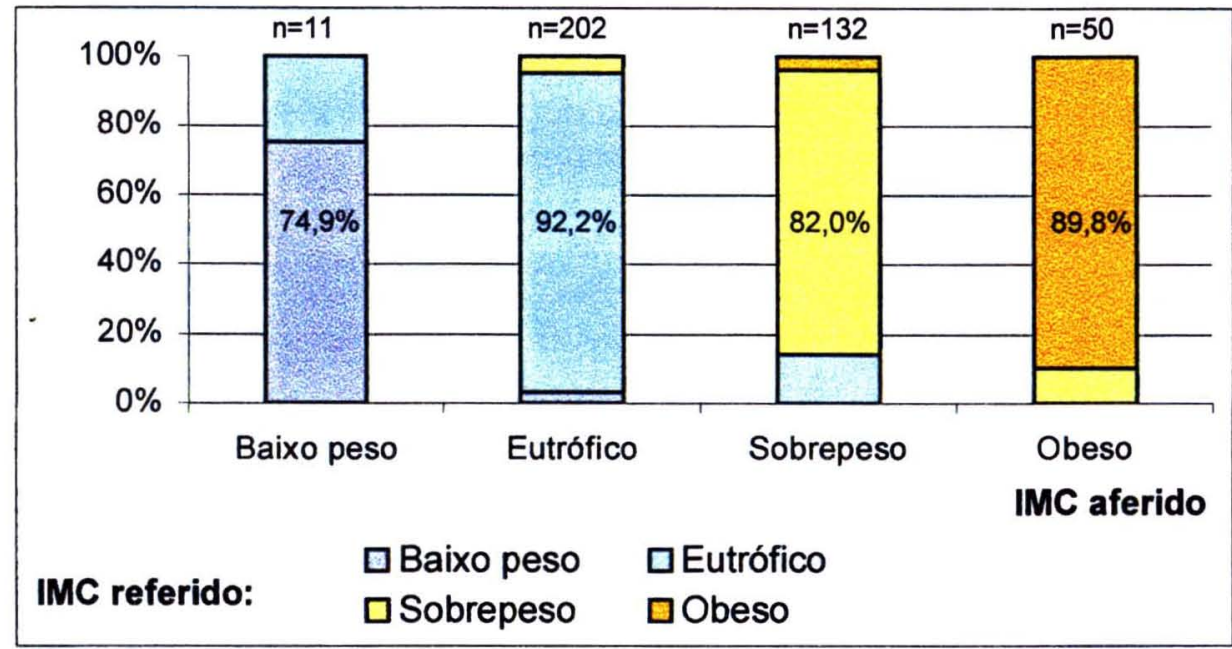

Figura 3.4 - Distribuição dos homens segundo categorias de classificação do IMC aferido e do IMC referido. Goiânia-GO, Brasil, 2001.

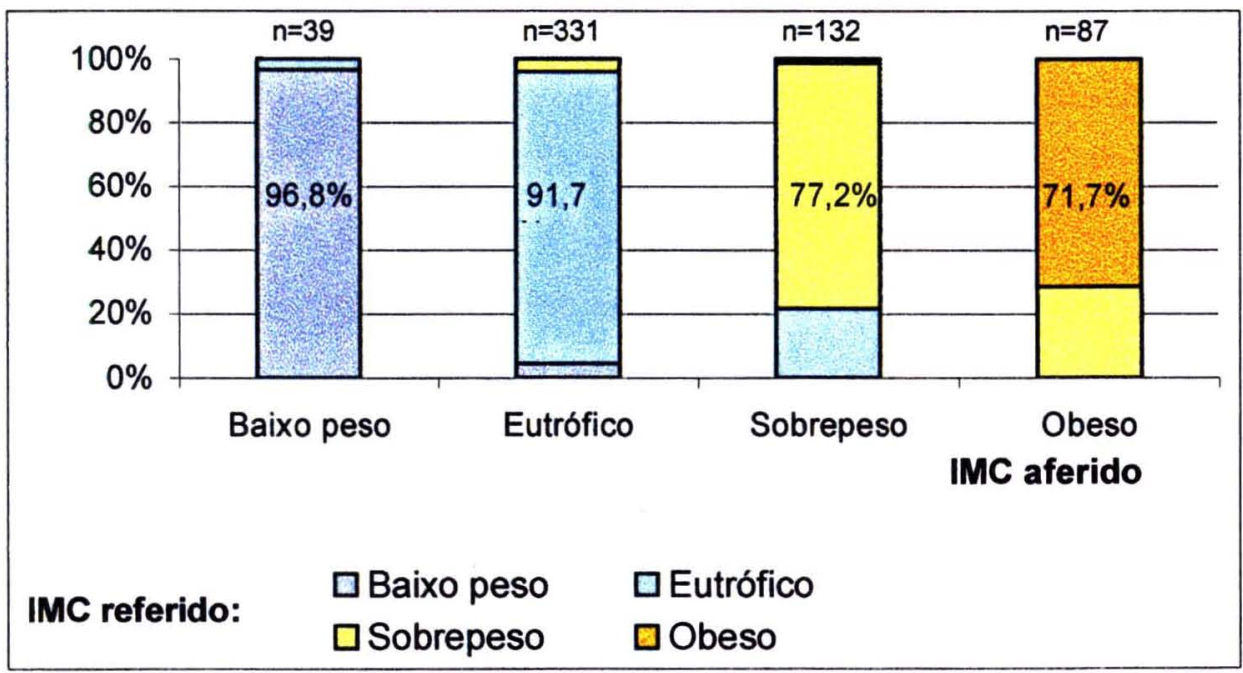

Figura 3.5 - Distribuição das mulheres segundo categorias de classificação do IMC aferido e do IMC referido*. Goiânia-GO, Brasil, 2001.

$\mathrm{Na}$ Tabela 3.4, são comparadas as prevalências (baixo peso, normalidade, sobrepeso e obesidade) baseadas nas medidas aferidas e referidas do IMC. Observa-se que embora haja algumas diferenças nas estimativas pontuais, na comparação da medida aferida com a referida os intervalos de confiança se sobrepõem. 
Tabela 3.4 - Distribuição (\%) e intervalo de confiança (95\%) da amostra segundo categorias de classificação do IMC a partir do peso e altura referidos e aferidos. Goiânia -GO, Brasil, 2001.

\begin{tabular}{|c|c|c|c|c|}
\hline \multirow{2}{*}{$\begin{array}{c}\text { Categorias } \\
\text { de IMC }\end{array}$} & \multicolumn{2}{|c|}{ Homens } & \multicolumn{2}{|c|}{ Mulheres } \\
\hline & $\begin{array}{l}\text { IMC aferido } \\
\% \quad(\text { IC- } 95 \%)\end{array}$ & $\begin{array}{l}\text { TMC referido } \\
\% \quad \text { (IC- } 95 \%)\end{array}$ & $\begin{array}{l}\text { IMC aferido } \\
\% \quad \text { (IC- } 95 \% \text { ) }\end{array}$ & $\begin{array}{l}\text { IMC referido } \\
\% \quad \text { (IC- 95\%) }\end{array}$ \\
\hline Baixo peso & $4,0(2,0 ; 8,0)$ & $4,6(3,0 ; 8,0)$ & $6,1(4,0 ; 9,0)$ & $8,2(6,0 ; 11,0)$ \\
\hline Normal & $54,7(45,0 ; 64,0)$ & $55,8(49,0 ; 62,0)$ & $51,7(49,0 ; 54,0)$ & $53,8(51,0 ; 57,0)$ \\
\hline Sobrepeso & $31,0(24,0 ; 39,0)$ & $29,0(25,0 ; 33,0)$ & $28,7(26,0 ; 32,0)$ & $28,0(24,0 ; 32,0)$ \\
\hline Obesidade & $10,4(7,0 ; 15,0)$ & $10,5(7,0 ; 14,0)$ & $13,4(11,0 ; 17,0)$ & $10,0(8,0 ; 13,0)$ \\
\hline
\end{tabular}

\section{DISCUSSÃo}

Este estudo mostrou alta concordância entre as medidas de peso reportado e aferido e entre altura reportada e aferida em um inquérito de base populacional realizado na cidade de Goiânia. Embora o peso e altura tenham sido reportados, em média com pequenos erros, vale considerar as observaçōes mencionadas a seguir, visto que, alguns sub-grupos de indivíduos apresentaram maior tendência para superestimar ou subestimar as medidas antropométricas.

Nesta pesquisa, foi perguntado ao entrevistado "Qual o seu peso atual?". Para garantir um controle da qualidade desta resposta, o mais pertinente seria perguntar, anteriormente, quando o individuo se pesou pela última vez, onde foi pesado, qual o tipo de balança utilizado e se estava descalço e com roupas leves nesta ocasião.

As diferenças entre os valores de peso referido e aferido poderiam ter sido menores se fossem excluidas da amostra as pessoas com história de doenças que provocam variabilidade do peso em curto tempo, como o diabetes e as doenças infecciosas, o que contribui para a menor exatidão com que estas pessoas informam o peso atual. No entanto, por ser o peso uma medida freqüentemente mensurada nos serviços de saúde, farmácias e mesmo em alguns domicilios, a falta dos itens anteriores interferiu pouco nos 
valores do peso referido, que mostrou um alto coeficiente de correlação intraclasse com o peso aferido.

Outros fatores que podem interferir na acúracia das medidas referidas e que não foram avaliadas neste estudo são: a freqüência com que os individuos se pesam ou medem; a percepção que os individuos tem de sua imagem corporal e o biótipo que gostariam de ter.

Para a coleta da altura referida foi feita a pergunta "Qual a sua altura atual?". Neste caso também não foi questionado quando foi realizada esta medida, por quem foi realizada e se a medida foi feita descalço.

O fato dos indivíduos terem sido informados que seriam pesados e medidos, pode ter inibido a informação incorreta. Algumas pessoas não souberam e, talvez, outras não quiseram informar seu peso e altura atual. A porcentagem de homens que não referiram o peso e/ou altura foi baixa, $8,8 \%$ no total. Por outro lado, $14,8 \%$ das mulheres não referiram a altura, 3,4 $\%$ não referiram o peso e $4,4 \%$ năo referiram ambos. Ao contrário do peso, a altura é verificada raramente entre os adultos. Já o menor número de homens, em relação às mulheres, que não souberam referir a altura, em parte, deve-se ao fato destes, geralmente, se lembrarem da altura coletada na época da convocação para o serviço militar. A comparação dos indivíduos excluídos com os estudados năo apresentou diferença segundo as categorias de idade e IMC.

As vantagens deste estudo foi ter sido de base populacional, com entrevista domiciliar realizada por entrevistadores treinados e utilizando instrumentos padronizados. A obtenção das medidas aferidas e reportadas no mesmo dia também foi um ponto positivo, pois o espaçamento entre as medidas gera vieses na interpretação das discrepâncias entre os valores referidos e aferidos. Além disso, as diferenças entre estas medidas foram avaliadas levando em consideração as características da população que podem influenciar nos resultados, como idade, escolaridade, renda, IMC e altura.

Neste estudo, os homens apresentaram uma tendência à superestimar o peso referido em $0,44 \mathrm{~kg}(p=0,06)$. Esta superestimação foi 
maior entre os mais jovens $(1,07 \mathrm{~kg})$, os de maior escolaridade $(0,89 \mathrm{~kg}) \mathrm{e}$, principalmente, para os de baixo peso $(3,23 \mathrm{~kg})$. Ao contrário, para os obesos houve uma subestimação de $1,38 \mathrm{~kg}$. Não houve variação da diferença entre os valores referido e aferido de peso pelos homens nas diversas categorias de renda e altura. Já para as mulheres não houve diferença significativa entre as médias de peso referido e aferido. No entanto, houve uma tendência significativa de subestimação do peso referido com o aumento do peso aferido.

Os resultados observados são consistentes com estudos prévios (STUNKARD e ALBAUM 1981; KUCZMARSKI et al. 2001; SPENCER et al. 2002) que observaram alta correlação entre peso e atura reportados com as medidas aferidas de peso e altura. Assim como uma tendência dos homens e mulheres com excesso de peso a subestimar o peso corpóreo, enquanto que os homens de baixo peso tendem a superestimar o peso (PIRIE et al. 1981; PALTA et al. 1982; STEWART et al. 1987; ROWLAND 1990; STEVEN et al. 1990; SCHMIDT et al. 1993; ROBERTS 1995; KUCZMARSKI et al. 2001; NAWAZ 2001; SPENCER et al. 2002). No entanto, ao contrário destes estudos, não foi observada subestimação do peso para o total das mulheres.

A altura foi superestimada pelos homens $(0,91 \mathrm{~cm})$, com maior magnitude entre aqueles de menor estatura $(2,11 \mathrm{~cm})$. Ao contrário do observado em outros estudos populacionais, a superestimação da altura entre os homens não aumentou de forma significativa com a idade (SPENCER et al 2001). Para as mulheres, a altura foi superestimada em $2,22 \mathrm{~cm}$, sendo que esta magnitude foi maior entre as mulheres mais velhas $(3,33 \mathrm{~cm})$ e também naquelas de menor escolaridade $(2,63 \mathrm{~cm})$ ou menor altura $(3,16 \mathrm{~cm})$. Na mesma linha, as mulheres com maior renda familiar medem a estatura com maior freqüência, portanto informam com maior precisão.

A superestimação da altura pelos individuos mais baixos e mais velhos foi observada em vários estudos para ambos os sexos (PALTA et al. 1982; KUCZMARSKI et al. 2001; SPENCER et al. 2002). O aumento da idade tem sido associado com o aumento no erro da informação da altura 
devido, em parte, ao fato das pessoas relatarem a altura que possuíam quando eram mais jovens, portanto sem a redução observada durante 0 processo de envelhecimento que é de cerca de $1 \mathrm{~cm}$ por década após os 40 anos (ROWLAND 1990; SHILS et al. 1999). Já a superestimação da altura pelos indivíduos mais baixos reforça a premissa de um erro sistemático na direção de um padrão cultural que, além da magreza, valoriza a alta estatura.

A Tabela 3.5 mostra que a magnitude das diferenças entre as médias referidas e aferidas de peso, altura e IMC varia entre os diversos estudos. $\mathrm{Na}$ maioria deles a altura é superestimada e o peso é subestimado pelas mulheres e homens e em alguns estudos superestimado pelos homens, especificamente os de baixo peso.

Neste estudo, o efeito conjunto das variações nos valores do peso e altura referidos em relação às medidas aferidas, concorreu para que o IMC fosse subestimado para homens e mulheres, exceto para os indivíduos de baixo peso. Os obesos foram os mais erroneamente classificados. Os homens e mulheres mais velhos também subestimaram seu IMC mais do que os mais jovens. Estes resultados indicam que a utilização da informação recordatória de peso e altura para medir a associação entre doenças e o aumento do IMC deve ser interpretada com cautela (SANTILLAN et al. 2003).

A sensibilidade para classificar corretamente a obesidade foi maior para os homens $(89,8 \%)$ do que para as mulheres $(71,7 \%)$, principalmente devido ao maior erro na informação da altura pelas mulheres. Os valores de sensibilidade para classificar a obesidade têm variado entre diversos estudos populacionais: STEWART 1987 (homens e mulheres - 63,0\%); SCHMIDT et al. 1993 (homens e mulheres - 87\%); ROBERTS et al. 1995 (homens- 66,2\% e mulheres- 72,5\%); SPENCER et al. 2001 (homens$59,1 \%$ e mulheres- $73,0 \%$ ).

A sensibilidade do IMC referido para classificação da obesidade, observada neste estudo, ocasionou uma subestimação da prevalência da obesidade de $0,1 \%$ para os homens e $3,4 \%$ para as mulheres, sendo a 
prevalência verdadeira da obesidade de $10,4 \%$ para os homens e $13,4 \%$ para as mulheres. No estudo realizado por SCHMIDT et al. (1993), na área urbana de Porto Alegre, foi observada uma subestimação na prevalência da obesidade em 1\% (para o total da amostra). ROBERTS (1995) encontrou a dobro deste percentual, em ambos os sexos, e SPENCER et al. (2202) observaram uma subestimação de 5,22\% para os homens e de $3,44 \%$ para as mulheres. A prevalência verdadeira da obesidade nestes estudos foi de $10,0 \%, 8,0 \%$ e cerca de $15,0 \%$, respectivamente.

A prevalência da obesidade baseada nas medidas referidas de peso e altura foi próxima à obtida pelos valores aferidos, o que permite a utilização de medidas aferidas de peso e altura em estudos de prevalência e monitoramento da obesidade. No entanto, é importante melhorar a qualidade com que esta informação é obtida e também esclarecer porque alguns obesos subestimam o peso e outros não, além de considerar o fato de que a validade destas medidas pode diminuir com o aumento da prevalência da obesidade. 
Tabela 3.5 - Médias das diferenças entre medidas referidas e aferidas de peso, altura e IMC em alguns estudos com grandes amostras.

\begin{tabular}{|c|c|c|c|c|c|c|}
\hline \multirow{2}{*}{ Autor } & \multirow{2}{*}{ Descrição } & \multirow{2}{*}{$\mathbf{N}$} & \multirow[b]{2}{*}{$\begin{array}{l}\text { Idade } \\
\text { (anos) }\end{array}$} & \multicolumn{3}{|c|}{ Média da diferença* } \\
\hline & & & & $\begin{array}{l}\text { Peso } \\
(\mathrm{Kg})\end{array}$ & $\begin{array}{l}\text { Altura } \\
(\mathrm{cm})\end{array}$ & $\underset{(\mathrm{Kg} / \mathrm{m} 2)}{\operatorname{IMC}}$ \\
\hline $\begin{array}{l}\text { Pirie et al. } \\
1981\end{array}$ & $\begin{array}{l}\text { Entrevista face a face } \\
\text { Amostra do Lipid } \\
\text { Research Clinics Program } \\
\text { Prevalence Study }\end{array}$ & $\begin{array}{l}H: 1799 \\
M: 1608\end{array}$ & $20-59$ & $\begin{array}{l}H:-0,54 \\
M:-1,86\end{array}$ & $\begin{array}{l}H:+0,56 \\
M:-0,71\end{array}$ & ND \\
\hline $\begin{array}{l}\text { Palta et al. } \\
1982\end{array}$ & $\begin{array}{l}\text { Entrevista face a face } \\
\text { Amostra do Hypertension } \\
\text { Detection and Follow-up } \\
\text { Program }\end{array}$ & $\begin{array}{l}H: 851 \\
M: 503\end{array}$ & $30-69$ & $\begin{array}{l}H:-1,5 \\
M:-2,4\end{array}$ & $\begin{array}{l}H:+2,3 \\
M:+0,9\end{array}$ & $\begin{array}{l}H:-0,9 \\
M:-0,8\end{array}$ \\
\hline $\begin{array}{l}\text { Stewart et al } \\
1987\end{array}$ & $\begin{array}{l}\text { Entrevista face a face } \\
\text { Amostra do Auckland Risk } \\
\text { Factor Study }\end{array}$ & $\begin{array}{l}H: 987 \\
M: 536\end{array}$ & $35-65$ & $\begin{array}{l}H:-1,4 \\
M:-1,1\end{array}$ & $\begin{array}{l}H:+2,0 \\
M:+1,7\end{array}$ & $\begin{array}{l}H:-0,9 \\
M:-0,8\end{array}$ \\
\hline $\begin{array}{l}\text { Jalkanen et } \\
\text { al. } 1987\end{array}$ & $\begin{array}{l}\text { Entrevista face a face } \\
\text { Amostra do estudo de } \\
\text { prevenção de DCV - } \\
\text { Finlândia }\end{array}$ & $\begin{array}{l}H: 5790 \\
M: 6090\end{array}$ & $30-64$ & $\begin{array}{l}H:-0,4 \\
M:-0,6\end{array}$ & ND & ND \\
\hline $\begin{array}{l}\text { Rowland } \\
1990\end{array}$ & $\begin{array}{l}\text { Entrevista face a face } \\
\text { Estudo populacional } \\
\text { (NHANES II) }\end{array}$ & $\begin{array}{l}H: 5396 \\
M: 5888\end{array}$ & $20-74$ & $\begin{array}{l}H:+0,4 \\
M:-1,0\end{array}$ & $\begin{array}{l}H:+1,4 \\
M:+0,6\end{array}$ & ND \\
\hline $\begin{array}{l}\text { Schmidt et } \\
\text { al. } 1993 \\
\end{array}$ & $\begin{array}{l}\text { Entrevista face a face } \\
\text { Estudo base populacional }\end{array}$ & $\begin{array}{l}H: 254 \\
M: 405 \\
\end{array}$ & $15-64$ & $\begin{array}{l}H:+0,30 \\
M:-0,29\end{array}$ & ND & ND \\
\hline $\begin{array}{l}\text { Roberts } \\
1995\end{array}$ & $\begin{array}{l}\text { Questionário auto- } \\
\text { preenchido } \\
\text { Amostra do Welsh Heart } \\
\text { Health Survey } \\
\end{array}$ & $\begin{array}{l}H: 806 \\
M: 816\end{array}$ & $18-64$ & $\begin{array}{l}H: N S \\
M:-1,1\end{array}$ & $\begin{array}{l}H:+1,4 \\
M:+0,7\end{array}$ & $\begin{array}{l}H:-0,33 \\
M:-0,51\end{array}$ \\
\hline $\begin{array}{l}\text { Hill e } \\
\text { Roberts } \\
1998\end{array}$ & $\begin{array}{l}\text { Questionário auto- } \\
\text { preenchido } \\
\text { População rural do } \\
\text { Sudeste da Inglaterra }\end{array}$ & $\begin{array}{l}H: 1007 \\
M: 1251\end{array}$ & $16-64$ & $\mathrm{~T}:-0,85$ & $\mathrm{~T}:+7,56$ & $T:-1,29$ \\
\hline $\begin{array}{l}\text { kuczmarski } \\
\text { et al. } 2001\end{array}$ & $\begin{array}{l}\text { Entrevista face a face } \\
\text { Estudo populacional } \\
\text { (NHANES III) }\end{array}$ & $\begin{array}{l}H: 4932 \\
M: 5425 \\
H: 2628 \\
M: 2662\end{array}$ & $\geq 60$ & $\begin{array}{l}H:+0,35 \\
M:-1,49 \\
H:+0,51 \\
M:-0,56\end{array}$ & $\begin{array}{l}H:+0,98 \\
M:+0,04 \\
H:+2,70 \\
M:+2,53\end{array}$ & $\begin{array}{l}H:-0,18 \\
M:-0,58 \\
H:-0,64 \\
M:-1,05\end{array}$ \\
\hline $\begin{array}{l}\text { Spencer et } \\
\text { al. } 2002\end{array}$ & $\begin{array}{l}\text { Questionário auto- } \\
\text { preenchido } \\
\text { Amostra do European } \\
\text { Prospective Investigation } \\
\text { into Câncer and Nutrition } \\
\text { (EPIC) }\end{array}$ & $\begin{array}{l}H: 1870 \\
M: 2938\end{array}$ & $35-76$ & $\begin{array}{l}H:-1,85 \\
M:-0,72\end{array}$ & $\begin{array}{l}H:+1,23 \\
M:+0,6\end{array}$ & $\begin{array}{l}H:-0,96 \\
M:-0,72\end{array}$ \\
\hline $\begin{array}{l}\text { Fonseca et } \\
\text { al. } 2004\end{array}$ & $\begin{array}{l}\text { Questionário auto- } \\
\text { preenchido } \\
\text { Funcionários públicos }\end{array}$ & $\begin{array}{l}H: 1682 \\
M: 2030\end{array}$ & $22-70$ & $\begin{array}{l}H:-1,02 \\
M:-1,14\end{array}$ & $\begin{array}{l}H:+0,17 \\
M:+1,05\end{array}$ & $\begin{array}{l}H:-0,37 \\
M:-0,77\end{array}$ \\
\hline
\end{tabular}




\section{REFERÊNCIAS BIBLIOGRÁFICAS}

1. Chor $D$, Coutinho ESF, Laurenti R. Confiabilidade da informação de peso e estatura em funcionários de banco estatal. Rev. Saúde Pública 1999; 33(1): 16-23.

2. Fonseca MJM, Faerstein E, Chor D, Lopes CS. Validade de peso e estatura informados e índice de massa corporal: estudo pró-saúde. Rev. Saúde Pública 12004; 38(13): 392-398.

3. Hill A, Roberts J. Body mass index: a comparison between selfreported and measured height and weight. J Public Med 2002; 20(2): 206-210.

4. Huang Z, Willet WC, Colditz GA, Hunter DJ, Manson JE, Rosner B, Speizer FE, Hankinson SE. Waist circunference, waist:hip ratio, and risk of breast cancer in the Nurses' Health Study. Am J Epidemiol 1999; 150 (12): 1316-1324.

5. Jalkanen L, Tuomilehto J, Tanskanen P, Puska P. Accuracy of selfreported body weight compared to measured body weight. A population survey. Scan J Soc Med 1987; 15:191-198.

6. kuczmarski MF, kuczmarski RJ, Najjar M. effects of age on validity of self-reported height weight, and body mass index: findings from of Third National Health and Nutrition Examination Survey, 1988-1994. J Am Diet Assoc 2001; 101(1): 28-34.

7. Lohman TG, Roche AF, Martorel R. Anthropometric standardization reference manual. Illinois: Human Kinetics Books, 1988.

8. Ministério da Saúde. Controle da hipertensão arterial: uma proposta de integração ensino-serviço. Rio de Janeiro: CDCVINUTES, 1993. 233p.

9. Nawaz H, Chan W; Abdulrahman M, Larson D; Katz DL. Self reported weight and height: implications for obesity research. Am J Prev Med 2001; 20(4):294-8. 
10. Palta M, Prineas RJ, Berman R, Hannan P. Comparison of selfreported and measured height and weight. Am J. Epidemiol 1982; 115:223-230.

11.Pirie $P$, Jacobs $D$, Jeffrey $R$, Hannan $P$. Distorcion in self-reported height and weight data. J Am Diet Assoc 1981; 78: 601-606.

12. Rimm EB, Stampfer MJ, Giovannucci E, Ascherio A, Spiegelman D, Colditz GA, Willet WC. Body size and fat distribution as predictors of coronary heart disease among middle-aged and older US men. Am J Epidemiol 1995; 141 (12): 1117-1127.

13. Roberts RJ. Can self-reported data accurately describe the prevalence of overweight? Public Health 1995; 109:275-284.

14. Rowland ML. Sel-reported weight and height. Am J Clin Nutr 1990; 52: $1125-1133$.

15. Santillan AA, Camargo Jr CA. Body mass index and astma amosng Mexican adults: the effect of using self-reported vs measured weight and height. Int J Obes. 2003; 27: 1430-1433.

16. Schmidt MI, Duncan BB, Tavares M, Polanczyk, Pellanda L, Zimmer PM. Validity of sef-reported weight - A study of urban brazilian adults. Rev. Saúde Pública 1993: 27 (4): 271-276.

17. Shils ME, Olson JA, Shike M, Ross AC. Modern Nutrition in the Health and Disease. $9^{\text {th }}$ ed. Baltimore: Lippincott Williams e Wilkins, 1999.

18. Spencer EA, Appleby Pn, Davey GK, Key TJ. Validity os self-reported height and weighi in 4808 EPIC-Oxford participants. Public Health Nutr 2002; 5(4): 561-565.

19. Stevens J, keil JE, Waid LR, Gazes PC. Accuracy of current, 4 year, and 28-year self-reported body weight in an elderly population. Am J Epidemiol 1990; 132: 1156-1163. 
20. Stata Corp. (2001). Stata Statistical Software: Release 7.0. Stata Corporation.

21. Stewart AW, Jackson RT, Ford MA, Beaglehole R. Understimation of relative weight by use self-reported height and weight. Am $\mathbf{J}$ Epidemiol 1987; 125:122-126.

22. Stunkard AJ, Albaum JM. The accuracy of self-reported weights. Am J Clin Nutr 1981; 34:1593-1599.

23. Szklo M. e F. Javier Nieto. Epidemiology - beyond the basics. Gaithersburg, Maryland: Aspen publishers, Inc, 2000. p. 343-401.

24. World Health Organization. Physical Status: The Use e Interpretation of Antropometry. Report Geneva; 1995. (WHO - Technical Report Series, 854). 
CONSIDERAÇÕES FINAIS 


\section{CONSIDERAÇŌES FINAIS}

A revisão da literatura e os resultados do estudo empírico realizado permitem formular as seguintes consideraçōes finais:

\section{Artigo 1}

A prevalência de excesso de peso foi de aproximadamente $42,0 \%$ para os homens ( $31,2 \%$ de sobrepeso e $10,7 \%$ de obesidade) e de $43,0 \%$ para as mulheres $(29,2 \%$ de sobrepeso e $13,9 \%$ de obesidade). O aumento da prevalência da obesidade no Brasil está ocorrendo em todos os centros urbanos, porém com características diferenciadas, dependendo do grau de desenvolvimento sócio-econômico da região. A população estudada encontra-se numa etapa da transição na qual a renda ainda é um importante determinante do IMC entre os homens, enquanto que para as mulheres foi observada uma situação intermediária entre as regiōes Nordeste e Sudeste do Brasil, ou seja, a renda não atua como fator de risco, situação observada para as mulheres de maior renda no Nordeste, ou como fator de proteção, a exemplo do que está ocorrendo para as mulheres de maior renda da região Sudeste.

Com o envelhecimento da população a repercussão da obesidade na saúde pública se tornará mais grave, uma vez que a média do IMC aumenta de forma acentuada com o avanço da idade, sendo que a prevalência da obesidade para a faixa etária de 55 a 64 anos foi de $63 \%$ (considerando-se homens e mulheres).

As ex-fumantes apresentaram média de IMC superior às nãofumantes, entretanto as fumantes apresentaram média de IMC semelhante ao das mulheres que nunca fumaram. Este achado representa argumento adicional para ser utilizado nas campanhas anti-tabagismo;

É importante destacar a alta prevalência de individuos sedentários nos momentos de lazer $(50,7 \%$ dos homens e $71,1 \%$ das mulheres), pois a falta de atividade física, juntamente com a má alimentação, são reconhecidamente as principais causas das doenças crônicas não 
transmissíveis tais como doenças cardiovasculares, certos tipos de cânceres e diabetes tipo 2.

Com relação ao consumo alimentar, observou-se que um maior consumo de carne, reconhecidamente uma importante fonte de proteína, mas também de gordura, associa-se positivamente com o IMC. Por outro lado, o consumo de cereais e de leguminosas apresentou associação negativa com o IMC.

Os resultados deste estudo reforçam, a necessidade da implementaçăo e/ou intensificação das ações propostas pela PNAN atualmente respaldadas pela estratégia global da OMS no sentido de promover políticas públicas que além do caráter meramente educativo contemple ações multissetoriais, interdisciplinares e sustentáveis que favoreçam o acesso a uma alimentação saudável e um estilo de vida mais ativo.

\section{Artigo 2}

O excesso de peso total, avaliado pelo IMC, apresentou associação com a hipertensão apenas entre as mulheres, sendo que para um IMC de 25 a $29 \mathrm{~kg} / \mathrm{m}^{2}$ foi observado um odds ratio de 2,5 e para um IMC $\geq 30 \mathrm{~kg} / \mathrm{m}^{2}$ um odds ratio de 4,7 .

Por sua vez, o excesso de adiposidade abdominal, avaliado pela $\mathrm{CC}$, apresentou associação com a hipertensão para homens e mulheres. Para eles, o odds ratio foi cerca de duas vezes maior com valores elevados de $\mathrm{CC}$ ( $\geq 94$ a 101 e $\geq 102 \mathrm{~cm}$ ) em comparação com a categoria de referência (<94 $\mathrm{cm}$ ). Para as mulheres, foi observado um odds ratio de 2,5 para uma CC de 80 a $88 \mathrm{~cm}$, que aumentou para $3,0 \mathrm{com}$ uma $\mathrm{CC} \geq 88 \mathrm{~cm}$ em comparação com a categoria de referência $(<80 \mathrm{~cm})$.

Os pontos de corte recomendados para o nível 2 da $\mathrm{CC}, \mathrm{CC} \geq 88 \mathrm{~cm}$ para mulheres e $C C \geq 102$ para homens, apresentaram alta especificidade $e$ baixa sensibilidade para identificar o risco de hipertensão, o que também foi observado para o IMC $\geq 30 \mathrm{~kg} / \mathrm{m}^{2}$. 
Os resultados deste estudo mostram, para as mulheres, a pertinéncia do uso do IMC $\geq 25 \mathrm{~kg} / \mathrm{m}^{2}$ (ponto de corte para o sobrepeso) e da $\mathrm{CC} \geq$ $80 \mathrm{~cm}$ (ponto de corte para o nível $1 \mathrm{da} \mathrm{CC}$ ), como indicadores antropométricos para identificaçăo do risco de hipertensão arterial.

Para os homens, o ponto de corte para IMC que apresentou maior capacidade de predição do risco de hipertensão ficou próximo ao valor recomendado para classificação de sobrepeso (IMC $\geq 25 \mathrm{~kg} / \mathrm{m}^{2}$ ), porém para a CC foi um pouco inferior ao valor recomendado para a classificação do nivel1. Este fato deve ser revisto em estudos posteriores.

Em programas para prevenção e controle da obesidade e também das doenças crônicas năo transmissíveis, a medida da $\mathrm{CC}$, pela sua simplicidade técnica e facilidade de interpretação, pode ser recomendada como uma medida de vigilância a ser utilizada pela população, como sinal de alerta para parar de ganhar peso, e procurar um serviço de saúde para avaliação da presença de fatores de risco associados ao ganho de peso.

\section{Artigo 3}

Este estudo mostrou alta concordância entre as medidas de peso reportado e aferido e entre altura reportada e aferida em um inquérito de base populacional realizado na cidade de Goiânia. Embora o peso e altura tenham sido reportados em média com pequenos erros, vale ressaltar que a distribuição destes erros não aconteceu de forma aleatória, visto que alguns sub-grupos de individuos apresentaram maior tendência para superestimar ou subestimar as medidas antropométricas.

Neste estudo, os homens apresentaram uma tendência a superestimar 0 peso referido em $0,44 \mathrm{~kg}$ em média $(p=0,06)$. Esta superestimação foi maior entre os mais jovens $(1,07 \mathrm{~kg})$, os de maior escolaridade $(0,89 \mathrm{~kg})$ e, principalmente, para os de baixo peso $(3,23 \mathrm{~kg})$. Ao contrário, para os obesos houve uma subestimação de $1,38 \mathrm{~kg}$. Já para as mulheres não houve diferença significativa entre as médias de peso referido e aferido. No entanto, houve uma tendência significativa de subestimação do peso referido com o aumento do peso aferido. 
A altura foi superestimada pelos homens $(0,91 \mathrm{~cm})$, com maior magnitude entre aqueles de menor estatura $(2,11 \mathrm{~cm})$. Ao contrário do observado em outros estudos populacionais, a superestimação da altura entre os homens não aumentou de forma significativa com a idade. Para as mulheres, a altura foi superestimada em $2,22 \mathrm{~cm}$, sendo que esta magnitude foi maior entre as mulheres mais velhas $(3,33 \mathrm{~cm})$ e também naquelas com menor escolaridade $(2,63 \mathrm{~cm})$ ou menor altura $(3,16 \mathrm{~cm})$.

O fato de a informação referida apresentar uma boa correlação com as medidas aferidas e ainda permitir uma classificação confiável do IMC, valida sua utilização em sistemas de monitoramento da prevalência da obesidade por meio de entrevistas telefônicas ou questionários enviados pelo correio. 


\section{RELATÓRIO TÉCNICO}




\section{APRESENTAÇÃO}

Para o desenvolvimento desta tese, foram utilizados dados do "Estudo da prevalência e do conhecimento da hipertensão arterial e alguns fatores de risco em uma região do Brasil" ( Estudo Centro-Oeste), projeto aprovado e financiado pelo CNPQ (processo n. 000520861/99) e realizado pela equipe da Liga de Hipertensão Arterial da Universidade Federal de Goiás em parceria com a Universidade Federal de Mato Grosso. $O$ objetivo geral do estudo foi estimar a prevalência e descrever o perfil epidemiológico da hipertensão arterial na população adulta nos estados de Goiás e Mato Grosso, através da coleta de dados das capitais (Goiânia e Cuiabá) e de dois núcleos urbanos do interior (Firminópolis e Nobres, respectivamente de Goiás e Mato Grosso).

A autora desta tese integra a equipe de profissionais da Liga de Hipertensão Arterial/UFG e atuou na pesquisa como coordenadora de campo juntamente com 2 bolsistas da Liga, que para este projeto receberam bolsa do CNPq.

\section{DELINEAMENTO E AMOSTRA DO "ESTUDO CENTRO-OESTE"}

Estudo de delineamento transversal de base populacional com amostragem aleatória sistemática.

O tamanho da amostra para o "Estudo da prevalência e do conhecimento da hipertensão arterial e alguns fatores de risco em uma região do Brasil município de Goiânia" foi calculado considerando-se uma população de 1.004.098 habitantes, conforme estimativa do IBGE/98; prevalência de hipertensão arterial no Brasil de $20 \%$ da população adulta (MS,1993); intervalo de confiança de $95 \%$ e erro de estimação de $10 \%$. À amostra obtida ( $n=1534)$, foram acrescidos $30 \%$ para cobrir as perdas $(n=1994)$. 
A seleção dos domicilios foi por amostragem probabilística, por conglomerados, em duas etapas. A primeira consistiu na identificação, junto ao IBGE, dos setores censitários utilizados na Pesquisa Nacional por Amostragem de Domicílios (PNAD) de 1998, na zona urbana do município de Goiânia. A segunda etapa constou da seleção dos domicilios. Para esta seleção, foram considerados o número de domicilios em cada setor e o tamanho total da amostra. A partir do cálculo do tamanho da amostra por setor, foram sorteados, de forma aleatória e sistemática, os domicílios de cada setor, utilizando-se o procedimento sorteio de números aleatórios do EXCEL;

Nos domicílios selecionados, foi entrevistado apenas um morador sorteado entre os moradores maiores de 18 anos, para evitar problemas de interdependência de informações entre entrevistados. Foram excluídas do estudo as gestantes e mulheres com crianças menores de 6 meses, para evitar erros na interpretação dos dados. Foram igualmente excluídos os moradores que estivessem hospitalizados.

A amostra estudada foi constituída por 1454 individuos $(72,9 \%)$ e abrangeu indivíduos maiores de 18 anos, de ambos os sexos, não institucionalizados, residentes na área urbana. Entre as perdas $(n=540), 121$ endereços foram classificados como inexistentes (não localizado ou não havia mais residência no endereço sorteado), outros 419 domicilios foram localizados, mas não foi realizada a entrevista por recusa dos moradores, por estar o domicilio vazio ou porque os moradores não foram encontrados após três visitas em dias e horários diferentes.

No presente estudo, foram analisados apenas os 1252 indivíduos adultos que se encontravam na faixa etária de 20 a 64 anos. Considerando-se uma amostra de 433 homens e 819 mulheres (20 a 64 anos); uma prevalência, segundo dados da PNSN (1989) para a região Centro-Oeste, de sobrepeso de $26,5 \%$ para as mulheres e $22,6 \%$ para os homens e $11,7 \%$ e $4,8 \%$ de obesidade para mulheres e homens, respectivamente e um intervalo de 
confiança de $95 \%$, esta amostra permite estimar, para homens e mulheres, a prevalência do sobrepeso e da obesidade com uma margem de erro de $3 \%$ e $2 \%$, respectivamente.

\section{LOGÍSTICA / OPERACIONALIZAÇÃO}

\section{Elaboração do questionário e outros instrumentos}

Para a elaboração do questionário, foi utilizado como modelo o instrumento do Projeto CARMEN(Conjunto de Ações para a Redução da Morbidade por Enfermidades não Transmissíveis), aplicado na região Leste de Goiânia, no ano de 1998, sendo realizados ajustes e modificações após discussão da equipe de trabalho e da execução do pré-teste.

Além dos questionários, foram elaborados: manual do entrevistador; cartazes para divulgação da pesquisa, fichas de controle de questionários e fichas de endereço por setor censitário. Foi também criada uma camiseta para o projeto.

\section{Pessoal}

Para a execução do trabalho de campo, contou-se com um coordenadorgeral, três coordenadoras de campo e seis duplas de entrevistadores, ficando cada coordenador de campo responsável por duas duplas. Além do pagamento por entrevista e dos passes de ônibus os entrevistadores receberam certificado de participação na pesquisa.

As coordenadoras de campo ficaram responsáveis pelo recrutamento e treinamento dos entrevistadores, pela distribuição do material necessário à pesquisa, pela leitura crítica dos questionários preenchidos e pelo contato semanal com os entrevistadores. Estes supervisores juntamente com a coordenação-geral do projeto, definiram a logística e administração do trabalho de campo. 


\section{Recrutamento e treinamento do pessoal de campo}

No recrutamento dos entrevistadores, considerou-se a entrevista, ter experiência em pesquisas e disponibilidade de tempo. Foram selecionados 16 acadêmicos para participarem do treinamento, sendo que quatro acadêmicos ficaram como reservas.

$\mathrm{Na}$ fase preparatória para coleta dos dados, os entrevistadores passaram por um treinamento que constou das seguintes etapas:

Treinamento teórico (4 horas) - Consistiu da apresentação do projeto, leitura minuciosa do Manual do Entrevistador e do Manual de Técnicas: medição da pressão arterial e avaliação nutricional. Durante a leitura destes manuais, foi realizada a descrição detalhada do questionário e das técnicas a serem adotadas na coleta dos dados. Foi também apresentada uma fita de vídeo com a demonstração da medida da pressão arterial.

Treinamento prático (16 horas) - Inicialmente foi feita uma demonstração da técnica das medidas antropométricas e do preenchimento do questionário. A partir desta demonstração, cada entrevistador aplicou questionários nos próprios colegas e em voluntários do ambulatório da Liga de Hipertensão Arterial. No decorrer do treinamento, os entrevistadores foram divididos em seis duplas. Após a correção de eventuais falhas e quando foi percebido que os entrevistadores estavam repetindo as técnicas recomendadas, cada dupla recebeu uma lista de quatro endereços situados no Bairro Vila Nova, situado na região leste do município de Goiânia, próximo ao Campus I da Universidade Federal de Goiás, onde foram aplicados questionários seguindo todos os passos recomendados na metodologia do estudo. Esta atividade foi supervisionada por um dos coordenadores de campo, que conferia as medidas realizadas.

Reunião de avaliação das entrevistas domiciliares (4 horas) - Foram apresentadas as entrevistas domiciliares realizadas, com enfoque nas dificuldades encontradas e instruções de como resolvê-las. Neste momento, foi 
realizada a re-leitura do manual de instruções, corrigindo eventuais questões que não estivessem perfeitamente esclarecidas.

O resultado do treinamento foi considerado satisfatório. Contribuiu para este resultado o fato de a maioria dos entrevistadores serem acadêmicos de enfermagem e nutrição com conhecimento prévio das técnicas empregadas no estudo.

Os bolsistas do CNPq participaram como instrutores no treinamento dos entrevistadores. Estes foram previamente treinados pela equipe da LHA, sendo que, nesta ocasião, aplicaram 50 questionários entre os usuários do Centro de Saúde do Jardim Novo Mundo, situado na região leste (Goiânia/GO).

\section{Logistica de campo, controle da amostra e supervisão dos questionários.}

O levantamento dos dados foi realizado usando dois métodos: a) dados colhidos por meio de medidas objetivas e equipamento padronizado; b) dados colhidos por meio de questionário apropriado (Anexo 2).

Antes da realização e no início da pesquisa, foram exibidas matérias em duas redes de televisão, uma rádio e um jornal, nas quais eram explicados os objetivos da pesquisa, sua população-alvo e os procedimentos que seriam realizados, aproveitava-se a oportunidade para solicitar à população que recebesse os entrevistadores. Na portaria dos condomínios, também foram entregues cartas dirigidas aos moradores dos apartamentos selecionados, informando sobre o projeto e que seriam procurados por entrevistadores do projeto na semana seguinte.

O trabalho de campo começou em junho de 2001 e terminou em janeiro de 2002. Para facilitar a identificação do domicilio a ser pesquisado, foi anexado um mapa do setor à ficha de endereços de cada setor censitário.

$\mathrm{Na}$ realização do trabalho de campo, os entrevistadores utilizaram camiseta do projeto e também o crachá de identificação da universidade que cursavam. 
O manual do entrevistador fazia uma descrição detalhada dos passos a serem seguidos antes, durante e após a realização das entrevistas.

Durante a fase de coleta dos dados, foram realizadas reuniōes semanais com os coordenadores de campo e, eventualmente, com o coordenador do projeto. Nessas reuniōes eram discutidas as dificuldades encontradas no trabalho de campo, além de ser feito o recebimento dos questionários preenchidos, a entrega de novas listas de endereços, a entrega de passes de ônibus e a reposição do material de consumo e dos questionários.

\section{Controle de qualidade}

O controle de qualidade foi garantido por meio de treinamento e aplicação de questionário padronizado, com respectivo manual de instruções; coleta de dados por dupla de entrevistadores; supervisão e monitoramento das equipes durante o trabalho de campo. Cada coordenadora de campo ficou responsável pelo desempenho de sua equipe. Para garantir a qualidade das informações coletadas, foi realizada uma leitura crítica dos questionários preenchidos pelos coordenadores de campo e, em alguns casos, foi solicitado um retorno ao domicílio para checar dúvidas ou obter dados não informados. As duplas de entrevistadores receberam reciclagens periódicas com o objetivo de reforçar o treinamento.

\section{PROCESSAMENTO DOS DADOS}

Após a revisão dos questionários, os dados foram digitados duplamente em bancos elaborados no ACCESS. Após a dupla digitação, foi realizada a avaliação da qualidade da digitação por meio do procedimento VALIDATE, do Epi-Info 6.04. A partir das informações geradas pelo VALIDATE, o banco de dados foi minuciosamente corrigido.

Após a correção, foi efetuada uma checagem da consistência do banco de dados, utilizando-se o comando "Auto Filtro" do programa EXCEL 2000. Todas as variáveis foram avaliadas em relação a possiveis valores aberrantes e a 
correta aplicação dos critérios de "não se aplica", sendo feitas às alterações necessárias.

As análises estatísticas foram realizadas utilizando-se o software STATA 7.0.

A partir do banco de dados gerado pelo estudo da prevalência da hipertensão (Estudo Centro-Oeste), foram selecionadas as variáveis para os três artigos que compõem esta tese.

\section{ASPECTOS ÉTICOS}

O projeto "Estudo da prevalência e do conhecimento da hipertensão arterial e alguns fatores de risco em uma região do Brasil", do qual foram retirados os dados para o presente estudo, foi aprovado pelo Comitê de Ética em Pesquisa Médica Humana e Animal do Hospital das Clínicas da Universidade Federal de Goiás (15/04/2000). Já o presente projeto foi aprovado na 7a/01 Sessão Ordinária (11/09/2001) do Comitê de Ética em Pesquisa da Faculdade de Saúde Pública da Universidade de São Paulo - COEP (Anexo 1).

Com o objetivo de facilitar a operacionalização e o controle no preenchimento do termo de consentimento, a via do entrevistador foi impressa na primeira página do questionário da pesquisa (Anexo2).

\section{TÉCNICAS E INTERPRETAÇÕES DAS MEDIDAS}

\section{ANTROPOMETRIA}

\section{Peso}

Para a medida do peso foram utilizadas balanças eletrônicas portáteis da marca Plenna, modelo Giant Lithium com capacidade para 150 quilogramas e precisão de 100 gramas. Esta balança contem bateria de longa vida de lítio com capacidade de realização de 30 mil pesagens e foi operada segundo instruções do fabricante.

Os indivíduos foram pesados descalços e com roupas leves, observando se não levavam objetos nas mãos ou nos bolsos e adornos na cabeça, sendo o valor 
encontrado expresso em quilogramas (Gibson, 1990; Lohman, 1988).

\section{Altura}

Para a medida da altura utilizou-se estadiômetros portáteis marca Seca com capacidade para medir 2 metros, com intervalos de $0,1 \mathrm{~cm}$, fixado em uma superfície plana, parede do domicilio, sendo utilizado segundo instruçōes do fabricante.

Os entrevistados foram colocados descalços sobre superfície plana, com os pés unidos e com calcanhares, ombros e cabeça em ângulo reto com a parede olhando para frente e os braços soltos ao longo do corpo. A leitura foi feita quando a haste horizontal tocou na cabeça, sem, contudo, fazer pressão que mudasse sua posição (Gibson, 1990; Lohman, 1988).

\section{Índice de Massa Corpórea - IMC}

$O$ IMC foi obtido através da equação:

$$
\text { IMC }\left(\mathrm{Kg} / \mathrm{m}^{2}\right)=\frac{\text { Peso }}{\text { Altura }^{2}}
$$

Para a interpretação dos valores de IMC, foram utilizados os pontos de corte recomendados pela Organização Mundial de Saúde (Word Health Organization 1997).

Quadro 1 - Classificação do sobrepeso e obesidade por IMC

\begin{tabular}{lc}
\hline \multicolumn{1}{c}{ Classificação do peso } & $\mathrm{IMC}\left(\mathrm{Kg} / \mathrm{m}^{2}\right)$ \\
\hline Baixo peso & $<18,5$ \\
Normal & $18,5-24,9$ \\
Pré-obesidade & $25-29,9$ \\
Obesidade I & $30-34,9$ \\
Obesidade II & $35-39,9$ \\
Obesidade III & $\geq 40$ \\
\hline
\end{tabular}

Fonte: World Health Organization, 1997. 


\section{Circunferência da cintura}

Essa medida foi realizada com fita métrica inextensível, com o indivíduo em pé, ereto e com os braços soltos ao longo do corpo, sem roupa ao nivel da cintura ou usando o mínimo de roupa.

A circunferência da cintura foi medida no plano horizontal, no nivel natural da cintura, ou no ponto médio entre a crista iliaca anterior superior e a última costela (Lohman, 1988).

Para interpretação dos valores da circunferência da cintura, foram utilizados os pontos de corte recomendados pela Organização Mundial de Saúde (World Health Organization 1997).

Quadro 2 - Classificação da circunferência da cintura por sexo que denota "risco aumentado" e "muito aumentado" de complicaçōes metabólicas associado com obesidade em caucasianos.

\begin{tabular}{|l|c|c|}
\hline \multicolumn{1}{|c|}{ Sexo } & Aumentado & Muito aumentado \\
\hline Masculino & $\geq 94 \mathrm{~cm}$ & $\geq 102 \mathrm{~cm}$ \\
\hline Feminino & $\geq 80 \mathrm{~cm}$ & $\geq 88 \mathrm{~cm}$ \\
\hline
\end{tabular}

Fonte: World Health Organization, 1997.

\section{PRESSÃo ARTERIAL}

A pressão arterial. Foram utilizados aparelhos semi-automáticos da marca OMRON - HEM $705 \mathrm{CP}$, este é um equipamento já validado pelas instituições internacionais tornando seus dados comparáveis aos obtidos através das medidas com esfigmanômetros de coluna de mercúrio (padrão ouro). Os aparelhos foram aferidos periodicamente contra um aparelho de coluna de mercúrio para comprovação de sua precisão.

A medição foi realizada na posição sentada, com o braço esquerdo apoiado em mesa, de acordo com os seguintes procedimentos: 
- Explicar o procedimento ao paciente

- Certificar-se de que o paciente: Não está com a bexiga cheia; Não praticou exercicios físicos; Năo ingeriu bebidas alcoólicas, café, alimentos ou fumou até 30 minutos antes da medida;

- Realizar a medida em ambiente calmo, com o indivíduo sentado e após descanso de pelo menos cinco minutos;

- Localizar a artéria braquial por palpação;

- Colocar o manguito firmemente cerca de $2 \mathrm{~cm}$ a $3 \mathrm{~cm}$ acima da fossa antecubital, centralizando a bolsa de borracha sobre aa rteria braquial. A largura da bolsa de borracha do manguito deve corresponder a $40 \%$ da circunferência da circunferência do braço e seu cumprimento envolver pelo menos $80 \%$ do braço. Manter o braço do paciente na altura do coração;

- Solicitar ao indivíduo que não fale durante o procedimento de medição;

- Registrar os valores das pressões sitólica e diastólica, da pressão;

- Realizar 2 aferiçōes da pressão arterial (uma no inicio e outra no final da entrevista).

Para fins de análise considerou-se o valor da última medição. A classificação da pressão arterial foi realizada conforme os pontos de corte especificados no quadro 3 . Os valores da pressão arterial e das medidas antropométricas, bem como suas interpretações foram informadas aos entrevistados. 
Quadro 3 - Classificação diagnóstica da hipertensão arterial em indivíduos maiores de 18 anos.

\begin{tabular}{|l|c|c|}
\hline \multicolumn{1}{|c|}{ Classificação } & PAD $(\mathrm{mmHg})$ & PAS $(\mathrm{mmHg})$ \\
\hline Normal & $<85$ & $<130$ \\
\hline Normal limítrofe & $85-89$ & $130-139$ \\
\hline Hipertensão leve & $90-99$ & $140-159$ \\
\hline Hipertensão moderada & $100-109$ & $160-179$ \\
\hline Hipertensão grave & $\geq 110$ & $\geq 180$ \\
\hline Hipertensão sistólica isolada & $<90$ & $\geq 140$ \\
\hline
\end{tabular}

Fonte: Sociedade Brasileira de Hipertensão, 1998. 


\section{ANEXOS}

\section{RELAÇÃO DE ANEXOS:}

Anexo 1: Aprovação da Comissão de Ética em Pesquisa da Faculdade de Saúde Pública de São Paulo

Anexo 2: Termo de Consentimento Informado do Paciente e Questionário de Entrevista. 


\section{ANEXO 1}

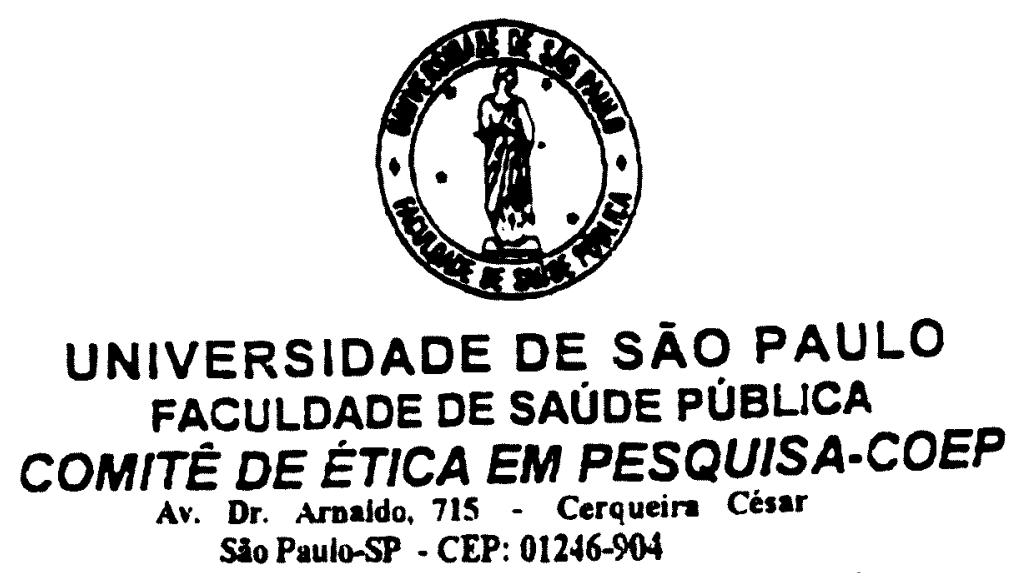

Telefone: (Oxx11) 3066-7779 - e-mail: mdgracas.ausp.br

Of.COEP/125/01

08 de agosto de 2001

Pelo presente, informo que o Comitè de Ética em Pesquisa da Faculdade de Saúde Pública da Ĺniversidade de São Paulo-COEP, analisou e aprovou, em sua 6. $\% 101$, Sessão Ordinária, realizada em 07.08 .01 . de acordo com os requisitos da Resolução CNS/196/96, o Protocolo de Pesquisa n. ${ }^{\circ}$ :24, intitulado: "PREVALÈNCIA E FATORES DETERMINANTES DA OBESIDADE NA POPLLAÇÃO ADULTA DE GOIÂNIA", apresentado pela pesquisadora Maria do Rosário Gondim Peixoto.

Atenciosamente,

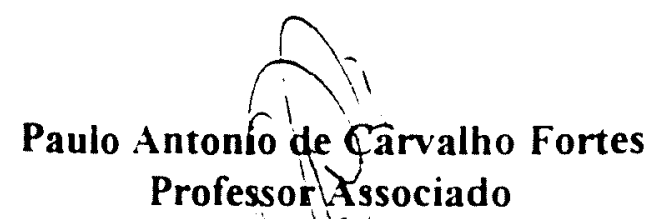

Vice-Coordenador do Comitếnelética em Pesquisa da FSP-COEP 


\section{ANEXO 2 \\ UNIVERSIDADE FEDERAL DE GOIÁS \\ UNIVERSIDADE FEDERAL DE MATO GROSSO \\ PRESSÃO ARTERIAL E FATORES DE RISCO CARDIOVASCULAR NA REGIÃO CENTRO-OESTE - BRASIL}

\begin{tabular}{|l|l|l|}
\cline { 2 - 3 } \multicolumn{1}{l|}{} & Município: & Equipe: \\
\cline { 2 - 3 } \multicolumn{1}{l|}{$N^{\circ}$. do setor } & Hor. Inicio: \\
\hline$N^{\circ}$. do domicilio & \\
\hline$N^{\circ}$. do controle & \\
\hline
\end{tabular}

Endereço:

telefone:

\section{TERMO DE CONSENTIMENTO LIVRE E ESCLARECIDO}

Bom diaboa tarde, meu nome é e estou trabalhando numa pesquisa sobre fatores de risco para as doenças do coração na cidade de Goiânia, apoiada pela Universidade Federal de Goiás. Se concordar em participar da pesquisa terá que responder perguntas de um questionário. Após responder ao questionário vocé será pesado e medido. Sua pressão também será medida em dois momentos, no início e no final da entrevista.

Suas respostas a essas perguntas são muito importantes e estritamente confidenciais, isto é, não serão mostradas a ninguém. As informaçôes serăo utilizadas apenas para fins estatísticos. Informamos que a entrevista terá uma duraçáo de 30 minutos aproximadamente.

Sua participação neste trabalho é voluntária. Vocé pode escolher não participar ou ainda pode deixáto a qualquer momento, sem que isto traga qualquer prejuízo a vocé.

Podemos começar?

Entrevistado(a) concordou: $1 \rightarrow$ CONTINUE / Entrevistado(a) recusou: $2 \rightarrow$ ENCERRE A ENTREVISTA Assinatura do(a) entrevistado(a) :

Assinatura do entrevistador(a):

Data:

Coordenador: Paulo César Veiga Jardim

Fone: $202-7831$

VISITAS

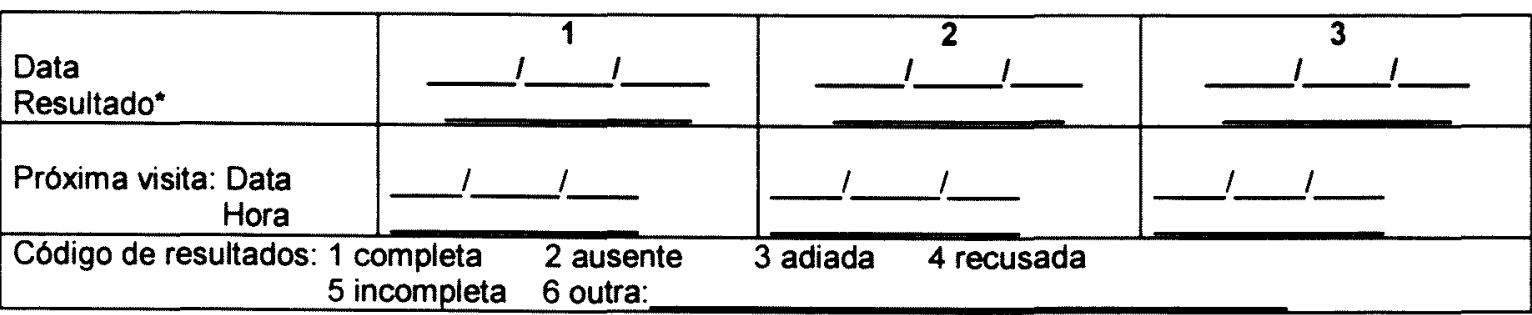




\section{A- IDENTIFICAÇÃO:}

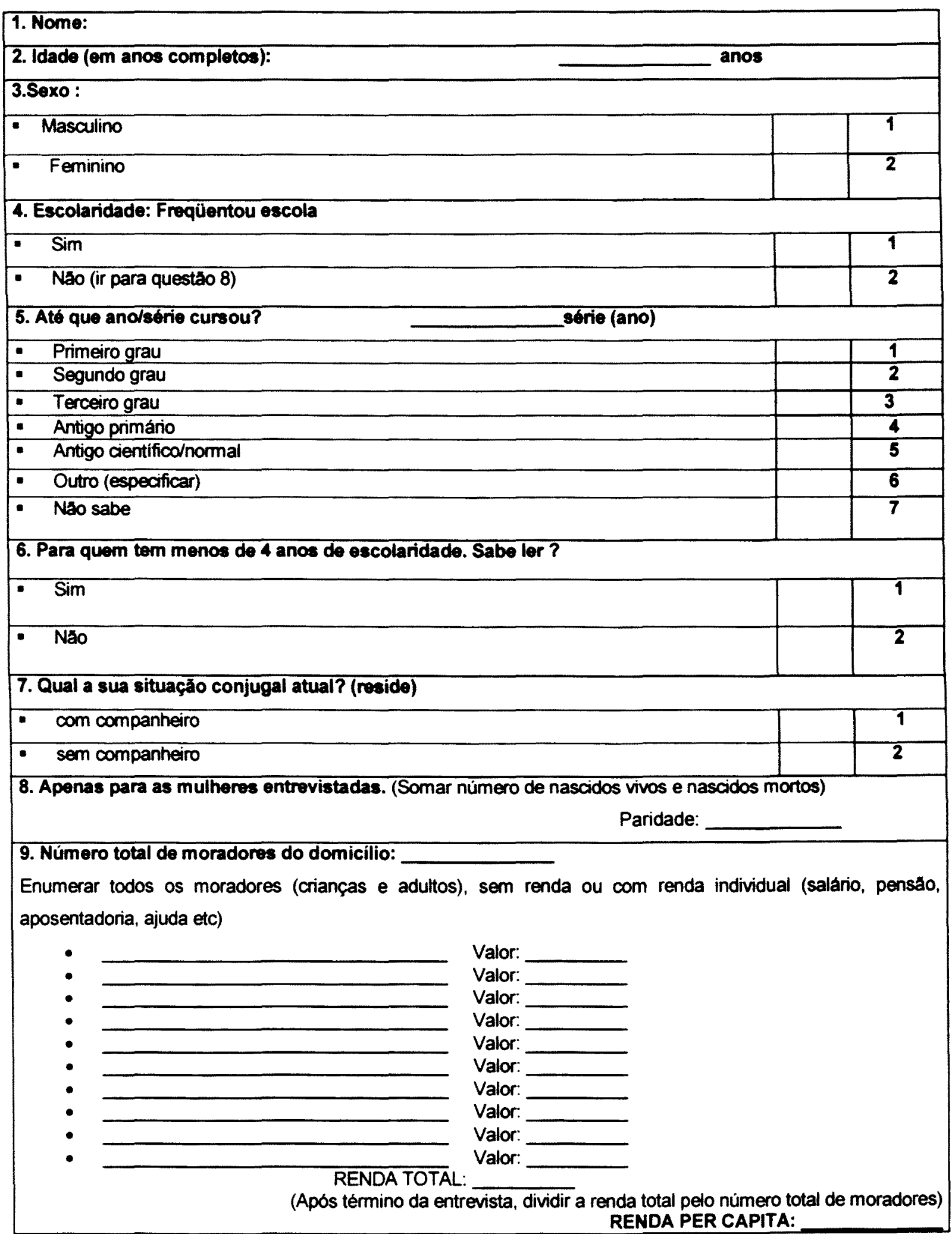


B-ALIMENTAÇĀO:

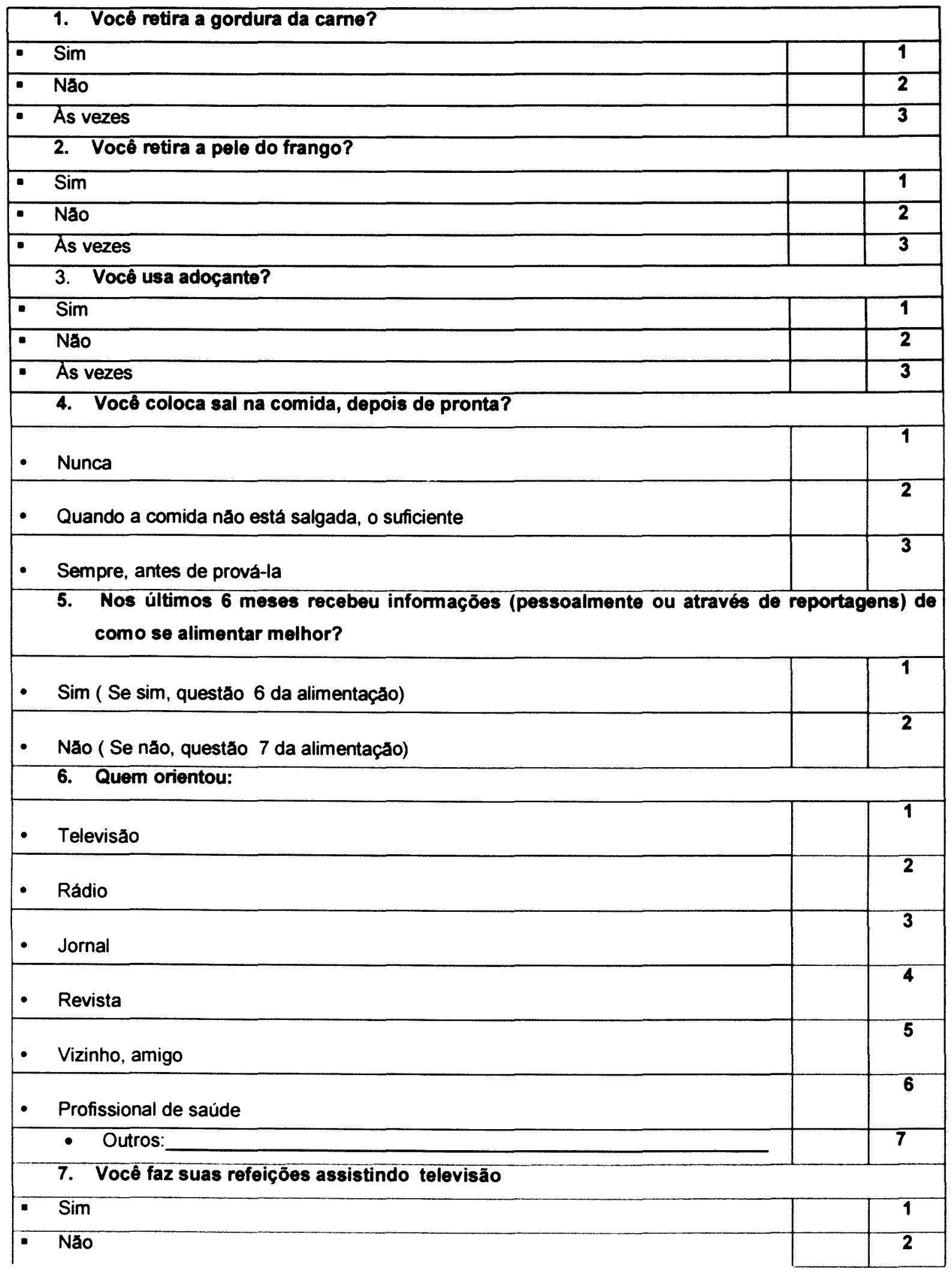




\begin{tabular}{|c|c|c|}
\hline - As vezes & & 3 \\
\hline 8. Qual destas refeiçōes você faz regulammente? & Năo & Sim \\
\hline - Café da manhã & & \\
\hline - Lanche da manhă & & \\
\hline - Almoço & & \\
\hline - Lanche da tarde & & \\
\hline - Jantar / Lanche da noite & & \\
\hline - Ceia (após o jantar/ lanche da noite) & & \\
\hline - Outros (além destas, faz outras refeições?): & & \\
\hline 9. Total de refeiçōes por dia: & & \\
\hline $\begin{array}{l}\text { 10. Vocế mudou sua alimentação por razões de saúde durante o ano passado } \\
\text { (últimos } 12 \text { meses)? }\end{array}$ & Não & Sim \\
\hline - Reduziu a quantidade de gorduras & & \\
\hline - Mudou o tipo de gorduras & & \\
\hline - Aumentou o uso de vegetais/frutas & & \\
\hline - Reduziu a quantidade de açúcar & & \\
\hline - Reduziu a quantidade de sal & & \\
\hline - Outros (especificar): & & \\
\hline
\end{tabular}

11 - Agora vou avaliar o seu consumo alimentar no último ano. Faça um esforço para lembrar o que você costuma comer. Vou ler o nome dos alimentos e vocé vai me dizer se come ou não o alimento. Se você comer, deve dizer também o número de vezes por semana ou més que come cada um.

\begin{tabular}{|c|c|c|c|c|c|c|c|c|}
\hline Alimento & nunca & $\begin{array}{c}\text { Menos } \\
\text { de } 1 x \\
\text { mès } \\
\text { (rarame } \\
\text { nte) }\end{array}$ & $\begin{array}{c}1 \text { a } 3 x \\
\text { mês }\end{array}$ & $\begin{array}{c}1 \times \text { por } \\
\text { sem }\end{array}$ & $\begin{array}{c}2 \text { a } 3 x \\
\text { sem } \\
\text { (poucas } \\
\text { vezes } \\
\text { na sem) }\end{array}$ & $\begin{array}{c}4 \text { a } 6 x \\
\text { sem } \\
\text { (Quase } \\
\text { to-dos } \\
\text { os dias) }\end{array}$ & $\begin{array}{l}1 \times \text { dia } \\
\text { (todos } \\
\text { os dias) }\end{array}$ & $\begin{array}{l}2 \text { ou }+x \\
\text { por dia }\end{array}$ \\
\hline \multicolumn{9}{|c|}{ LEITES E PRODUTOS DERIVADOS } \\
\hline \multicolumn{9}{|l|}{ 1- leite integral } \\
\hline \multicolumn{9}{|l|}{ 2- leite desnatado } \\
\hline \multicolumn{9}{|l|}{ 3-iogurte, coalhada } \\
\hline \multirow{2}{*}{\multicolumn{9}{|c|}{ 4-queijo, requeijão, }} \\
\hline & & & & & & & & \\
\hline \multicolumn{9}{|l|}{ 5- carne de vaca } \\
\hline \multicolumn{9}{|l|}{ 6-frango } \\
\hline \multicolumn{9}{|l|}{ 7- peixe } \\
\hline \multicolumn{9}{|l|}{ 8- sardinha, atum } \\
\hline \multicolumn{9}{|l|}{$\begin{array}{l}\text { 9- carne de porco, } \\
\text { linguiça }\end{array}$} \\
\hline $\begin{array}{l}10-\text { ovo frito, cozido, } \\
\text { mexido, omelete }\end{array}$ & & & & & & & & \\
\hline
\end{tabular}




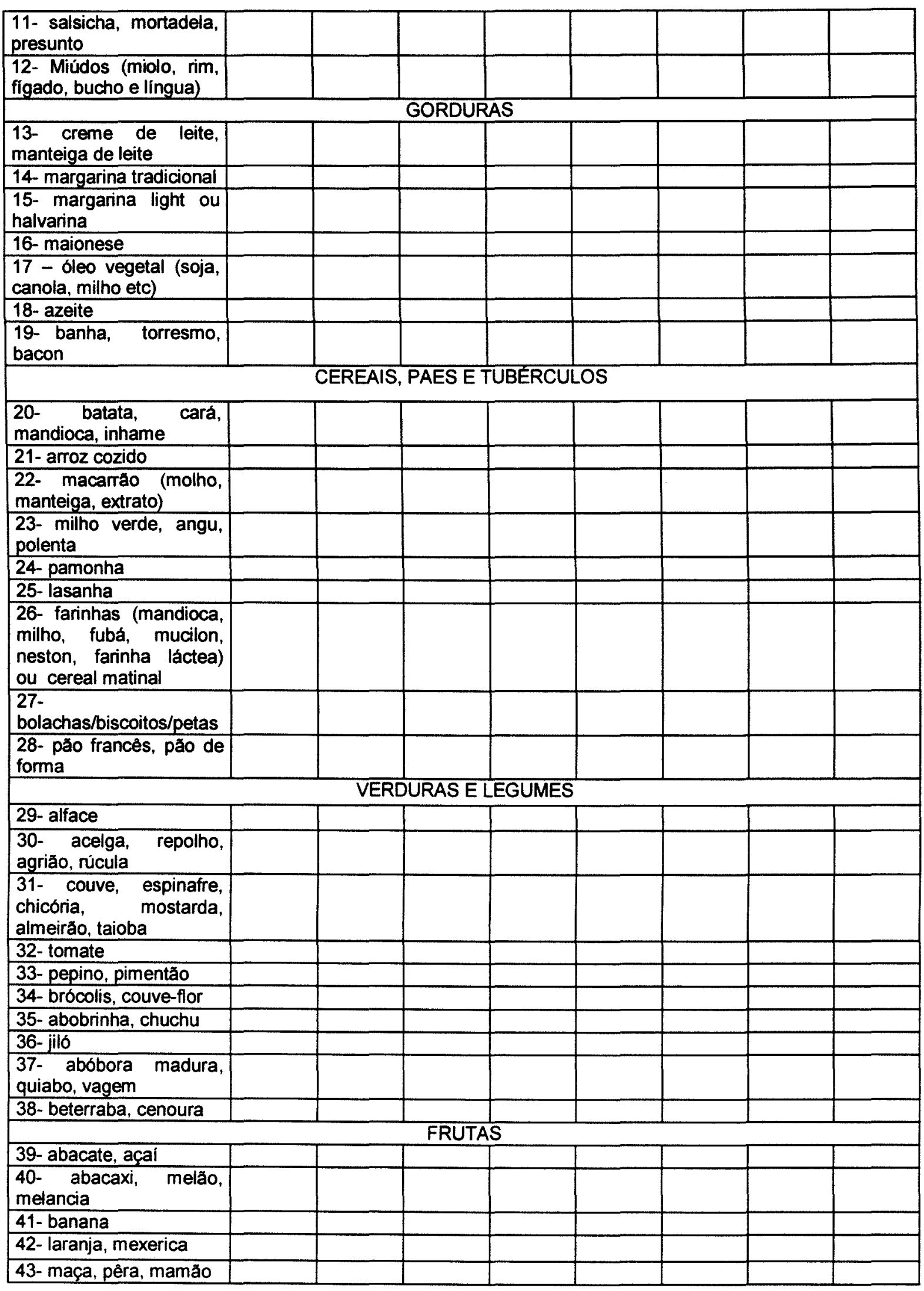




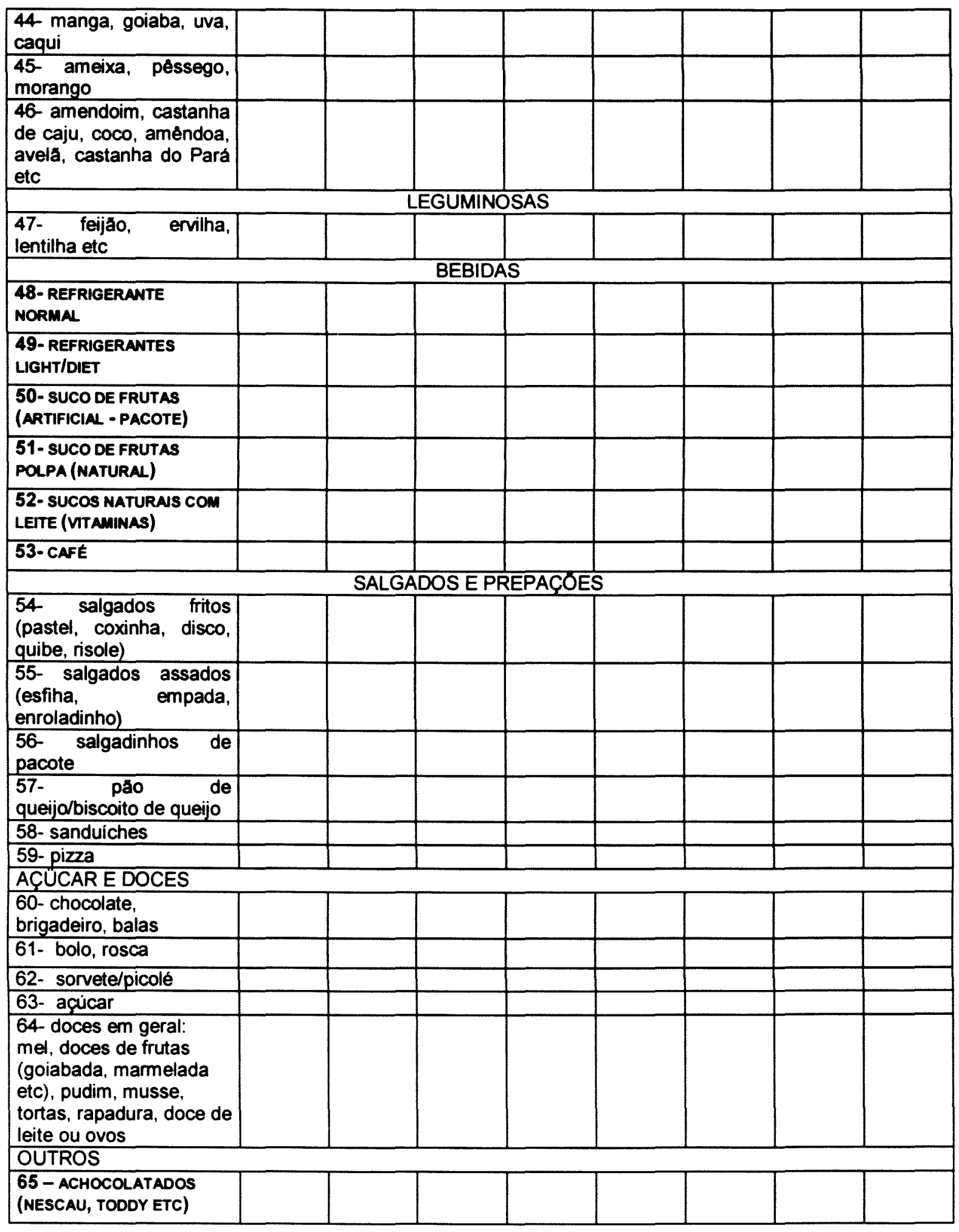




\begin{tabular}{|l|l|l|l|l|l|l|l|l|}
\hline $\begin{array}{l}\text { 66- FRITURAS EM GERAL } \\
\text { (OVO FRITO, BANANA } \\
\text { FRITA, BATATA FRITA, } \\
\text { CARNE FRITA, MANDIOCA } \\
\text { FRITA, PAMONHA FRITA } \\
\text { ETC) }\end{array}$ & & & & & & & & \\
\hline $\begin{array}{l}\text { 67- CONSERVAS OU } \\
\text { ENLATADOS (EXTRATO DE } \\
\text { TOMATE, AZEITONA OU } \\
\text { PALMITO) }\end{array}$ & & & & & & & & \\
\hline $\begin{array}{l}\text { 68- ALIMENTOS INTEGRAS } \\
\text { (FARELO DE TRIGO, FARELO } \\
\text { DE AVEIA, ARROZ } \\
\text { INTEGRAL, PAO INTEGRAL } \\
\text { ETC) }\end{array}$ & & & & & & & & \\
\hline
\end{tabular}

\section{ATIVIDADE FÍSICA:}

1. Que tipo de atividade física vocé desenvolve em seu trabalho? (dividimos as ocupaçōes em quatro grupos. Caso não trabalhe, mencione o grupo 1. Marque somente um grupo)

- Meu trabalho tem atividades para as quais tenho que ficar sentado. Năo caminho muito enquanto trabalho.

Exemplos: relojoeiro, eletrotécnico em rádios, costureira industrial, trabalho burocrático em escritório

- Caminho bastante enquanto trabalho, mas năo tenho que levantar nem carregar coisas pesadas.

Exemplos: empregados comerciais, trabalho industrial leve, trabalho de escritório que implique movimento

- Tenho que caminhar e mover muitas coisas ou subir escadas ou rampas em meu trabalho.

Exemplos: carpinteiros ou trabalhadores agricolas, trabalho em oficina mecânica, trabalho industrial pesado.

- Meu trabalho exige atividades físicas pesadas, como por exemplo mover levantar coisas pesadas, trabalhar com madeira ou cortar muito. Exemplos: trabalhador florestal, trabalho agrícola pesado, construçăo, trabalho industrial pesado.

\begin{tabular}{|l|l|l|}
\hline 0 & 1 \\
\hline & & 2 \\
\hline & & 3 \\
\hline
\end{tabular}

2. Quantos minutos por dia vocé se dedica a caminhar, andar de bicicleta ou a qualquer outra atividade física quando vai trabalhar? Inclua o tempo que passa indo e vindo de seu trabalho.

- Năo trabalho ou realizo atividade física alguma quando vou trabalhar

- Menos de 15 minutos por dia

- 15-29 minutos por dia

- 30-44 minutos por dia

- 45-59 minutos por dia

- Mais de 1 hora por dia

3. Que tipo de atividade física vocé faz durante seu tempo livre ou momentos de folga?

- No meu tempo livre, vejo televisão e faço coisas que não precisam de atividade física

- No meu tempo livre, caminho, ando de bicicleta ou me movimento de alguma maneira que tenha atividade física durante um minimo 30 minutos por dia, inclusive caminhar pescar ou caçar, jardinagem e outros, porem năo ir e vir do trabalho 
- No meu tempo livre, faço atividades fisicas para manter meu estado físico, como por exemplo, correr, ginástica, natação, jogos com bola ou trabalhos pesados de jardinagem ou equivalente durante um minimo 30 minutos por dia

- No meu tempo livre, treino periodicamente, vários dias por semana para participar de competicóes, corridas, jogos com bola ou alguma outro esporte que exjja muita atividade física

4. Quantas vezes por semana vocé participa nas atividades que mencionou ao responder à pergunta 3 ?

5. Alguma vez vocé tentou aumentar suas atividades físicas durante os momentos de folga? Caso afirmativo, quando foi a última vez?

\begin{tabular}{|l|c|}
\hline - nunca & 1 \\
\hline faz mais de 6 meses & 2 \\
\hline faz de 1-6 meses & 3 \\
\hline
\end{tabular}

6. Vocé alterou a atividade física que desenvolve durante seu tempo livre durante os últimos 6 meses?

\begin{tabular}{|c|c|}
\hline - Aumentou muito & 1 \\
\hline - Aumentou um pouco & 2 \\
\hline - não mudou & 3 \\
\hline - diminuiu um pouco & 4 \\
\hline - diminuiu muito & $\overline{5}$ \\
\hline \multicolumn{2}{|c|}{ 7. O que você acha do seu preparo físico atual? } \\
\hline - Muito bom & 1 \\
\hline - bom & 2 \\
\hline - regular & 3 \\
\hline - fraco & 4 \\
\hline - péssimo & $\overline{5}$ \\
\hline \multicolumn{2}{|c|}{ 8. O que vocé acha do seu estado de saúde atual? } \\
\hline - Muito bom & 1 \\
\hline - Bom & $\overline{2}$ \\
\hline - $\quad$ Regular & 3 \\
\hline - Fraco & 4 \\
\hline - Péssimo & $\overline{5}$ \\
\hline \multicolumn{2}{|c|}{ 9. O que vocé acha do seu peso atual? } \\
\hline - Muito abaixo do normal & 1 \\
\hline - Abaixo do normal & 2 \\
\hline - Normal & 3 \\
\hline - Um pouco acima do normal & 4 \\
\hline - Muito acima do normal & 5 \\
\hline
\end{tabular}




\begin{tabular}{|l|c|}
\hline 10. Quantas horas por dia vocé assiste televisão? & 1 \\
\hline Menos de 2 horas por dia & \\
\hline De 2 a 4 horas por dia & \\
\hline De 4 a 6 horas por dia & 3 \\
\hline Mais de 6 horas por dia & 4 \\
\hline
\end{tabular}

\section{D- FUMO:}

\section{Vocé :}

- Nunca fumou (ir para o item D-Alcool)

- Fuma, mesmo que às vezes (ir para a questão 2 - Fumo)

- Parou de fumar (ir para a questăo 3 - Fumo)

2. Vocé fuma quantos cigarros por dia?

[ ] às vezes (menos de 1 cigarro por dia)

3. Parou de fumar há [ ] meses ou [ ] anos

\section{E-ÁLCOOL:}

1.Qual a sua bebida preferida?

\section{Você consome bebida alcoólica?}

- Sim

- Nắo

3. Nos últimos 7 dias, vocé bebeu alguma das seguintes bebidas: Se não consumir escrever "0"

1. Cerveja (garrafa)

2. Vinho (cálice/copo)

3. Bebidas destiladas tipo uísque, vodka (dose)

4. Cachaça (dose)

5. Outros: (especificar)

F- CONTROLE DA PRESSÃO ARTERIAL E DOENÇAS CRÓNICAS:

1. Alguma vez alguém já lhe disse que você têm pressão alta?

- $\quad$ Sim

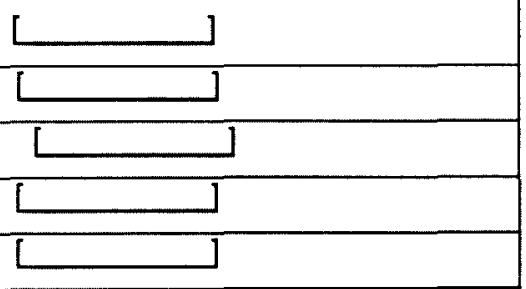

2. De onde veio esta informação?

- Farmácia

- Médico 


\begin{tabular}{|c|c|}
\hline - Enfermagem & 3 \\
\hline - Campanhas & 4 \\
\hline - Outros (especificar) & 5 \\
\hline \multicolumn{2}{|l|}{ 3. Vocé faz tratamento para a pressão alta? } \\
\hline - Sim (regular, pelo menos 2 consultas por ano) & 1 \\
\hline - Năo & 2 \\
\hline - Ás vezes & 3 \\
\hline \multicolumn{2}{|l|}{ 4. Onde você faz tratamento para a pressão alta? } \\
\hline - No CAIS ou posto de saúde & 1 \\
\hline - No hospital & 2 \\
\hline - Em consultório médico & 3 \\
\hline - Lugar variável & 4 \\
\hline Outros (especificar): & 5 \\
\hline \multicolumn{2}{|l|}{ 5. Com relação ao uso de medicamentos para pressão alta, você? } \\
\hline - Nunca usou medicamento & 1 \\
\hline - Usou medicamento, mas năo usa mais & 2 \\
\hline $\begin{array}{l}\text { - Está usando medicamento } \\
\text { ( ) regular (tomou todos os dias nos últimos } 3 \text { meses) } \\
\text { (especificar medicaçăo) }\end{array}$ & 3 \\
\hline \multicolumn{2}{|l|}{ 6. Você, alguma vez, já foi internado por problemas com a pressão? } \\
\hline - Sim & 1 \\
\hline - Năo (ir para a questão 8) & 2 \\
\hline \multicolumn{2}{|c|}{ 7. Qual foi o problema que vocé teve, que precisou ser intemado? (pode marcar mais de uma opção) } \\
\hline - Derrame ou acidente vascular cerebral (AVC) & 1 \\
\hline - Infarto ou ameaça de infarto & 2 \\
\hline - Angina ou dor no peito & 3 \\
\hline - Pressão alta ou descondensada & 4 \\
\hline Outros (especificar): & $\mathbf{5}$ \\
\hline \multicolumn{2}{|l|}{ 8. Você sabe o que pode fazer mal para o coraçăo? } \\
\hline - $\operatorname{Sim}$ & 1 \\
\hline - Não & 2 \\
\hline - Já ouviu falar & 3 \\
\hline \multicolumn{2}{|c|}{$\begin{array}{l}\text { 9. Agora vou ler alguns itens e vocé vai me dizer quais destes podem ajudar no surgimento das doenças do } \\
\text { coraçăo ou "fazem mal" para o coraçăo (pode marcar quantos achar) }\end{array}$} \\
\hline - $\quad$ Cigarro & 1 \\
\hline
\end{tabular}




\begin{tabular}{|c|c|}
\hline - Bebida alcoólica & 2 \\
\hline - Doces & 3 \\
\hline - Diabetes (aquicar no sangue) & 4 \\
\hline - Colesterol alto (gordura no sangue) & 5 \\
\hline - Sal & 6 \\
\hline - Excesso de Peso (obesidade) & 7 \\
\hline - Falta de exercicios & 8 \\
\hline - Nervosismo (estresse) & 9 \\
\hline - Pressão alta (hipertensão arterial) & $\mathbf{1 0}$ \\
\hline - Outros (especificar): & $\overline{11}$ \\
\hline \multicolumn{2}{|l|}{ 10. Medida da P.A (sentado) no membro superior esquerdo: } \\
\hline 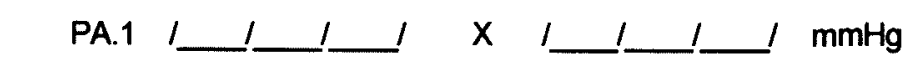 & \\
\hline 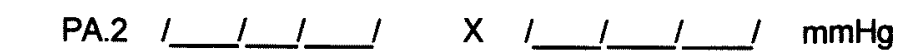 & \\
\hline
\end{tabular}

G- ANTROPOMETRIA:

\begin{tabular}{|c|c|c|}
\hline Indicador & valor referido & valor aferido \\
\hline - Altura & {$\left[\begin{array}{lllllll}{[} & ],[ & ][ & ][ & ] \mathrm{m}\end{array}\right.$} & $\left.\begin{array}{llllll}{[} & ],[ & ] & ] & ]\end{array}\right] \mathrm{m}$ \\
\hline - Peso & $\left.\begin{array}{lllll}{[} & ]\end{array}\right]$ & {$\left[\begin{array}{lllll}{[} & ] & ]\end{array}\right],[\mathrm{kg}$} \\
\hline - Circunferéncia da cintura & & $\begin{array}{llll} & \text { ][ } & \text { ][ } & ],[\end{array}$ \\
\hline
\end{tabular}

\begin{tabular}{|l|l|}
\hline Data da entrevista: & Horário de término: \\
\hline Entrevistadores: & 2. \\
\hline 1. & 2. \\
\hline Supervisor:
\end{tabular}

